\title{
3 \\ Cobertura, Qualidade e Eqüidade da Atenção Pré-natal e ao Parto, segundo a forma de pagamento destes serviços, em Criciúma-SC
}

\section{NELSON ARNS NEUMANN}

Tese de Doutorado apresentada ao Departamento de Saúde Materno-Infantil da Faculdade de Saúde Pública da Universidade de São Paulo para obtenção do Grau de Doutor.

Área de Concentração: Saúde MaternoInfantil

ORIENTADOR: PROF. DR. OSWALDO YOSHIMI TANAKA

São Paulo

2.000 


\section{Dedicatória}

\section{À minha esposa Luciane}

e às minhas diletas filhas Nicole e Nátali 


\title{
Agradecimentos
}

A Paula Guimarães,

pelo imprescindivel apoio na organização e realização do trabalho de campo.

\begin{abstract}
À minha mãe, Zilda Arns Neumann, a Dom Paulo Evaristo Arns e a Cesar Gomes Victora pelos exemplos de compromisso, persistência e solidariedade, e também pelo encorajamento e apoio para a concretização deste trabalho.
\end{abstract}

Ao CNPQ pela bolsa concedida. 


\section{Resumo}

Objetivo: avaliar a eqüidade e qualidade da atenção de pré-natal, ao parto e ao recém-nascido, e seu resultado sobre o aleitamento materno

Delineamento: Estudo transversal de base populacional.

Local: Área urbana do município de Criciúma, SC.

População: Amostra probabilística de 2180 crianças menores de três anos.

Resultados: Os mais pobres e gestantes com maior risco reprodutivo tiveram atendimento menos adequado. Dos 13 procedimentos de pré-natal e parto pesquisados, foram realizados, em média, 8,6 e 9,4, respectivamente, para o $1^{\circ}$ e $4^{\circ}$ quartil de renda familiar total. O SUS atendeu a população mais pobre e com maior risco reprodutivo, apresentando qualidade menos adequada principalmente quanto aos procedimentos médicos (exames ginecológico e de mamas). $O$ atendimento pelo SUS é fator de proteção contra a cesariana. $O$ uso de forma diferente de pagamento do parto, em relação ao pré-natal, por parte da usuária, não foi aleatório. Os procedimentos relativos ao aleitamento materno, no geral, foram pouco realizados. O exame das mamas e a orientação sobre amamentação no pré-natal aumentaram em quatro vezes a chance de amamentação exclusiva.

Conclusões: Deve-se captar precocemente os mais pobres e utilizar enfoque de risco com discriminação positiva. Os médicos devem ser retreinados quanto aos seus procedimentos. Merecem atenção especial as motivações pessoais do grupo que utilizou distintas formas de pagamento no pré-natal e parto. Os baixos índices de amamentação podem ser reflexo da atenção deficiente dos serviços de saúde. O exame das mamas e a orientação da amamentação podem ser marcadores de qualidade do pré-natal em relação a amamentação exclusiva.

Descritores: criança, gestante, eqüidade, atenção ao recém-nascido, atenção primária à saúde, avaliação de serviços, pré-natal, parto, forma de pagamento, cesariana, esterilização cirúrgica, aleitamento materno 


\section{Summary}

Study objective: to evaluate the justness and quality of the attention of prenatal to the childbirth and to the newly born, and its result on the maternal nursing. Design: Transverse study of populational base Place: Urban area of the Municipality of Criciuma, southern Brazil. Population: Probalistic sample of 2180 children under three years old. Results: The poorest and the pregnant with larger reproductive risk had less appropriate attendance. From the 13 procedures of prenatal and researched child births, they were accomplished, on the average, 8,6 and 9,4, respectively, for the 1 st and 4 th quarter of the total family income. The SUS assisted the poorest population and with larger reproductive risk, presenting less appropriate quality mainly with relationship to the medical procedures (gynecological exams and breast). The attendance by the SUS is a protection factor against the Cesarean section. The use of a different form of parturition's payment, in relation to the prenatal, by the user, was not aleatory. The relative procedures to the maternal nursing, in general, were not very accomplished. The exam of the breast and the orientation on breast-feeding in the prenatal, could increased in four times the chance of exclusive breast-feeding.

Conclusions: It should be captured early the poorest and it should be utilized the risk focus with positive discrimination. The doctors should be recycled in relationship to its procedures The personal motivations of the group that had used different forms of payment of the childbirth deserve special attention, in relation to the prenatal. The low breast-feeding prevalence can be reflex of the faulty attention of the services of health. The breast exam and the orientation of the breast-feeding could be a quality marker of the prenatal care in relation to the exclusive breast-feeding.

Keywords: child, pregnant, justness, attention to the newly born, primary health care, evaluation of services, prenatal, birth, payment form, Cesarean section, female surgical sterilization, maternal nursing 


\section{Índice}

1. Introdução

$\begin{array}{ll}1.1 & \text { Atenção Pré-natal } \\ 1.2 & \text { Aleitamento Materno } \\ 1.3 & \text { Municipio de Criciúma }\end{array}$

2. Objetivos da Tese $\quad 7$

3. Materiais e Métodos 8

3.1 Coleta de dados 8

3.2 Variáveis coletadas e Indicadores Construídos 9

$\begin{array}{ll}\text { 4. Plano de Análise } & 14\end{array}$

5. Resultados 19

$\begin{array}{ll}5.1 \text { Descrição da Amostra } & 19\end{array}$

$\begin{array}{ll}5.2 \text { Análise da Eqüidade } & 24\end{array}$

5.3 Análise da Qualidade Técnica da Atenção Prestada

5.4 Análise do Desfecho (Aleitamento Materno) 39

6. Discussão $\mathbf{4 5}$

6.1 Representatividade do Estudo 45

6.2 Comparação Geral do Atendimento Pré-Natal e
"Parto/RN"

6.3 Eqüidade 48

$\begin{array}{ll}\text { 6.4 Qualidade Técnica da Atenção Prestada conforme a } & \\ \text { Forma de Pagamento } & 51\end{array}$

6.5 Desfecho (Aleitamento Materno) 55

7. Resumo dos principais resultados $\quad 59$

8. Recomendações 61

$\begin{array}{lr}\text { 9. Bibliografia } & 62\end{array}$

Anexos

1. Questionário do Estudo sobre saúde das crianças menores de três anos em Criciúma - 1996

II. Manual de Instruções do Estudo sobre saúde das crianças menores de três anos em Criciúma - 1996

III. Questionário de revisita e hemoglobina do Estudo sobre saúde das crianças menores de três anos em Criciúma - 1996

IV. Relatório do trabalho de campo 


\section{Introdução}

Todos os povos do mundo têm consciência de que a motivação que os leva a envidar esforços para aumentar seus rendimentos não está no acúmulo puro e simples de riqueza. O aumento do poder aquisitivo pode e deve proporcionar às pessoas e a seus filhos melhorias das condições de vida tais como: alimentação e habitação adequadas, educação, oportunidades de recreação e também saúde. Aos individuos, às familias e às comunidades só será dado desfrutar dos outros benefícios do desenvolvimento quando houverem alcançado um nivel aceitável de saúde ${ }^{47}$.

O Brasil além de sofrer com a imensa desigualdade social (o decil de renda mais elevado tem 43 vezes a renda per capita das familias pertencentes ao decil das familias de mais baixa renda - nos Estados Unidos esta diferença é de 24 vezes $^{24}$ ) sofre ainda com a grande proporção de brasileiros em estado de pobreza, isto é um quarto da população em $1996^{25}$.

Dentro deste contexto, e reforçando a desigualdade, os Serviços de Saúde são regidos pela "lei da assistência inversa", fenômeno praticamente universal, descrito por $\mathrm{Hart}^{21}$ (1971): os que mais necessitam dos serviços de saúde são os menos beneficiados pelos mesmos. Assim, os programas de saúde atingem maiores coberturas nos grupos populacionais que deles menos necessitam ${ }^{4,12.48}$. Em amplos estudos realizados no Sul e no Nordeste do Brasil, ficou evidente que a cobertura de ações básicas de saúde da criança é sistematicamente superior nos niveis sócio-econômicos mais elevados quando, justamente, as crianças de famílias pobres são as que mais necessitariam de tais cuidados ${ }^{53,54}$

Depois de décadas de pesquisa sobre a existência e descrição de desigualdades sócio-econômicas em saúde, há uma crescente consciência de que algo pode ser feito para reduzi-las. Não somente provendo acesso universal e eqüitativo aos Serviços de Saúde mas também implementando programas públicos de saúde e envolvendo outros atores politicos para melhorar a saúde das comunidades menos favorecidas ${ }^{34}$. A distribuição desigual de recursos em saúde é uma das condições que agravam a 
iniqüidade: fatores biológicos, sociais e outros determinantes de desigualdades são fatores que demandam ajustes profundos (discriminação positiva) ${ }^{50}$.

$\mathrm{Na}$ investigação da qualidade da atenção médica é particularmente interessante descrever: o universo para o qual é prestada a atenção e os reais ou potenciais beneficiários desta atenção" 14 É importante lembrar que o "uso dos serviços de saúde é função das necessidades e do comportamento dos individuos diante dos seus problemas de saúde, assim como das formas de financiamento dos serviços e recursos disponiveis para a população, incluindo a estrutura administrativa e os mecanismos de pagamento" (Travassos e col. ${ }^{50}$ 2000 , p.134). Um melhor conhecimento destes é essencial para a compreensão do acesso e da qualidade do serviço prestado

A gravidez e o parto são determinantes importantes do estado de saúde da mulher A gravidez pode ser, ainda, o único contato que uma mulher em idade reprodutiva tem com os serviços de saúde, sendo assim valiosa oportunidade para intervenções direcionadas à promoção da saúde da mulher como um todo ${ }^{20}$

\subsection{Atenção Pré-Natal}

As normas do Ministério da Saúde ${ }^{35}$ (1988) preconizam a inscrição e o início do acompanhamento da gestante no primeiro trimestre de gravidez e a a realização de seis consultas (sendo, no mínimo, duas realizadas por médico). Os principais procedimentos preconizados para as consultas são: exame físico (peso e estado nutricional da gestante; estatura; pulso e temperatura; pressão arterial; inspeção de pele, mucosas e tireóide; ausculta cárdio-pulmonar; exame de membros inferiores), exame ginecológico (exame de mamas, altura uterina, batimentos cardio-fetais, palpação de gânglios e genitália, exame especular); exames laboratoriais de rotina (tipagem sangüínea, VDRL, urina e hemoglobina). Todas as gestantes devem receber, segundo estas normas, suplementação de ferro (independentemente do nível de hemoglobina) e orientação quanto ao aleitamento materno, entre outros 
procedimentos. Serão feitos exames de secreção vaginal "preventivo de câncer de colo de útero" e vacina antitetânica apenas se houver indicação.

A mediana de consultas pré-natais no Brasil em 1996 era de 7.4. variando de 6.3 na região Norte a 8,5 na região Sul. Nesta região, 6,3\% das mães não realizaram consultas de Pré-Natal ${ }^{48}$. Realizaram a primeira consulta de Pré-Natal até o terceiro mês de gestação $66,0 \%$ das gestantes. No Sul, este indice foi de $79.7 \%$ e no Nordeste, $51,9 \%{ }^{48}$.

Estudo longitudinal realizado em Pelotas/RS em 1982, apontou que o número de consultas de Pré-Natal foi inadequado para $5,5 \%$ das gestantes particulares, 22,9\% das atendidas pelo sistema previdenciário e a $77 \%$ das sem filiação previdenciária (indigentes). Quando nesse mesmo estudo foi utilizado um critério de risco, baseado na presença de fatores que aumentam a probabilidade de que a gestação resulte em uma morte perinatal ou em criança de baixo peso, verificou-se que o atendimento Pré-Natal foi inadequado em $31,7 \%$ das mulheres de alto risco e em $12,1 \%$ das mulheres de baixo risco ${ }^{53}$.

Os dados do estudo longitudinal de 1993 em Pelotas/RS apontam a mesma conclusão: quanto pior o nível de renda e maior o escore de fatores de risco, mais baixo o desempenho da assistência à saúde ${ }^{12}$. As mães atendidas pelo SUS foram as que, proporcionalmente, receberam menos cuidados prénatais, apresentaram a menor média de consultas e procuraram assistência médica mais tardiamente ${ }^{12}$

Análise realizada com os nascidos no Estado de Washington entre 1983 e 1988, comparando o uso do Pré-Natal e seus desfechos conforme o tipo de pagamento recebido pelo serviço ("Medicaid Managed Care" comparado com outras formas), aponta que, uma vez iniciado o Pré-Natal, as mulheres recebiam um número similar de visitas, independentemente do tipo de pagamento. Na comparação entre o "Medicaid Managed Care" e os não usuários deste sistema, percebe-se que é dada menos atenção Pré-Natal para os primeiros. Estes apresentam também maior incidência de baixo peso ao nascer mas esta diferença não é significativa após o ajuste para fatores de confusão (o "Medicaid" tem maior proporção de usuárias jovens, negras e solteiras). Segundo os autores, a medida não ajustada revela que o "Medicaid" 
não conseguiu compensar a iniqüidade e levar os usuários deste sistema ao mesmo nível do grupo "Não-Medicaid". Os autores apontam, ainda, a necessidade de esforços adicionais para facilitar a adesão precoce das mães ao Pré-Natal ${ }^{29}$

\subsection{Aleitamento materno}

O aleitamento materno tem efeito relevante na queda da mortalidade infantil e nos niveis de morbidade por infecções gastroinstestinais ${ }^{52,55}$ e respiratórias $^{9,33}$

Crianças desmamadas têm dez vezes mais risco de serem acometidas de desidratação do que crianças aleitadas somente ao seio ${ }^{55}$. Crianças que recebem outro leite e suplementos tem 17 vezes mais chance de morrer de diarréia no primeiro ano de vida se comparadas às aleitadas exclusivamente ao seio ${ }^{52}$. Tão grande é a importância do aleitamento materno que um editorial do $\mathrm{BMJ}^{33}$ sugere a divulgação explícita de que crianças alimentadas com fórmulas infantis têm mais doenças e pior desenvolvimento psicológico que bebês normais. Deve ser lembrado, ainda, o direito da mãe em amamentar, tendo em vista. inclusive, a satisfação da mesma em fazê-lo e o desenvolvimento emocional da relação mãe-filho ${ }^{58}$.

Intervenções de Serviços de Saúde na promoção do aleitamento materno foram capazes de aumentar a prevalência de aleitamento materno. Mães que freqüentaram o Centro de Lactação de Guarujá/SP apresentaram maior prevalência de amamentação exclusiva ao quarto mês de vida em relação às mães não atendidas pelo serviço (43\% versus $18 \%)^{4}$. Mães que receberam visitas após o nascimento em um estudo de intervenção randomizado em Pelotas apresentaram maior mediana de amamentação (120 dias versus 105 dias para as não visitadas) e maior mediana de introdução da mamadeira (90 versus 60 dias, respectivamente) $)^{3}$. A "Iniciativa Hospital Amigo da Criança" tem sido apontada como um dos elementos que contribuiu para o aumento dos índices de amamentação no Brasil ${ }^{31}$.

É importante frisar que a orientação quanto à amamentação jeve ocorrer antes do nascimento da criança tendo em vista que os dias de 
internamento para o parto não são suficientes para interferir na multiplicidade de fatores que afetam a decisão de amamentar ${ }^{26}$. Estudo com voluntárias canadenses $^{19}$ apontou que aproximadamente $80 \%$ delas tomou a decisão sobre como alimentar sua criança antes mesmo da gravidez, sendo a convicção desta decisão evidenciada pela estrita aderência à mesma.

Por outro lado, estudo americano ${ }^{46}$ de 1988 apontou, em análise ajustada para fatores de confusão, que mães com Pré-Natal adequado (tempo de início e número de consultas ajustado para a duração da gestação adequados) amamentaram de forma semelhante às mães com Pré-Natal inadequado

Desta forma, não se espera que apenas a atenção Pré-Natal e ao parto garantam a melhoria da amamentação, dada à multiplicidade e mesmo à complexidade dos fatores que a influenciam, tendendo os condicionantes sócio-culturais a se sobrepor aos determinantes biológicos ${ }^{1}$. Ainda assim, optamos por estudar este desfecho pelo fato do pré-natal e parto serem oportunidades que não podem ser desperdiçadas, tendo em vista a importância do aleitamento materno e o direito das mães de receberem as informações necessárias.

\subsection{Município de Criciúma}

O Município de Criciúma está situado na Região Sul do Brasil, no Estado de Santa Catarina. Sua população era constituída por 159.101 os habitantes segundo a contagem da população realizada pelo IBGE em $1996^{23}$.

A rede hospitalar do SUS, em Criciúma, era composta em março de 1996, por quatro hospitais, todos privados, sendo três contratados e um Filantrópico, totalizando 814 leitos $^{37}$. Segundo informações da Secretaria Municipal de Saúde de Criciúma, a rede ambulatorial era composta por 39 Unidades de Saúde, das quais 17 contavam com o Programa Saúde da Familia (PSF), iniciado no final de 1994. Compunham ainda a rede municipal, quatro Unidades Referenciais de Saúde, duas Unidades Especializadas (Pronto Atendimento Médico), um Centro de Saúde e seis Univades Odontológicas móveis Vinculados ao Conselho Municipal de Saúde havia 26 
Conselhos Populares de Saúde. A gestão do Sistema de Saúde era Estadual, regida, então, pela Norma Operacional Básica 1/93. No município, havia ainda o programa de atenção materno-infantil, de base comunitária, desenvolvido pela Pastoral da Criança, com cobertura de $4,8 \%$ das crianças menores de três $\operatorname{anos}^{39}$.

Dados do Censo de $1991^{51}$ apontam que, das 23.679 crianças menores de seis anos do Municipio de Criciúma, 10,1\% viviam em domicilios cujo chefe de familia recebia até um salário minimo; $6,7 \%$ dos domicilios eram chefiados por pessoa com menos de um ano de estudo; apenas $2,6 \%$ dos domicílios apresentavam abastecimento de água inadequado

Segundo o índice de sobrevivência elaborado pelo IBGE e UNICEF 51 com base nos indicadores supra-citados, Criciúma está entre os trinta melhores municipios do Estado de Santa Catarina e entre os cinqüenta melhores do Brasil.

Dados já publicados do presente estudo, realizado em 1996, descrevem que $3,3 \%$ das mães referiram perda de filho menor de cinco anos, sendo que metade das famílias moram no município há pelo menos 19 anos e no mesmo bairro há seis anos ou mais ${ }^{39}$. Praticamente, todas as mães possuiam a Caderneta de Saúde e esta foi vista pelo entrevistador em $93,7 \%$ da amostra, sendo que $72.8 \%$ das crianças foram pesadas no trimestre (segundo relato da mãe $)^{38}$. As coberturas vacinais foram elevadas, ainda que se considerassem apenas as doses anotadas na Caderneta de Saúde: 96,3\% para a BCG; 93,2\% para a DPT; $93,8 \%$ para a anti-pólio e $92,6 \%$ para a anti-sarampo ${ }^{38}$.

Ao lado destes indicadores que apontam boa qualidade dos serviços de saúde, Criciúma tem um desempenho aquém do esperado em relação à amamentação. Apenas uma em cada 12 crianças foi amamentada exclusivamente ao seio até os quatro meses de idade a e mediana de duração do aleitamento materno foi de apenas 4,7 meses $^{38}$. A mediana nacional de amamentação segundo a PNDS realizada no mesmo ano foi de 7,0 meses $^{48}$.

Assim, dentre os programas existentes em Criciúma, optamos neste estudo por avaliar a atenção de Pré-Natal, ao parto e ao recém-nascido, e seu resultado sobre a amamentação. 


\section{Objetivos da Tese}

Esta tese tem como objetivo geral avaliar a cobertura, qualidade e eqüidade da atenção Pré-Natal, ao parto e ao recém-nascido no Municipio de Criciúma-SC, segundo a forma de pagamento destes serviços e possíveis repercussões no aleitamento materno. Seus objetivos especificos são:

1. Avaliar a cobertura dos serviços de Pré-Natal, parto e atenção ao recém nascido, segundo critérios sócio-econômicos:

2. Avaliar a qualidade dos serviços oferecidos, por meio da análise de procedimentos técnicos realizados na atenção Pré-Natal, ao parto e ao atenção ao recém nascido, segundo a renda familiar total;

3. Avaliar a influência da forma de pagamento do prestador sobre a qualidade dos serviços oferecidos;

4. Avaliar a qualidade dos serviços oferecidos em relação ao aleitamento materno 


\section{Materiais e Métodos}

O estudo foi realizado em 1996. na área urbana de Criciúma, sendo incluída a sede do municipio e seu único distrito, Rio Maina.

Para a coleta da amostra de estudo partiu-se dos 113 setores censitários utilizados pelo IBGE no município. Estes continham em média, 317 domicilios particulares ocupados.

O presente estudo faz parte de um trabalho mais amplo ${ }^{38,39,40}$ que visava avaliar o estado nutricional das crianças menores de três anos de Criciúma, bem como a cobertura e o desempenho da Pastoral da Criança. Assim, o total de setores censitários foi dividido em dois estratos: o primeiro, com forte presença da Pastoral da Criança, abrangia 37 setores e o segundo, 76 setores. A amostra selecionada para o presente estudo foi composta dos 37 setores $(100 \%)$ do primeiro estrato e 15 setores (20\%) do segundo estrato selecionados através de amostragem proporcional ao tamanho. No primeiro estrato foram visitados $54 \%$ dos domicilios de cada setor e, no segundo estrato, foram visitados 155 domicilios em cada setor.

Ainda que em cada estrato houvesse igual chance de entrada no estudo para todas as crianças, houve proposital sobreamostragem do primeiro estrato Esta foi compensada na análise, através de ponderação, tornando os resultados representativos para a totalidade da população urbana do município.

\subsection{Coleta de dados}

Realizaram a coleta de dados 14 entrevistadoras com, no mínimo, dez anos de escolaridade. Estas foram selecionadas após um treinamento teóricoprático de 80 horas e um estudo piloto. Fizeram ainda parte da equipe três supervisores de campo, um supervisor de qualidade (responsável pelas revisitas) e os dois coordenadores da pesquisa. A coleta de dados foi conduzida nos meses de março a junho de 1996

Para iniciar a coleta, foi sorteada uma quadra em cada setor escolhido. Nesta quadra, uma esquina foi sorteada e, no sentido horário, foram visitados, 
consecutivamente, todos os domicilios inicialmente previstos para cada setor. Foi aplicado um questionário para todas as crianças residentes e com até três anos de idade. Caso o domicilio estivesse fechado, perguntava-se, a pelo menos dois vizinhos, se havia alguma criança no domicilio. Caso houvesse, retornava-se em outro dia e horário a fim de entrevistar o responsável pela criança: se, após quatro visitas em dias e horas diferentes, o mesmo não fosse encontrado, considerava-se essa criança como perda

A coleta de dados consistiu na aplicação de um questionário précodificado aplicado à mãe ou pessoa responsável pela criança menor de três anos

No próprio dia da entrevista, o questionário era codificado pelo entrevistador. O supervisor de campo revisava-os na mesma semana e os entregava para a equipe central. Esta conferia novamente os questionários antes da digitação. Um programa de entrada de dados verificava a amplitude e consistência das variáveis. Uma segunda digitação comparava os questionários com os dados anteriormente digitados, sendo as eventuais correções feitas imediatamente.

\subsection{Variáveis Coletadas e Indicadores Construídos}

As seguintes variáveis foram investigadas através do questionário (anexo I) aplicado à mãe ou à pessoa responsável pela criança menor de três anos. Em base nestas variáveis, foram construídos indicadores especificos para análise neste estudo.

\subsubsection{Qualidade técnica do Serviço de Saúde oferecido:}

\subsubsection{Variáveis coletadas de Pré-Natal:}

- utilização dos serviços de Pré-Natal: realização ou não do mesmo, mês de início e número total de consultas realizadas;

- procedimentos técnicos realizados, por médico ou enfermeira, durante alguma das consultas de Pré-Natal, segundo informe do entrevistado: verificação da data da última menstruação, do peso, da altura uterina e da pressão arterial; exame de sangue; exame ginecológico, das mamas e 
especular orientação sobre amamentação e imunização anti-tetânica: e prescrição de ferro.

\subsubsection{Indicadores construidos de Pré-Natal:}

- Cobertura de Pré-Natal: número de crianças com Pré-Natal realizado dividido pelo número total de crianças na amostra;

- Número adequado de consultas: número de crianças com ao menos seis consultas de Pré-Natal dividido pelo número total de crianças na amostra;

- Início do Pré-Natal adequado: número de crianças que iniciaram o Pré-Natal no primeiro trimestre dividido pelo número total de crianças na amostra;

- Cobertura de Pré-Natal adequado: número de crianças com ao menos seis consultas de Pré-Natal e que iniciaram o mesmo no primeiro trimestre dividido pelo número total de crianças na amostra.

3.2.1.3 Variáveis coletadas de atendimento ao parto e ao recém-nascido ("Parto/RN"):

- local (hospital) de ocorrência do parto

- tempo em que a criança, depois de nascida, foi colocada para mamar (em minutos):

- utilização de alojamento conjunto: a criança ficou o tempo todo com a mãe ou foi para o berçário (parcial ou tempo integral);

- orientação sobre como cuidar da criança: foi dada ou não, no hospital do parto; caso o hospital tivesse oferecido alguma orientação, perguntou-se qual.

\subsubsection{Indicador construido de atendimento "Parto/RN":}

- Cobertura de parto hospitalar (número crianças com parto hospitalar dividido pelo nümero total de crianças). 
3.2.1.5 Indicadores construídos através do agrupamento das atividades normatizadas no controle Pré-Natal e "Parto/RN".

- atendimento adequado: realização de no mínimo 11 procedimentos técnicos dos 13 previstos (dez referentes ao Pré-Natal e três ao atendimento "Parto/RN")

- relacionadas ao desfecho aleitamento materno: (1) Pré-Natal: exame das mamas e orientação sobre amamentação: (2) "Parto/RN": alojamento conjunto, tempo após o parto em que a criança foi colocada ao seio e orientação dada, na maternidade. sobre como cuidar da criança.

\subsubsection{Forma de pagamento do Serviço de Saúde:}

3.2.2.1 Variável coletada da forma de pagamento dos serviços: caso a gestante tenha utilizado mais de um serviço de Pré-Natal, foi considerado o utilizado com maior freqüência.

- forma de pagamento dos serviços de Pré-Natal e "Parto/RN": (1) SUS Sistema Único de Saúde; (2) particular; ou (3) outro tipo de pagamento (convênio/sindicato/seguro saúde/plano de saúde)

3.2.2.2 Indicador construído: forma de pagamento considerando ambos os serviços (Pré-Natal e "Parto/RN"). Foram agrupados na mesma categoria as formas de pagamento particulares e outros tipos de pagamento. Para este indicador, foram excluidas as crianças para as quais não foi realizado o Pré-Natal ou não foi possível identificar se o mesmo foi realizado. Excluíram-se, ainda, crianças para as quais não foi possivel identificar o local de realização do Pré-Natal.

- forma de pagamento de ambos os serviços (Pré-Natal e "Parto/RN"):

"Sempre SUS": realizaram o Pré-Natal e o "Parto/RN" pelo SUS; (2) "Sempre Particular": realizaram o Pré-Natal e o "Parto/RN" particular/outro tipo de pagamento; (3) "SUS->Particular": realizaram o Pré-Natal pelo SUS e o "Parto/RN" particular/outro tipo de pagamento; (4) "Particular->SUS": realizaram o Pré-Natal particular/outro tipo de pagamento e "Parto/RN" pelo SUS 


\subsubsection{Variáveis demográficas:}

- sexo da criança: masculino ou feminino;

- cor da pele: branca parda ou negra:

- idade da criança no momento da entrevista: em dias, calculada por programa de computador através da diferença entre as datas da entrevista e do nascimento.

\subsubsection{Variáveis sócio-econômicas:}

- renda familiar total no último mês em reais;

- escolaridade da mãe em anos de estudo completos com aprovação:

- presença de companheiro.

\subsubsection{Variáveis Ambientais:}

- aglomeração: número de pessoas por peça utilizada para dormir;

- tipo de moradia:(1) maloca, casa de madeira irregular ou tijolo sem reboco e (2) casa de tijolos com reboco, madeira regular ou apartamento.

\subsubsection{Antecedentes de saúde reprodutiva:}

\subsubsection{Variáveis coletadas:}

- idade da mãe em anos completos:

- idade da mãe em anos completos à época do nascimento da criança: idade da mãe subtraída da idade da criança no momento da entrevista;

- ordem de nascimento da criança: número de filhos nascidos vivos antes da criança (nenhum irmão ou irmã = primogênita);

- intervalo interpartal;

3.2.6.2 Indicador construido de risco de saúde reprodutiva. Consideraram-se fatores de risco idade da mãe à época do parto menor de 18 anos ou maior que 34 anos; ordem de nascimento maior que terceiro filho; e intervalo interpartal menor do que 24 meses.

- "Risco de saúde reprodutiva": número de fatores de risco $(0,1,2$ ou 3$)$. 


\subsubsection{Aleitamento Materno:}

3.2.7.1 Variáveis coletadas relativas ao padrão alimentar (informação do entrevistado):

- aleitamento materno: se a criança foi amamentada e por quanto tempo;

- uso de mamadeira: se a criança a utilizou e idade em meses, em que começou a utilizá-la;

- idade de introdução de outros alimentos ou líquidos (aplicado apenas para as crianças menores de um ano):

- recordatório alimentar das últimas 24 horas:

\subsubsection{Indicadores construidos}

- mediana da curva de sobrevivência para aleitamento materno total;

- mediana da curva de sobrevivência para introdução da mamadeira:

- aleitamento materno com duração igual ou superior a seis meses (apenas as crianças com seis meses ou mais);

- aleitamento materno exclusivo ou predominante por quatro meses ou mais (apenas crianças entre quatro e doze meses incompletos no momento da entrevista). Considerou-se aleitamento predominante quando, além do leite materno, a criança recebia tão somente chás, sucos ou água:

- introdução da mamadeira antes dos quatro meses de idade (crianças que nunca utilizaram mamadeiras foram agrupadas com aquelas que iniciaram a recebê-las com quatro meses ou mais).

A fim de verificar a qualidade da entrevista, revisitou-se cerca de $10 \%$ dos domicílios. Nestes foram repetidas algumas das questões acima descritas, avaliando-se a concordância entre respostas da primeira visita e da revisita através da estatistica kappa ${ }^{17}$.

Utilizar-se-ão, no contexto desta pesquisa, os termos "pai" ou "mãe" para designar os pais sociais que moram com a criança, biológicos ou não. 


\section{Plano de análise}

O Plano de Análise foi realizado em etapas subseqüentes, compreendendo: descrição da amostra; análise da eqüidade; análise da qualidade técnica da atenção prestada conforme a forma de pagamento e análise do desfecho aleitamento materno.

\subsection{Descrição da Amostra}

- descrição geral da amostra, das perdas e das exclusões;

- distribuição da população do estudo conforme as variáveis demográficas, sócio-econômicas, caracteristicas de saúde reprodutiva;

- descrição do Pré-Natal:

- descrição do "Parto/RN";

- descrição do Aleitamento Materno.

\subsection{Análise da Eqüidade}

Esta etapa da análise visa a estudar e comparar a qualidade técnica dos serviços prestados em relação a um indicador sócio-econômico (renda familiar total) e ao indicador construído de "Risco de saúde reprodutiva".

- análise da qualidade técnica dos serviços de saúde em relação à renda familiar total;

- análise da qualidade técnica dos serviços de saúde em relação ao escore de risco referente a características de saúde reprodutiva 


\subsection{Análise da qualidade técnica da atenção prestada conforme a forma de pagamento}

Esta etapa da análise visa a identificar a influência da forma de pagamento em relação à qualidade do serviço prestado, independentemente da estrutura disponivel.

- análise da amostra por forma de pagamento dos serviços de saúde;

- análise das características das mães que utilizaram diferentes formas de pagamento para os serviços de Pré-Natal e "Parto/RN";

- análise das variáveis com potencial na mudança, por parte da usuária, da forma de pagamento do parto em relação ao Pré-Natal:

- análise bivariada;

- análise multivariada (controle de fatores de confusão);

- análise da qualidade técnica do Pré-Natal e "Parto/RN" e a forma de pagamento

- estratificação por "Risco de saúde reprodutiva".

\subsection{Análise da qualidade técnica da atenção prestada em relação ao desfecho Aleitamento materno}

O desfecho selecionado neste estudo para análise do impacto da qualidade técnica dos serviços prestados sobre indicadores de saúde foi o Aleitamento Materno, tendo em vista sua importância para a saúde da criança e a possibilidade de relação concreta com as atividades realizadas pelos serviços de saúde.

- análise bivariada de cada procedimento relacionado эo Aleitamento materno e o seu desfecho;

- análise bivariada do conjunto dos procedimentos relacionados ao Aleitamento materno e o seu desfecho;

- análise multivariada de cada procedimento relacionado ao Aleitamento materno e o seu desfecho; 
- análise multivariada do conjunto dos procedimentos relacionados ao Aleitamento materno e o seu desfecho.

A análise estatística bivariada incluiu o teste do qui-quadrado para as tabelas de contingência ${ }^{28}$. Nas tabelas $2 \times 2$ foi utilizada a correção de continuidade de Pearson ${ }^{28}$. Utilizou-se o teste exato de Fischer quando a freqüência esperada era inferior a $\mathrm{cinco}^{28}$. Calcularam-se as medianas de duração de aleitamento materno e de introdução da mamadeira através das curvas de sobrevivência ${ }^{2}$. Para estimar o viés de memória para o aleitamento materno, construiu-se uma curva, para as crianças menores de 12 meses, considerando apenas o padrão alimentar no momento da entrevista (Current Status). Esta curva foi comparada com a curva de sobrevivência para aleitamento materno das crianças menores de 12 meses. A fim de comparar as proporções de desmame dentro de cada intervalo (de um mês) utilizou-se o teste do Qui-quadrado de Mantel_Haenszel, com correção de Yates, Este procedimento foi proposto por Kirkwood ${ }^{28}$ para comparação de curvas de sobrevivência. Estes testes foram realizados pelo programa Epi Info ${ }^{8}$.

Uma vez que outros fatores em estudo poderiam estar confundindo ${ }^{44}$ as associações entre a condição de segurado e o desfecho "Aleitamento Materno", utilizou-se a hierarquização das variáveis em níveis (figura 1) para selecionar as variáveis de confusão mais relevantes ${ }^{18,41}$. Assim, variáveis sócioeconômicas, biológicas (primeiro nível), ambientais (segundo nivel), e reprodutivas (terceiro nivel), foram controladas a fim de obter o efeito ajustado dos serviços ofertados sobre os desfechos propostos.

A qualidade técnica do atendimento está situada, no modelo hierárquico, abaixo da forma de pagamento dos serviços por ser uma das formas de atuação destes sobre o desfecho. Deste modo, para a obtenção das variáveis de qualidade técnica mais relevantes em relação ao Aleitamento Materno, a análise multivariada foi ajustada também para a forma de pagamento dos serviços.

A análise multivariada foi realizada por regressão logística para os desfechos dicotômicos; para as médias, utilizou-se a análise de variânci ${ }^{28}$. 
Na regressão logística, foram considerados como potenciais fatores de confusão as variáveis com valor de $p$ menor que 0,20 dentro de cada nivel. Para as análises subseqüentes, mantiveram-se aquelas variáveis que permaneceram associadas ao desfecho após controladas para as variáveis de confusão do mesmo nivel e para aquelas hierarquicamente superiores ${ }^{44}$. Além disto, cada variável ordinal - por exemplo, a renda familiar total - foi avaliada para tendência linear. Quando esta associação era significativa e não desviava da linearidade, a variável foi incluída no modelo como linear ${ }^{26}$. Nas análises ajustadas, foi incluída a variável de estratificação dos setores censitários ${ }^{40}$ : a mesma foi eliminada do modelo por não se caracterizar como fator de confusão ( $p>0,2$ ); os resultados não foram afetados mesmo quando se forçou a permanência desta variável no modelo.

\section{Figura 1. Modelo Conceitual da análise multivariada}

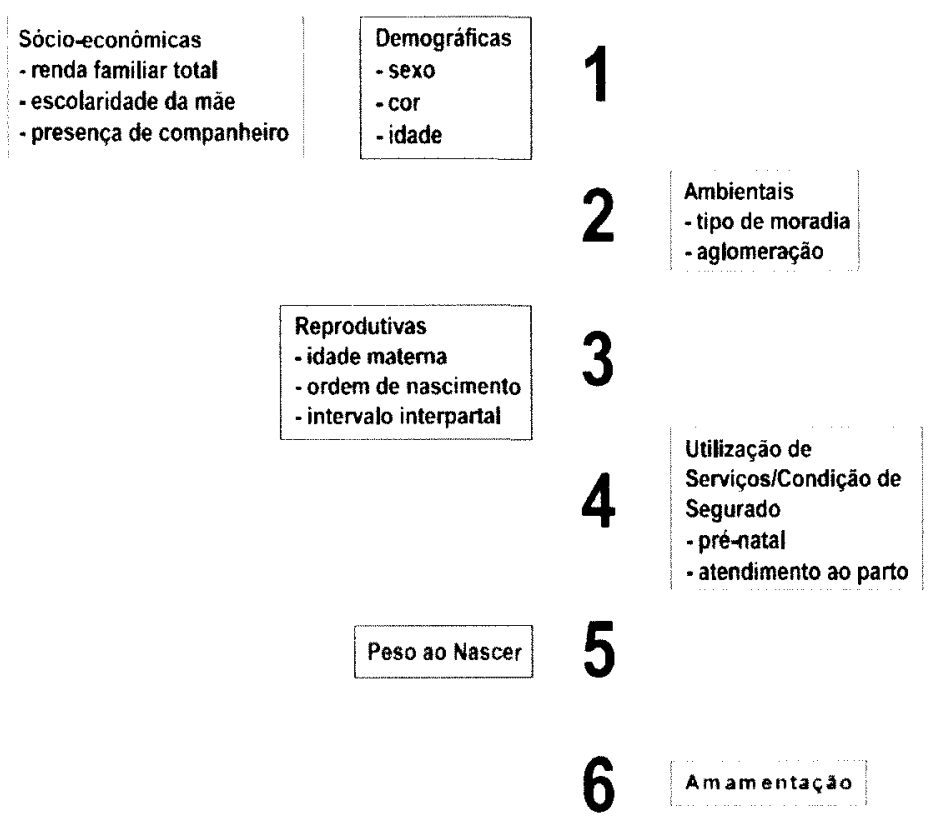

Na regressão logística, quando os valores ignorados foram menores que $5 \%$ de todos os casos, eles foram recodificados para a moda ${ }^{26}$. Não houve, neste estudo, variáveis com mais de $5 \%$ de valores ignorados. 
A regressão logística condicional escolhida foi a retrógrada condicional através do módulo de passos. Os testes estatísticos foram realizados pelo programa SPSS ${ }^{49}$

Não foi possivel estudar a relação entre o tempo e o aleitamento materno, com controle de fatores de confusão, através da Regressão de Cox em virtude de os riscos não serem proporcionais ao longo do tempo. 


\section{Resultados}

\subsection{Descrição da amostra}

No total, foram visitados 9.152 domicilios, tendo sido entrevistados os responsáveis por 2.208 crianças menores de três anos. No primeiro estrato, foram visitados 6.827 domicilios nos quais havia 1.791 crianças $(81,1 \%$ do total de crianças) e, no segundo estrato, 2.325 domicilios onde havia 417 crianças (18,9\%). Não foi possivel entrevistar os responsáveis por 63 crianças $(2,8 \%)$. A causa principal destas perdas foi a ausência do morador (37 casos). No primeiro estrato, as perdas e recusas foram menores do que no segundo estrato $(2,1 \%$ versus $5,7 \%-p<0,001)$.

Para efeitos deste estudo, foram excluídas 20 crianças por parto gemelar e nove por parto trigemelar, tendo em vista a alteração das práticas de amamentação em caso de partos múltiplos e a correlação entre o peso ao nascer (menor em gestações múltiplas) e o aleitamento materno ${ }^{22}$. Estas 20 crianças representaram 21 crianças, após ponderação. Tendo em vista que o objetivo da tese é analisar os serviços prestados no território nacional, foi excluída uma criança cujo pré-natal e parto foi realizado nos Estados Unidos da América. Esta criança representou três crianças após ponderação. Foram ainda excluídas do presente estudo três crianças por terem realizado parto domiciliar (embora uma tenha sido atendida imediatamente após o parto no Hospital São João), representando quatro crianças após ponderação $(0,2 \%)$. Assim, excluiu-se um total de 33 crianças, representando 28 crianças após ponderação. Foram portanto incluídas, neste estudo, 2.180 crianças

\subsubsection{Descrição das variáveis demográficas, sócio-econômicas, ambientais e caracteristicas de saúde reprodutiva para o total da amostra}

Houve pequena predominância na amostra de crianças do sexo masculino $(51,0 \%)$, sendo a distribuição homogênea quanto à idade As crianças amostradas eram predominantemente brancas $(88,8 \%)$; viviam em 
familias com renda familiar total mediana de $\mathrm{R} \$ 478,00^{*}$; seus pais e mães completaram. respectivamente, 7,3 e 6,7 anos de estudo (d.p. 3.5 anos para ambos): $9,9 \%$ das mães relataram não ter companheiro; a idade média das mães era 27,6 anos completos (d.p. 6,8 anos); moravam em malocas, casas de tijolo sem revestimento ou de madeira irregular $18,0 \%$ das crianças; a mediana de aglomeração era 2.5 moradores para cada peça utilizada para dormir Eram primogênitas 38,5\% das crianças. Para os não primogênitos. o intervalo interpartal foi menor que 24 meses para $17,6 \%$ das crianças.

\subsubsection{Descrição do pré-natal para o total da amostra}

Dos 2.180 entrevistados, $47(2,2 \%)$ não souberam informar se a mãe freqüentara alguma consulta de Pré-Natal. Dos que souberam informar, 2.060 realizaram o pré-natal $(96,6 \%), 83,1 \%$ iniciaram o mesmo durante o primeiro trimestre de gestação e $77,5 \%$ fizeram seis ou mais consultas, sendo sete a mediana de consultas. A cobertura de pré-natal adequado foi de $76,6 \%$.

Quatorze entrevistados $(0,7 \%)$ não souberam relatar os procedimentos realizados durante as consultas de Pré-Natal. Segundo relato do responsável pela criança, durante o pré-natal $98,6 \%$ das gestantes tiveram seu peso determinado; $98,3 \%$, a medida da altura uterina verificada; $97,4 \%$, a pressão arterial mensurada; a data da última menstruação foi verificada em 96,9\% dos casos; realizaram exame de sangue $93,0 \%$ das gestantes; receberam orientação sobre imunização anti-tetânica 79,3\%; sobre amamentação, 71,3\%. Houve prescrição de ferro para $58,7 \%$ das gestantes. O exame ginecológico especular foi realizado em $51,0 \%$ das gestantes e $50,6 \%$ das gestantes tiveram suas mamas examinadas

Foram realizados em média no Pré-Natal 7,9 procedimentos do total de dez procedimentos pesquisados (d.p. 1,5). Para este cálculo foram excluídas além das mães que não souberam informar se foi realizado qualquer procedimento (14), outras duas mães que souberam informar apenas um procedimento (estas mães estavam a 4,6 d.p. da média). Dentre as mães que

\footnotetext{
* No inicio da pesquisa (março/96) um dólar equivalia a 98 centavos de real; ao final da mesma (junho/96) um dólar equivalia a um real, permitindo a comparabilidade em termos de equivalência dólar/real
} 
foram incluídas na análise, três mães souberam informar sete procedimentos e uma mãe informou apenas seis procedimentos. As demais mães souberam informar se foram realizados ou não ao menos oito dos dez procedimentos pesquisados.

A forma de pagamento do pré-natal foi: SUS para $1.533(74,5 \%)$ das gestantes; particular para $359(17,4 \%)$; e outras formas de pagamento para 167 $(8,1 \%)$.

Conforme pode ser visto na figura 2, houve maior participação do SUS no atendimento Pré-Natal entre as crianças nascidas nos últimos 11 meses $(p=0,02)$ em relação às nascidas há 12 meses ou mais.

Figura 2. Forma de pagamento do pré-natal e parto, por idade da criança, no município de Criciúma - 1996

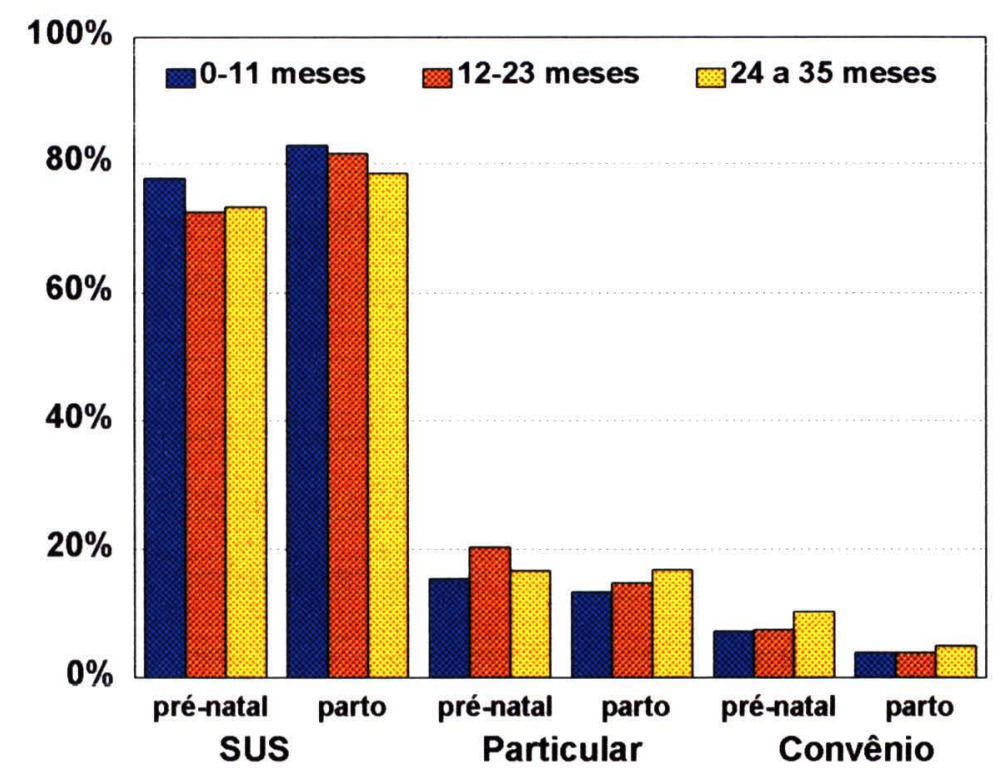




\subsubsection{Descrição do atendimento ao "Parto/RN" para o total da amostra}

$\mathrm{O}$ atendimento "Parto/RN" foi realizado basicamente em dois hospitais (São João $46,4 \%$ e São José $40,3 \%$ ). O pagamento do "Parto/RN" foi efetivado pelo SUS em $81,0 \%$ dos casos, particular em $14,9 \%$ e, através de outras formas de pagamento, em 4,1\%. Foram pagos pelo SUS $83,9 \%$ dos atendimentos "Parto/RN" no Hospital São João e 81,3\% no Hospital São José. Estes diferiram significativamente dos outros hospitais, onde $69,5 \%$ dos atendimentos "Parto/RN" foram pagos pelo SUS $(p<0,001)$

Das 2.180 crianças, apenas $37(1,8 \%)$ foram colocadas para mamar, logo após o nascimento, em tempo igual ou inferior a 30 minutos; para 50,3\% das crianças o tempo foi superior a seis horas

O alojamento conjunto integral foi oferecido a $35,0 \%$ das crianças. Houve associação significativa entre o hospital do parto e a utilização do alojamento conjunto: apenas $17,5 \%$ das crianças do Hospital São João permaneceram em alojamento conjunto em comparação com $48,4 \%$ no Hospital São José e $57,5 \%$ em outros hospitais.

No hospital receberam orientação sobre como cuidar da criança 44,2\% das mães. As principais orientações recebidas foram: amamentação (80,5\%); higiene $(37,6 \%)$; como cuidar do umbigo $(24,1 \%)$; imunização $(19,4 \%)$ e cólicas $(10,9 \%)$

De forma semelhante ao que ocorreu no Pré-Natal, houve maior participação do SUS no atendimento ao "Parto/RN" no último ano $(p=0,04$ linear). Pode ser observado ainda, na figura 2, que há maior número de atendimentos ao "Parto/RN" pelo SUS em relação ao Pré-Natal em todos os três anos pesquisados

\subsubsection{Descrição geral do Aleitamento Materno}

A mediana de duração do aleitamento materno, obtida através da curva de sobrevivência foi de 4,8 meses. As medianas por quartis de renda familiar total foram: 4,$7 ; 4,1 ; 4,6$ e 6,0 do primeiro ao quarto quartil respectivamente (figura 3) 
A prevalência de aleitamento materno predominante, no quarto mês de vida, foi $32,1 \%$. Apenas $8,1 \%$ destas crianças foram amamentadas exclusivamente ao seio.

Figura 3. Curva de sobrevivência para o tempo amamentaçăo segundo quartis de renda familiar total - Criciúma - 1996

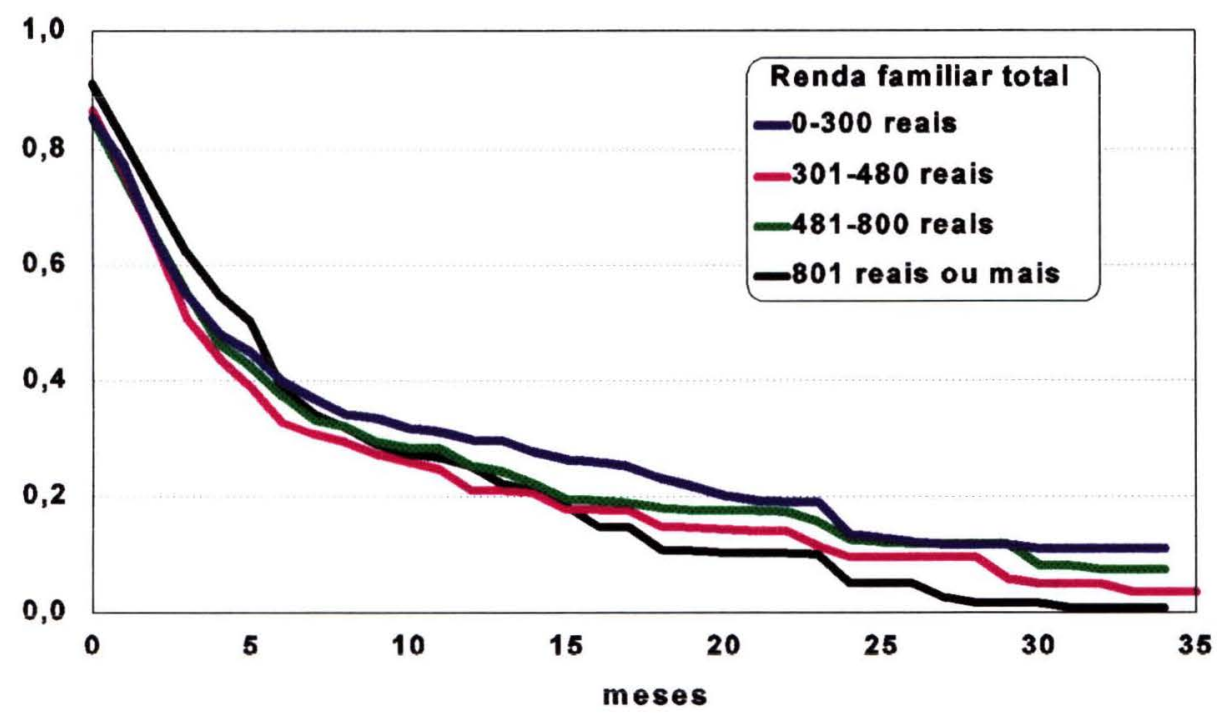

A maior renda familiar total esteve associada linearmente com o aumento da prevalência de aleitamento materno predominante, sendo $21,8 \%$ a prevalência no primeiro quartil e $48,5 \%$ no quarto quartil $(p<0,001)$. Não foram encontradas diferenças significativas no aleitamento materno exclusivo conforme a renda familiar total.

A introdução da mamadeira ocorreu antes dos quatro meses para $62,2 \%$ das crianças, sendo a mediana de introdução da mamadeira obtida através da curva de sobrevivência de 2,7 meses. Observou-se ainda que, quanto menor a renda, maior a prevalência de introdução da mamadeira antes dos quatro meses $(64,5 \%$ para o primeiro quartil e $57,4 \%$ para o último quartil, $p=0,004$ linear). 
$\mathrm{Na}$ figura 4, pode ser observado as proporções de crianças menores de um ano que foram amamentadas, segundo dois critérios: (1) padrão alimentar no momento da entrevista e (2) curva de sobrevivência para o aleitamento materno. Houve diferença significativa aos dois meses de idade $(p=0,002)$ e aos 12 meses $(p=0,03)$. O padrão alimentar no momento da entrevista foi comparado também com a curva de sobrevivência do aleitamento materno de todas as crianças menores de três anos: houve diferença significativa aos dois meses de idade $(p=0,003)$, aos 10 meses $(p=0,02)$ e aos 12 meses $(p=0,04)$.

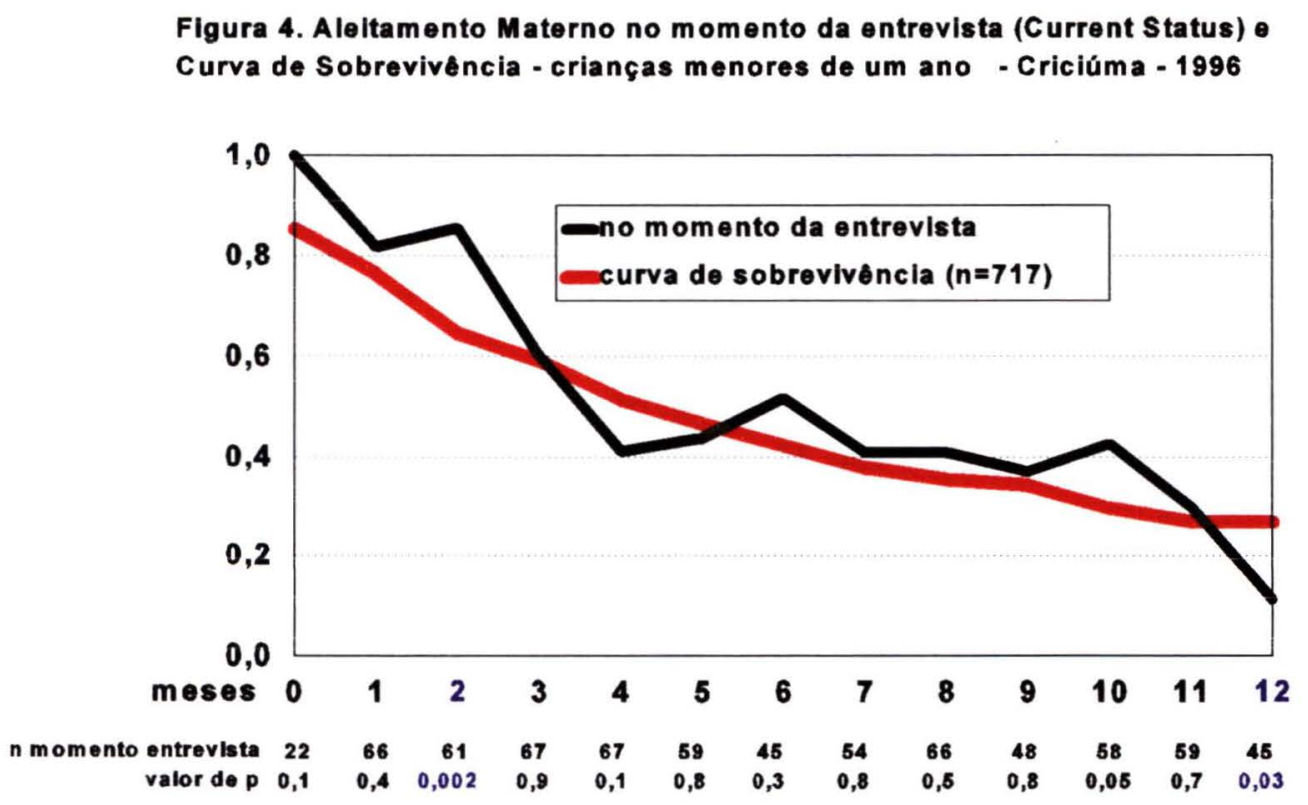

\subsection{Análise da Eqüidade}

\subsubsection{Qualidade técnica dos Serviços de Saúde em relação à Renda} Familiar Total

A tabela 1 mostra as associações entre a qualidade técnica do atendimento de Pré-Natal em relação aos quartis de renda familiar total. Observou-se que 95,2\% das mães do primeiro quartil de renda familiar total realizaram o Pré-Natal, havendo tendência linear de maior prevalência de realização deste com o aumento da renda. As mães com menor renda 
Tabela 1. Análise não ajustada da qualidade técnica do Pré-Natal, conforme renda familiar total em quartis*. Criciúma, 1996.

\begin{tabular}{|c|c|c|c|c|c|}
\hline \multirow[b]{2}{*}{ Atividades } & \multirow{2}{*}{$\begin{array}{c}\% \\
\text { crianças } \\
\text { (n total) }\end{array}$} & \multicolumn{4}{|c|}{ Renda Familiar Total } \\
\hline & & $\begin{array}{c}1^{\circ} \\
\text { quartil }\end{array}$ & $\begin{array}{l}2^{\circ} \\
\text { quartil }\end{array}$ & $\begin{array}{c}3^{\circ} \\
\text { quartil }\end{array}$ & $\begin{array}{c}4^{\circ} \\
\text { quartil } \\
(+)\end{array}$ \\
\hline \multicolumn{6}{|c|}{ Pré-Natal } \\
\hline \multirow[t]{2}{*}{ Fizeram Pré-Natal } & $(2118)$ & & & & $(p=0,006)$ \\
\hline & $96.6 \%$ & $95,2 \%$ & $95,7 \%$ & $98,1 \%$ & $97,5 \%$ \\
\hline \multirow[t]{2}{*}{ Iniciaram no $1^{\circ}$ trimestre } & $(2032)$ & & & & $(p<0,001)$ \\
\hline & $83,2 \%$ & $73,9 \%$ & $86,7 \%$ & $86,5 \%$ & $87,7 \%$ \\
\hline \multirow[t]{2}{*}{ Foram a 6 ou + consultas } & $(2032)$ & & & & $(p<0,001)$ \\
\hline & $77,6 \%$ & $66.7 \%$ & $80,0 \%$ & $81,7 \%$ & $84,4 \%$ \\
\hline \multirow{2}{*}{$\begin{array}{l}\text { Iniciaram no } 1^{\circ} \text { trimestre e } \\
\text { foram a } 6 \text { ou }+ \text { consultas }\end{array}$} & $(1690)$ & & & & $(p<0,001)$ \\
\hline & $92,3 \%$ & $88,3 \%$ & $91,9 \%$ & $92,8 \%$ & $96,1 \%$ \\
\hline \multirow{2}{*}{$\begin{array}{l}\text { Inicio e } n^{\circ} \text { consultas } \\
\text { adequado }\end{array}$} & $(2032)$ & & & & $(p<0,001)$ \\
\hline & $76,7 \%$ & $65.3 \%$ & $79,7 \%$ & $80,2 \%$ & $84,4 \%$ \\
\hline \multicolumn{6}{|c|}{ Conduta no Pré-Natal } \\
\hline $\begin{array}{l}\text { Verificação da data última } \\
\text { menstruação }\end{array}$ & $\begin{array}{c}(2019) \\
96,9 \%\end{array}$ & $95,0 \%$ & $96,1 \%$ & $97,6 \%$ & $\begin{array}{r}(p<0,001) \\
99,3 \%\end{array}$ \\
\hline Determinação do peso & $\begin{array}{l}(2030) \\
98,6 \%\end{array}$ & $98,3 \%$ & $97,8 \%$ & $99,2 \%$ & $\begin{array}{r}(p=0,2 \ddagger) \\
99,1 \%\end{array}$ \\
\hline Medida da altura uterina & $\begin{array}{l}(2029) \\
98,3 \%\end{array}$ & $97,6 \%$ & $98,3 \%$ & $98,3 \%$ & $\begin{array}{r}(p=0,4 f) \\
99,0 \%\end{array}$ \\
\hline Medida da pressão arterial & $\begin{array}{l}(2027) \\
97,4 \%\end{array}$ & $98,0 \%$ & $97,0 \%$ & $96,1 \%$ & $\begin{array}{r}(p=0,05 \ddagger) \\
98,7 \%\end{array}$ \\
\hline $\begin{array}{l}\text { Exame ginecológico } \\
\text { especular }\end{array}$ & $\begin{array}{l}(2014) \\
50,9 \%\end{array}$ & $47,2 \%$ & $40,3 \%$ & $46,4 \%$ & $\begin{array}{r}(p<0,001) \\
70,2 \%\end{array}$ \\
\hline Prescrição de ferro & $\begin{array}{l}(2020) \\
58,7 \%\end{array}$ & $63,8 \%$ & $60,5 \%$ & $57,0 \%$ & $\begin{array}{r}(p<0,001) \\
52,6 \%\end{array}$ \\
\hline $\begin{array}{l}\text { Orientação sobre } \\
\text { amamentação }\end{array}$ & $\begin{array}{l}(2027) \\
71,5 \%\end{array}$ & $67,6 \%$ & $69,6 \%$ & $70,1 \%$ & $\begin{array}{r}(p<0,001) \\
79,7 \%\end{array}$ \\
\hline Exame de sangue & $\begin{array}{l}(2030) \\
93,0 \%\end{array}$ & $91,8 \%$ & $94,1 \%$ & $92,3 \%$ & $\begin{array}{r}(p=0,3 \ddagger) \\
94,1 \%\end{array}$ \\
\hline Exame das mamas & $\begin{array}{l}(2029) \\
50,6 \%\end{array}$ & $38,5 \%$ & $41,7 \%$ & $52,2 \%$ & $\begin{array}{r}(p<0,001) \\
71,9 \%\end{array}$ \\
\hline $\begin{array}{l}\text { Orientação sobre vacina } \\
\text { anti-tetânica }\end{array}$ & $\begin{array}{l}(2022) \\
79,4 \%\end{array}$ & $79,5 \%$ & $81,8 \%$ & $78,9 \%$ & $\begin{array}{r}(p=0,4 \ddagger) \\
77,4 \%\end{array}$ \\
\hline $\begin{array}{l}\text { O primeiro quartil incluiu fam } \\
\text { quartil: } R \$ 301 \text { a } R \$ 408 \text {; terc } \\
\text { R\$800. } \\
\dagger \quad p \text { valor }=\text { Teste para tendênc } \\
\ddagger \quad \text { p valor }=\text { Teste do qui-quadr }\end{array}$ & $\begin{array}{l}\text { linear em pr } \\
\text { o de Pearsor }\end{array}$ & $\begin{array}{l}\text { amiliar tot } \\
481 \text { a } R \$ 8\end{array}$ & $\begin{array}{l}\text { Imenor ou } \\
\text { ao; quarto }\end{array}$ & $\begin{array}{l}\text { igual a R } \\
\text { quartil: re }\end{array}$ & $\begin{array}{l}\text { 300; segundo } \\
\text { da maiur que }\end{array}$ \\
\hline
\end{tabular}


iniciaram o pré-natal mais tarde e realizaram menos consultas. As mães com menor renda relataram com menos freqüência a verificação da data da última menstruação, a realização de exame ginecológico (especular e de mamas) e a orientação sobre amamentação. Estas mães referiram, no entanto, maior prescrição de ferro.

No atendimento ao "Parto/RN" (tabela 2) não foi encontrada diferença no tempo de colocação da criança para mamar após o parto. Este mesmo resultado foi encontrado quando esta análise foi refeita excluindo as 27 crianças que nunca mamaram. Esta exclusão foi testada em virtude das características especiais destas crianças, das quais destacamos o baixo peso ao nascer $(42,5 \%$ contra $5,6 \%$ das demais crianças - $p<0,001)$. As mães de menor renda utilizaram mais o alojamento conjunto integral e receberam menos orientação no hospital sobre como cuidar da criança e amamentação.

Tabela 2. Análise não ajustada da qualidade técnica do atendimento ao "Parto/RN", conforme quartis de renda familiar total`. Criciúma, 1996.

Renda Familiar Total

\begin{tabular}{|c|c|c|c|c|c|}
\hline Atividades & $\begin{array}{c}\% \\
\text { crianças } \\
\text { (n total) }\end{array}$ & $\begin{array}{c}1^{\circ} \\
\text { quartil }\end{array}$ & $\begin{array}{c}2^{\circ} \\
\text { quartil }\end{array}$ & $\begin{array}{c}3^{\circ} \\
\text { quartil }\end{array}$ & $\begin{array}{c}4^{\circ} \\
\text { quartil } \\
(\dagger)\end{array}$ \\
\hline $\begin{array}{l}\text { Colocada para mamar até } 2 \\
\text { horas após o nascimento }\end{array}$ & $\begin{array}{l}(2034) \\
11,5 \%\end{array}$ & $13,4 \%$ & $11,3 \%$ & $9,5 \%$ & $\begin{array}{r}(p=0,2 \ddagger) \\
11,6 \%\end{array}$ \\
\hline Alojamento conjunto integral & $\begin{array}{l}(2104) \\
34,9 \%\end{array}$ & $38,4 \%$ & $34,7 \%$ & $33,1 \%$ & $\begin{array}{r}(p=0,03) \\
32,5 \%\end{array}$ \\
\hline $\begin{array}{l}\text { Orientação geral para a mãe } \\
\text { no hospital }\end{array}$ & $\begin{array}{l}(2087) \\
44,3 \%\end{array}$ & $37,6 \%$ & $43,1 \%$ & $43,0 \%$ & $\begin{array}{r}(p<0,001) \\
55,6 \%\end{array}$ \\
\hline $\begin{array}{l}\text { Orientação sobre } \\
\text { amamentação para a mãe } \\
\text { no hospital }\end{array}$ & $\begin{array}{l}(2087) \\
35,8 \%\end{array}$ & $30,0 \%$ & $34,0 \%$ & $35,2 \%$ & $\begin{array}{r}(p<0,001) \\
45,3 \%\end{array}$ \\
\hline $\begin{array}{ll} & \text { O primeiro quartil incluiu fam } \\
\text { segundo quartil: } R \$ 301 \text { a } \\
\text { renda maior que } R \$ 800 . \\
+\quad p \text { valor }=\text { Teste para tendên } \\
\ddagger \quad p \text { valor }=\text { Teste do qui-quad }\end{array}$ & $\begin{array}{l}\text { ias com re } \\
408 \text {; terce }\end{array}$ & $\begin{array}{l}\text { Ja famili } \\
\text { o quartil }\end{array}$ & total me & $\begin{array}{l}\text { hor ou ig } \\
\text { र\$800; }\end{array}$ & $\begin{array}{l}\text { al a } R \$ 300 \\
\text { arto quartil }\end{array}$ \\
\hline
\end{tabular}


Na tabela 3, pode-se observar que as mães do quarto quartil de renda apresentaram média de procedimentos significativamente superiores aos demais quartis, tanto para os procedimentos de Pré-Natal como para os de atenção ao "Parto/RN".

Tabela 3. Análise não ajustada da média de procedimentos* de qualidade técnica do Pré-Natal e atendimento ao "Parto/RN", conforme a renda familiar total. Criciúma, 1996.

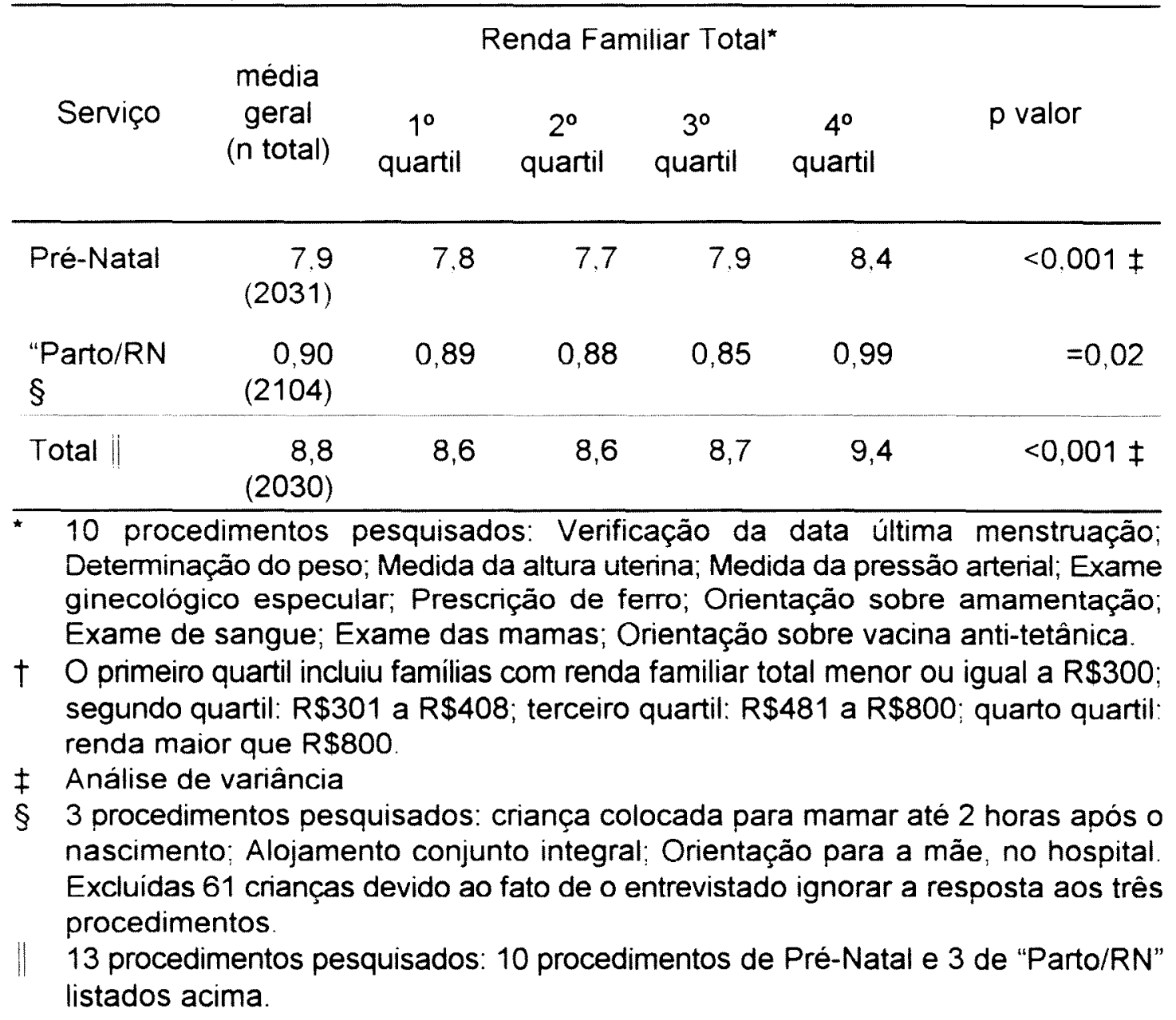




\subsubsection{Qualidade técnica dos Serviços de Saúde em relação ao "Risco de} saúde reprodutiva"

Na tabela 4 , pode ser observado que as mães com duas ou três situações de "Risco de saúde reprodutiva" apresentaram menor percentagem de atendimento com qualidade adequada (realização de no mínimo 11 procedimentos técnicos dos 13 previstos para o Pré-Natal e "Parto/RN"). A média de procedimentos realizados foi semelhante para os diversos grupos de risco.

Tabela 4. Análise não ajustada comparando de procedimentos de qualidade técnica do Pré-Natal e atendimento ao "Parto/RN" conforme escore de risco referente a características de saúde reprodutiva. Criciúma, 1996.

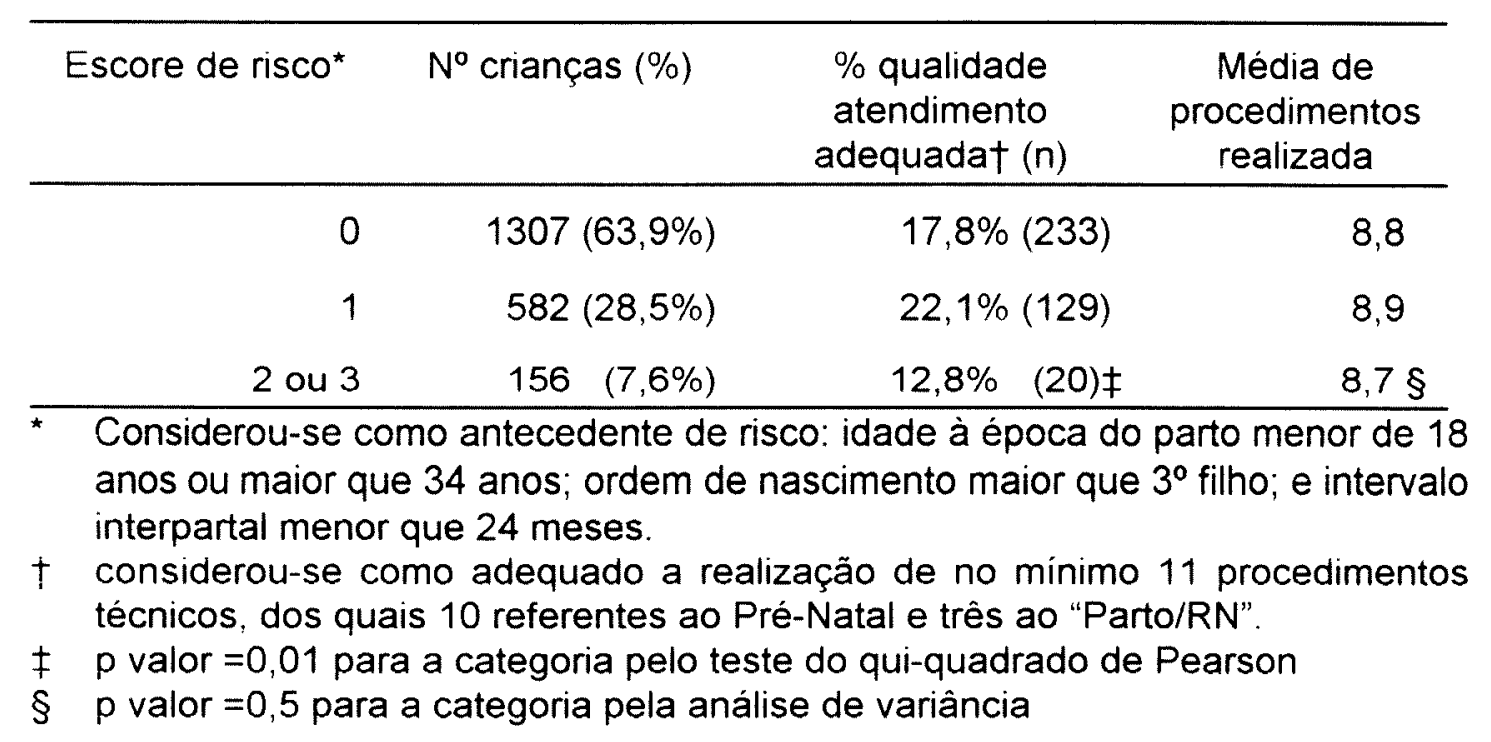

\subsection{Análise da Qualidade Técnica da Atenção Prestada conforme a Forma de Pagamento}

\subsubsection{Descrição da amostra por forma de pagamento dos Serviços de Saúde}

$\mathrm{Na}$ análise da forma de pagamento tanto, do Pré-Natal como do "Parto/RN", foram excluídas $122(5,6 \%)$ crianças: $72(3,3 \%)$ por não terem realizado o Pré-Natal; 48 (2,2\%) por não ter sido possivel identificar se fizeram 
o Pré-Natal; e duas crianças $(0,1 \%)$, por não ter sido possível identificar onde - pré-natal foi realizado. Foram, portanto, incluidas nesta análise 2.158 crianças.

Constituiram o grupo "Sempre SUS" 1.437 crianças $(69,9 \%)$; o grupo "Sempre Particular" 307 crianças (14,9\%); o grupo "Particular->SUS" 218 crianças (10,6\%); e o grupo "SUS->Particular" 96 crianças $(4,6 \%)$.

A tabela 5 apresenta as análises entre a forma de pagamento do PréNatal e "Parto/RN" e as variáveis demográficas e sócio-econômicas. O grupo "Sempre SUS" foi significativamente distinto dos demais grupos por ser proporcionalmente composto por menos brancos; parto mais recente; familias com menor renda familiar total; menor escolaridade materna; maior número de mães jovens e sem companheiro.

A relação entre a forma de pagamento e as variáveis ambientais e de saúde reprodutiva podem ser vistas na tabela 6 . Com relação às condições de moradia, as mães "Sempre SUS" moram em casas mais precárias e com maior aglomeração; em relação à história reprodutiva, suas crianças têm maior ordem de nascimento e menor intervalo interpartal.

Apresentaram uma ou mais características de saúde reprodutiva de risco 39,7\% das mães "Sempre SUS"; 39,0\% das "SUS->Particular"; 30,3\% das "Particular->SUS" e 23,9\% das "Sempre Particular" $(p<0,001)$.

\subsubsection{Descrição das características das mães que utilizaram diferentes} formas de pagamento para os serviços de Pré-Natal e "Parto/RN"

A fim de destacar as diferenças demográficas, sócio-econômicas, ambientais e de saúde reprodutiva entre os grupos, a análise entre os mesmos foi realizada separadamente, dois a dois.

O grupo "SUS->Particular" apresentou maior renda familiar total ( $p<0,001$ linear), maior escolaridade $(p=0,001$ linear), mães mais velhas $(p<0,001$ linear) e maior ordem de nascimento $(p=0,01$ linear) que o grupo "Sempre SUS". Estes grupos eram semelhantes em termos de sexo e cor da criança (esta com $p=0,05$ ), presença do companheiro, aglomeração no domicilio, tipo de moradia e intervalo intergestacional. Ao analisar a mudança, por parte da usuária, da forma de pagamento do parto em relação ao Pré-Natal 
Tabela 5 Percentuais de crianças conforme variáveis demográficas e sócioeconômicas e forma de pagamento do atendimento Pré-Natal e "Parto/RN". Criciúma, 1996.

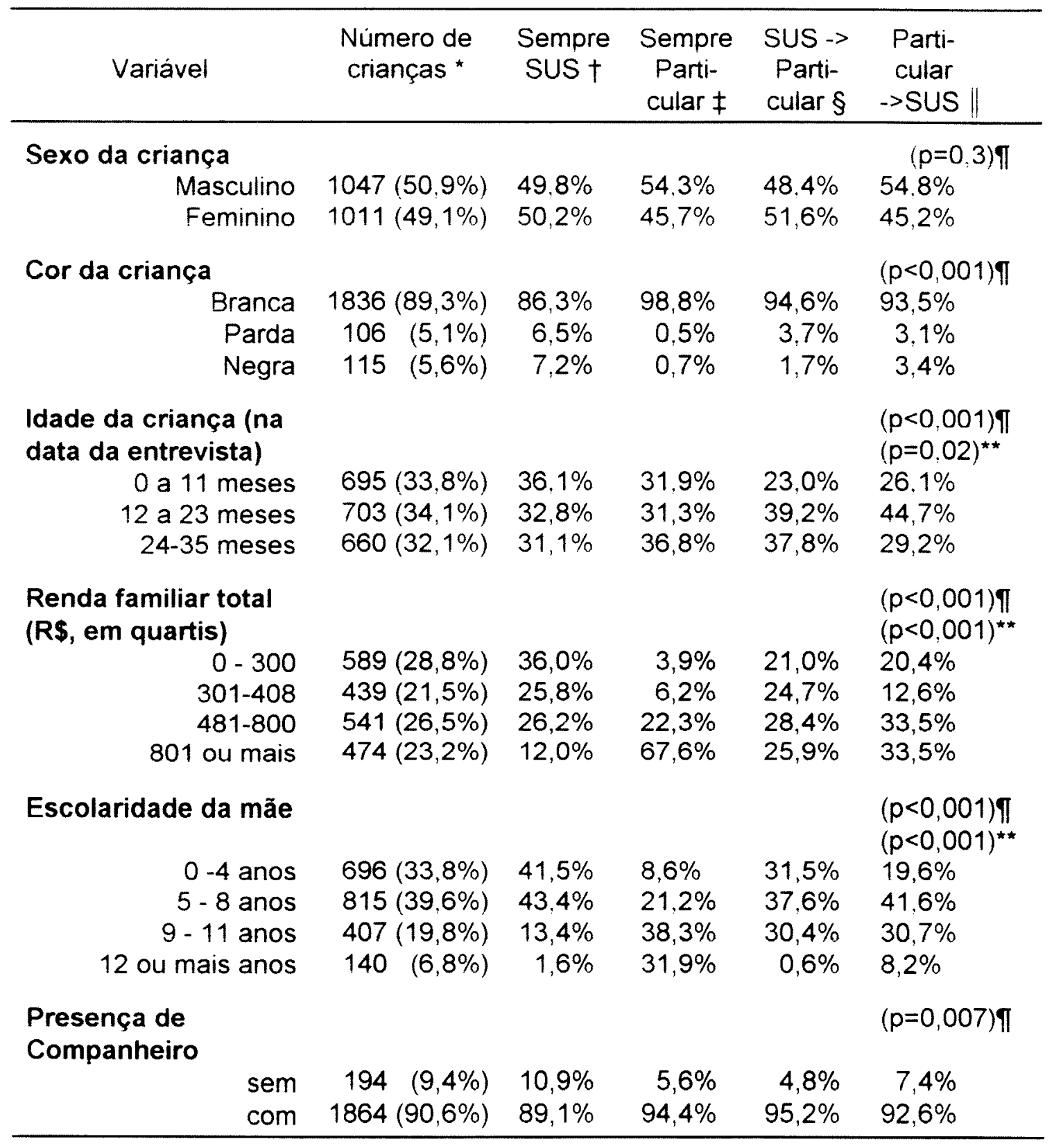

* Das 2.180 crianças deste estudo 72 (3,3\%) não fizeram o Pré-Natal, para outras 48 crianças $(2,2 \%)$ não foi possivel identificar se fizeram o Pré-Natal e para 2 $(0,1 \%)$ crianças que fizeram o Pré-Natal não foi possivel identificar onde o mesmo foi realizado. Portanto, esta análise refere-se a 2.058 crianças.

$\dagger$ Realizaram o Pré-Natal e o "Parto/RN" pelo SUS ( $n=1437)$

† Realizaram o Pré-Natal e o "Parto/RN" particular/outro tipo de pagamento $(n=307)$

$\S$ Realizaram o Pré-Natal pelo SUS e o "Parto/RN" particular/outro tipo de pagamento $(n=96)$

|| Realizaram o Pré-Natal particular/outro tipo de pagamento e "Parto/RN" pelo SUS $(n=218)$

IT $\mathrm{p}$ valor $=$ Teste do qui-quadrado de Pearson

** Teste de associação linear de Mantel-Haenszel 
Tabela 6. Percentuais de crianças conforme variáveis ambientais e de saúde reprodutiva e forma de pagamento do atendimento Pré-Natal e "Parto/RN". Criciúma, 1996

\begin{tabular}{|c|c|c|c|c|c|}
\hline Variável & $\begin{array}{l}\text { Número de } \\
\text { crianças } \\
(n=2.058)\end{array}$ & $\begin{array}{c}\text { Sempre } \\
\text { SUS }+\end{array}$ & $\begin{array}{c}\text { Sempre } \\
\text { Parti- } \\
\text { cular } \ddagger\end{array}$ & $\begin{array}{l}\text { SUS -> } \\
\text { Parti- } \\
\text { cular } \$\end{array}$ & $\begin{array}{l}\text { Parti- } \\
\text { cular } \\
\text {->SUS || }\end{array}$ \\
\hline \multicolumn{6}{|c|}{ Variáveis ambientais } \\
\hline $\begin{array}{l}\text { Tipo de moradia } \\
\text { irregular (maloca,...) } \\
\text { regular }\end{array}$ & $\begin{array}{r}356(17,6 \%) \\
1663(82,4 \%)\end{array}$ & $\begin{array}{l}23,1 \% \\
76,9 \%\end{array}$ & $\begin{array}{r}1,6 \% \\
98,4 \%\end{array}$ & $\begin{array}{l}15,3 \% \\
84,7 \%\end{array}$ & $\begin{array}{l}(p<0,001) \pi \\
5,3 \% \\
94,7 \%\end{array}$ \\
\hline $\begin{array}{l}\text { Aglomeração } \\
\text { (moradores/peça) }\end{array}$ & & & & & $\begin{array}{l}(p<0,001) \Uparrow \\
(p<0,001)^{\star *}\end{array}$ \\
\hline $\begin{array}{r}<=2 \\
2,1 \text { a } 3 \\
3,1 \text { ou mais }\end{array}$ & $\begin{array}{l}859(41,7 \%) \\
837(40,7 \%) \\
362(17,6 \%)\end{array}$ & $\begin{array}{l}35,9 \% \\
42,5 \% \\
21,6 \%\end{array}$ & $\begin{array}{r}59,6 \% \\
32,6 \% \\
7,8 \%\end{array}$ & $\begin{array}{l}41,9 \% \\
39,5 \% \\
18,6 \%\end{array}$ & $\begin{array}{l}55,3 \% \\
40,3 \% \\
4,4 \%\end{array}$ \\
\hline \multicolumn{6}{|c|}{ Características de saúde reprodutiva } \\
\hline $\begin{array}{r}<20 \\
20-24 \\
25-29 \\
30-34 \\
>=35\end{array}$ & $\begin{array}{l}246(11,9 \%) \\
523(25,4 \%) \\
537(26,2 \%) \\
475(23,1 \%) \\
277(13,4 \%)\end{array}$ & $\begin{array}{l}15,2 \% \\
28,9 \% \\
24,7 \% \\
19,4 \% \\
11,8 \%\end{array}$ & $\begin{array}{r}1,8 \% \\
14,6 \% \\
30,5 \% \\
34,2 \% \\
18,9 \%\end{array}$ & $\begin{array}{r}3,7 \% \\
15,5 \% \\
29,9 \% \\
39,8 \% \\
11,1 \%\end{array}$ & $\begin{array}{c}(p<0,001) \prod \\
(p<0,001)^{\star \star} \\
8,2 \% \\
22,4 \% \\
27,9 \% \\
23,9 \% \\
17,6 \%\end{array}$ \\
\hline $\begin{array}{l}\text { Ordem de } \\
\text { nascimento } \\
\text { primogênito } \\
2^{\circ} \text { ou } 3^{\circ} \text { filho } \\
4^{\circ} \text { filho ou mais }\end{array}$ & $\begin{array}{r}796(38,7 \%) \\
1023(49,7 \%) \\
239(11,6 \%)\end{array}$ & $\begin{array}{l}37,8 \% \\
48,7 \% \\
13,5 \%\end{array}$ & $\begin{array}{c}41,8 \% \\
53,5 \% \\
4,7 \%\end{array}$ & $\begin{array}{l}22,8 \% \\
60,5 \% \\
16,7 \%\end{array}$ & $\begin{array}{l}(p<0,001) \prod \\
(p=0,008)^{\star \star} \\
47,2 \% \\
46,0 \% \\
6,8 \%\end{array}$ \\
\hline $\begin{array}{l}\text { Intervalo interpartal } \\
\text { (meses) } \dagger \dagger\end{array}$ & & & & & $(p=0,007) \pi$ \\
\hline $\begin{array}{l}<24 \\
>=24\end{array}$ & $\begin{array}{r}217(17,6 \%) \\
1020(82,4 \%)\end{array}$ & $\begin{array}{l}19,1 \% \\
80,9 \%\end{array}$ & $\begin{array}{l}15,8 \% \\
84,2 \%\end{array}$ & $\begin{array}{l}20,4 \% \\
79,6 \%\end{array}$ & $\begin{array}{r}5,9 \% \\
94,1 \%\end{array}$ \\
\hline
\end{tabular}

* Das 2.180 crianças deste estudo $72(3,3 \%)$ não fizeram o Pré-Natal, para outras 48 crianças $(2,2 \%)$ não foi possivel identificar se fizeram o Pré-Natal e para 2 $(0,1 \%)$ crianças que fizeram o Pré-Natal não foi possivel identificar onde o mesmo foi realizado. Portanto, esta análise refere-se a 2.058 crianças.

$\dagger$ Realizaram o Pré-Natal e o "Parto/RN" pelo SUS

‡ Realizaram o Pré-Natal e o "Parto/RN" particular/outro tipo de pagamento

$\S$ Realizaram o Pré-Natal pelo SUS e o "Parto/RN" particular/outro tipo de pagamento

II Realizaram o Pré-Natal particular/outro tipo de pagamento e "Parto/RN" pelo SUS

I $\mathrm{p}$ valor $=$ Teste do qui-quadrado de Pearson

** Teste de associação linear de Mantel-Haenszel

t† Exclui os primogênitos 
no grupo "SUS->Particular", verifica-se que esta ocorreu em menor proporção no último ano, em relação aos dois anos anteriores.

O grupo "Particular->SUS" era composto por menor número de brancos $(p=0,005)$, tinham menor renda familiar total $(p<0,001$ linear), mães com menos anos de estudo ( $p<0,001$ linear), maior proporção de moradias precárias $(p=0,04)$, mães mais jovens $(p<0,001$ linear) e maior intervalo interpartal $(p=0,02)$ que o grupo "Sempre Particular". Estes grupos eram semelhantes em termos de sexo da criança, presença do companheiro, aglomeração no domicilio e ordem de nascimento. O pré-natal Particular e parto pelo SUS ("grupo Particular->SUS") foi mais freqüente para as crianças entre 12 e 23 meses de idade. O pagamento Particular para ambos os serviços (grupo "Sempre Particular") foi mais freqüente para as crianças com 24 meses ou mais.

Ao se comparar as que mudaram de forma de pagamento, o grupo "SUS ->Particular" apresentou menor escolaridade ( $p=0,009$ linear), maior aglomeração ( $p<0,001$ linear), moradias mais precárias $(p=0,007)$, mulheres entre 30 e 34 anos de idade $(p=0,02)$, maior ordem de nascimento $(p<0,001$ linear) e menor intervalo interpartal $(p=0,007)$ em relação ao grupo "Particular>SUS". Não foi encontrada variação significativa em relação ao período de ocorrência da a mudança da forma de pagamento do parto em relação ao PréNatal.

\subsubsection{Mudança da forma de pagamento do parto em relação ao Pré-Natal}

\section{e a medicalização do atendimento ao parto}

O tipo de parto oferecido para cada forma de pagamento pelo serviço pode ser visto na tabela 7. A maior parte dos partos particulares foi cesariana: $57,0 \%$ para as "Sempre Particular" e 65,8\% para as "SUS->Farticular". Neste último grupo, 56,2\% das mulheres encontravam-se laqueadas no momento da entrevista. A prevalência de laqueadura tubária no grupo "SUS->Particular" foi 2,1 vezes maior que o grupo "Sempre Particular" e 5,2 vezes maior que o grupo com menor prevalência de laqueadura tubária ("Sempre SUS"). 
Dentre as mulheres que fizeram parto normal, 7,2\% encontravam-se laqueadas no momento da entrevista. Entre as que fizeram parto cesariano, a proporção de laqueadas era de $32,6 \%(p<0,001)$

Tabela 7. Caracteristicas selecionadas do atendimento ao "Parto/RN" conforme forma de pagamento do atendimento Pré-Natal e "Parto/RN". Criciúma, 1996.

\begin{tabular}{|c|c|c|c|c|c|}
\hline Variável & $\begin{array}{c}\% \\
\text { crianças } \\
(n=2058) \\
\star\end{array}$ & $\begin{array}{c}\text { Sempre } \\
\text { SUS }+\end{array}$ & $\begin{array}{l}\text { Sempre } \\
\text { Parti- } \\
\text { cular } \neq\end{array}$ & $\begin{array}{l}\text { SUS -> } \\
\text { Parti- } \\
\text { cular } \$\end{array}$ & $\begin{array}{l}\text { Parti- } \\
\text { cular } \\
\text {->SUS \| } \\
(p \text { valor } \mathbb{T})\end{array}$ \\
\hline \multirow{2}{*}{$\begin{array}{l}\text { Parto cesariano } \\
\text { Estava laqueada no } \\
\text { momento da entrevista }\end{array}$} & $31,7 \%$ & $24,0 \%$ & $57,0 \%$ & $65,8 \%$ & $\begin{array}{l}(p<0,001) \\
31,9 \%\end{array}$ \\
\hline & $15,3 \%$ & $10,8 \%$ & $27,3 \%$ & $56,2 \%$ & $\begin{array}{l}(p<0,001) \\
10,2 \%\end{array}$ \\
\hline \multirow{5}{*}{\multicolumn{6}{|c|}{$\begin{array}{ll}\text { Das } 2.180 \text { crianças deste estudo } 72(3,3 \%) \text { não fizeram o Pré-Natal, para outras } \\
48 \text { crianças }(2,2 \%) \text { não foi possivel identificar se fizeram o Pré-Natal e para } 2 \\
(0,1 \%) \text { crianças que fizeram o Pré-Natal não foi possivel identificar onde o mesmo } \\
\text { foi realizado. Portanto, esta análise refere-se a } 2.058 \text { crianças. } \\
\dagger \quad \text { Realizaram o Pré-Natal e o "Parto/RN" pelo SUS ( } n=1437) \\
\text { † Realizaram o Pré-Natal e o "Parto/RN" particular/outro tipo de pagamento ( } n=307) \\
\S \quad \begin{array}{l}\text { Realizaram o Pré-Natal pelo SUS e o "Parto/RN" particular/outro tipo de pagamento } \\
(n=96)\end{array} \\
\text { || } \\
\begin{array}{l}\text { Realizaram o Pré-Natal particular/outro tipo de pagamento e "Parto/RN" pelo SUS } \\
(n=218)\end{array}\end{array}$}} \\
\hline & & & & & \\
\hline & & & & & \\
\hline & & & & & \\
\hline & & & & & \\
\hline I valor $=$ Teste do qui & & & & & \\
\hline
\end{tabular}

No grupo "SUS->Particular" 67,9\% das mulheres que sofreram cesariana estavam laqueadas $(p=0,003) ; 40,3 \%$, entre as "Sempre Particular" $(p<0,001) ; 26,6 \%$, entre as "Sempre SUS" $(p<0,001)$; e 15,5\%, entre as "Particular->SUS" $(p=0,12)$.

$\mathrm{Na}$ análise não ajustada, quanto maior a renda familiar total maior a chance de laqueadura tubária: a razão de produtos cruzados (RC) foi de 1,12, com intervalo de confiança (IC) de 95\% entre 1,01 e 1,24. Já a escolaridade materna não apresentou associação com a mesma ( $R C=0,94 ; 1 C 95 \%$ 0,831,07). O ajuste para os fatores de confusão do primeiro nivel hierárquico aumenta o efeito da renda como risco $(R C=1,18 ; I C 95 \% 1,05-1,33)$ e o efeito da escolaridade materna como fator de proteção ( $R C=0,81 ; I C 95 \% 0,69-0,95)$. Para este ajuste permaneceram no modelo a idade da criança, a renda familiar total, a escolaridade da mãe e o estado conjugal. 
A análise da laqueadura tubária ajustada para fatores de confusão (tabela 8) mostrou que, quando comparadas com o grupo "Sempre Particular", o grupo "SUS->Particular" tem maior chance de laqueadura tubária e os grupos "Sempre SUS" e "Particular->SUS" apresentaram menor chance de laqueadura tubária.

Tabela 8. Regressão logística para laqueadura tubária

Razão de Produtos Cruzados (IC 95\%)

\begin{tabular}{|c|c|c|c|c|}
\hline & Variável & Não ajustada & Ajustada * & $\begin{array}{c}\text { Ajustada para } \\
\text { hospital do parto** }\end{array}$ \\
\hline & empre Particular & 1 & 1 & 1 \\
\hline & US->Particular§ & $3,41(2,12-5,49)$ & $2,63(1,39-4,97)$ & $2,21(1,13-4,31)$ \\
\hline & articular->SUS\| & $0,30(0,18-0,50)$ & $0,33(0,18-0,61)$ & $0,31(0,17$ \\
\hline & empre SUSt & $0,32(0,24-0,43)$ & $0,22(0,14-0,34)$ & $0,23(0,15-0,37)$ \\
\hline \multicolumn{5}{|c|}{ Hospital do "Parto/RN" } \\
\hline & ão José & 1 & & 1 \\
\hline & ão João & $0,42(0,32-0,56)$ & -- & $0,33(0,24-0,46)$ \\
\hline & utros & $1,30(0,94-1,78)$ & & $1,07(0,70-1,63)$ \\
\hline & \multicolumn{4}{|c|}{$\begin{array}{l}\text { Ajustado para idade da criança, renda familiar total no último mês (variável continua), } \\
\text { escolaridade da mãe (variável continua), estado conjugal, aglomeração, tipo de } \\
\text { moradia, idade da mãe à época do nascimento da criança, ordem de nascimento da } \\
\text { criança, intervalo interpartal e forma de pagamento do atendimento Pré-Natal e } \\
\text { "Parto/RN". }\end{array}$} \\
\hline 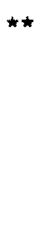 & \multicolumn{4}{|c|}{$\begin{array}{l}\text { Ajustado para idade da criança, renda familiar total no último mês (variável continua), } \\
\text { escolaridade da mãe (variável continua), estado conjugal, aglomeração, tipo de } \\
\text { moradia, idade da mãe à época do nascimento da criança, ordem de nascimento da } \\
\text { criança, intervalo interpartal, forma de pagamento do atendimento Pré-Natal e } \\
\text { "Parto/RN" e hospital do "Parto/RN". }\end{array}$} \\
\hline & \multicolumn{4}{|c|}{ Realizaram o Pré-Natal e o "Parto/RN" pelo SUS ( $n=1437)$} \\
\hline & \multicolumn{4}{|c|}{ Realizaram o Pré-Natal e o "Parto/RN" particular/outro tipo de pagamento $(n=307)$} \\
\hline & \multicolumn{4}{|c|}{$\begin{array}{l}\text { Realizaram o Pré-Natal pelo SUS e o "Parto/RN" particular/outro tipo de pagamento } \\
(n=96)\end{array}$} \\
\hline & \multicolumn{4}{|c|}{$\begin{array}{l}\text { Realizaram o Pré-Natal particular/outro tipo de pagamento e "Parto/RN" pelo SUS } \\
(n=218)\end{array}$} \\
\hline & \multicolumn{4}{|c|}{$p$ valor $=$ Teste do qui-quadrado de Pearson } \\
\hline
\end{tabular}

Ao ser acrescentado no modelo o hospital do parto, diminuiu o risco de laqueadura tubária apontado pela forma de pagamento para as pacientes "SUS->Particular" (RC diminuiu de 2,63 para 2,21). 


\subsubsection{Descrição da qualidade técnica do Pré-Natal e "Parto/RN" e a forma} de pagamento

Na tabela 9 , encontra-se a análise dos procedimentos de qualidade técnica do pré-natal conforme a forma de pagamento do atendimento. O grupo "Sempre SUS" fez menos consultas e iniciou o pré-natal mais tarde tendo pré-natal adequado em $71,8 \%$ dos casos em comparação com $90,9 \%$ do grupo "Sempre Particular". Em relação a terem realizado seis ou mais consultas, a diferença entre os grupos "Sempre SUS" e "Sempre Particular" foi de 19\% para todas as gestantes e de $4 \%$ ao serem analisadas apenas as mães que iniciaram o Pré-Natal no primeiro trimestre

Chama a atenção o fato de as usuárias "Sempre SUS" apresentarem menos da metade da freqüência de exames ginecológico (especular e de mamas) que as "Sempre Particular". O único procedimento mais prevalente nas "Sempre SUS" foi a prescrição de ferro. As usuárias que mudaram de forma de pagamento entre o Pré-Natal e o "Parto/RN" apresentaram atendimento intermediário entre as "Sempre SUS" e as "Sempre Particular".

Os procedimentos de qualidade técnica do atendimento "Parto/RN" conforme a forma de pagamento do atendimento pré-natal estão descritos na tabela 10. O grupo "Sempre Particular" utilizou menos o alojamento conjunto e recebeu mais orientação no hospital, tanto sobre como cuidar da criança quanto sobre aleitamento materno. Não foi encontrada diferença, no entanto, no tempo que a criança foi colocada para mamar após o nascimento. Este mesmo resultado foi encontrado quando a citada análise foi refeita excluindo 27 crianças que nunca mamaram. No limiar da significância, o Hospital São José proporcionou mais às mães particulares a colocação da criança para mamar em menor tempo $(p=0,05)$, nos outros hospitais, maior proporção de mães do SUS receberem mais esse cuidado $(p=0,04)$, enquanto para o São João não houve diferença significativa $(p=0,6)$.

$A$ análise das mães que fizeram o "Parto/RN" particular mostra que as mães "SUS->Particular" utilizaram significativamente mais o alojamento conjunto do que as "Sempre Particular" $(p=0,009)$. A forma de pagamento do Pré-Natal não influenciou na utilização do alojamento entre as mães que fizeram "Parto/RN" pelo SUS $(p=0,2)$ 
Tabela 9. Análise não ajustada comparando qualidade técnica do Pré-Natal conforme forma de pagamento do atendimento Pré-Natal e "Parto/RN". Criciúma, 1996.

\begin{tabular}{|c|c|c|c|c|c|}
\hline Variável & $\begin{array}{c}\% \\
\text { crianças } \\
\star\end{array}$ & $\begin{array}{l}\text { Sempre } \\
\text { SUS }+\end{array}$ & $\begin{array}{l}\text { Sempre } \\
\text { Parti- } \\
\text { cular } ¥\end{array}$ & $\begin{array}{l}\text { SUS -> } \\
\text { Parti- } \\
\text { cular } \S\end{array}$ & $\begin{array}{l}\text { Parti- } \\
\text { cular } \\
\text {->SUS }\end{array}$ \\
\hline \multicolumn{5}{|c|}{ Pré-Natal } & $(p$ valor $\mathbb{T})$ \\
\hline Iniciaram no $1^{\circ}$ trimestre & $\begin{array}{c}(2046) \\
83,1 \%\end{array}$ & $78,6 \%$ & $95.3 \%$ & $85.8 \%$ & $\begin{array}{l}(p<0,001) \\
93,8 \%\end{array}$ \\
\hline $\begin{array}{l}\text { Foram a } 6 \text { ou + } \\
\text { consultas }\end{array}$ & $\begin{array}{l}(2046) \\
77,6 \%\end{array}$ & $72,9 \%$ & $91,9 \%$ & $84,1 \%$ & $\begin{array}{l}(p<0,001) \\
85,1 \%\end{array}$ \\
\hline $\begin{array}{l}\text { Iniciaram no } 1^{\circ} \text { trimestre } \\
\text { e foram a } 6 \text { ou }+ \\
\text { consultas }\end{array}$ & $\begin{array}{l}(1568) \\
92,3 \%\end{array}$ & $91,4 \%$ & $95,4 \%$ & $97,3 \%$ & $\begin{array}{l}(p=0,03) \\
90,8 \%\end{array}$ \\
\hline $\begin{array}{l}\text { Início e } n^{\circ} \text { consultas } \\
\text { adequado }\end{array}$ & $\begin{array}{l}(2046) \\
76,6 \%\end{array}$ & $71,8 \%$ & $90,9 \%$ & $83,5 \%$ & $\begin{array}{l}(p<0,001) \\
85,1 \%\end{array}$ \\
\hline \multicolumn{6}{|c|}{ Conduta no Pré-Natal } \\
\hline $\begin{array}{l}\text { Verificação da data } \\
\text { última menstruação }\end{array}$ & $\begin{array}{l}(2033) \\
96,9 \%\end{array}$ & $96,1 \%$ & $99,8 \%$ & $98,3 \%$ & $\begin{array}{l}(p=0,006) \\
97,6 \%\end{array}$ \\
\hline Determinação do peso & $\begin{array}{l}(2043) \\
98,6 \%\end{array}$ & $98,3 \%$ & $100,0 \%$ & $100,0 \%$ & $\begin{array}{l}(p=0,07) \\
98,1 \%\end{array}$ \\
\hline Medida da altura uterina & $\begin{array}{l}(2043) \\
98,3 \%\end{array}$ & $98,1 \%$ & $98,9 \%$ & $96,9 \%$ & $\begin{array}{l}(p=0,3) \\
99,5 \%\end{array}$ \\
\hline $\begin{array}{l}\text { Medida da pressão } \\
\text { arterial }\end{array}$ & $\begin{array}{l}(2040) \\
97,4 \%\end{array}$ & $97,4 \%$ & $98,7 \%$ & $93,8 \%$ & $\begin{array}{l}\quad(p=0,08) \\
97,4 \%\end{array}$ \\
\hline $\begin{array}{l}\text { Exame ginecológico } \\
\text { especular }\end{array}$ & $\begin{array}{l}(2028) \\
51,0 \%\end{array}$ & $41,2 \%$ & $84,2 \%$ & $59,5 \%$ & $\begin{array}{l}(p<0,001) \\
64,2 \%\end{array}$ \\
\hline Prescrição de ferro & $\begin{array}{l}(2034) \\
58,7 \%\end{array}$ & $61,4 \%$ & $50,1 \%$ & $54,3 \%$ & $\begin{array}{l}(p=0,001) \\
55,2 \%\end{array}$ \\
\hline $\begin{array}{l}\text { Orientação sobre } \\
\text { amamentação }\end{array}$ & $\begin{array}{l}(2041) \\
71,3 \%\end{array}$ & $67,4 \%$ & $87,5 \%$ & $72,4 \%$ & $\begin{array}{l}(p<0,001) \\
74,6 \%\end{array}$ \\
\hline Exame de sangue & $\begin{array}{l}(2044) \\
93,0 \%\end{array}$ & $92,0 \%$ & $97,8 \%$ & $95,2 \%$ & $\begin{array}{l}(p=0,003) \\
91,8 \%\end{array}$ \\
\hline Exame das mamas & $\begin{array}{l}(2043) \\
50,6 \%\end{array}$ & $40,5 \%$ & $85,4 \%$ & $52,0 \%$ & $\begin{array}{l}(p<0,001) \\
66,7 \%\end{array}$ \\
\hline $\begin{array}{l}\text { Orientação sobre vacina } \\
\text { anti-tetânica }\end{array}$ & $\begin{array}{l}(2036) \\
79,3 \%\end{array}$ & $81,5 \%$ & $74,1 \%$ & $83,9 \%$ & $\begin{array}{l}(p<0,001) \\
70,6 \%\end{array}$ \\
\hline $\begin{array}{l}\text { Das } 2.180 \text { crianças dest } \\
\text { crianças }(2,2 \%) \text { não foi pos } \\
\text { que fizeram o Pré-Natal nã } \\
\text { esta análise refere-se a } 2 \\
\text { Realizaram o Pré-Natal e } \\
\text { Realizaram o Pré-Natal e } \\
\text { Realizaram o Pré-Natal pe } \\
\text { Realizaram o Pré-Natal pa } \\
\text { p valor = Teste do qui-que }\end{array}$ & $\begin{array}{l}\text { estudo } 72 \\
\text { ivel identifice } \\
\text { foi possivel } \\
058 \text { crianças } \\
\text { "Parto/RN" } \\
\text { "Parto/RN" } \\
\text { SUS e o "P } \\
\text { licular/outro ti } \\
\text { drado de Pe }\end{array}$ & $\begin{array}{l}(3,3 \%) \text { não } \\
\text { ar se fizeran } \\
\text { lidentificar } \\
\text { pelo sus } \\
\text { particular/o } \\
\text { arto/RN" par } \\
\text { ipo de paga } \\
\text { arson }\end{array}$ & $\begin{array}{l}\text { fizeram o } \\
\text { n o Pré-Na } \\
\text { onde o me } \\
\text { (n=1437) } \\
\text { titro tipo dt } \\
\text { ticular/outr } \\
\text { mento e "P }\end{array}$ & $\begin{array}{l}\text { pagament } \\
\text { tipo de pa } \\
\text { arto/RN" pe }\end{array}$ & $\begin{array}{l}\text { para outras } 48 \\
(0,1 \%) \text { crianças } \\
\text { izado. Portanto } \\
\text { o (n=307) } \\
\text { gamento }(n=96) \\
\text { lo SUS }(n=218)\end{array}$ \\
\hline
\end{tabular}


A análise das médias de procedimentos realizados no Pré-Natal e "Parto/RN" aponta que as mães "Sempre SUS" têm menor número de procedimentos realizados (tabela 11). As mães que mudaram de forma de pagamento entre o Pré-Natal e o "Parto/RN" apresentaram médias intermediárias entre as "Sempre SUS" e as "Sempre Particular"

Obtiveram atendimento com qualidade adequada (11 ou mais procedimentos realizados no Pré-Natal e "Parto/RN") 14,3\% do grupo "Sempre SUS"; $31,9 \%$ do "Sempre Particular"; $25,9 \%$ do "SUS->Particular"; e 25,2\% das "Particular->SUS" ( $p<0,001)$

Tabela 10. Análise não ajustada comparando qualidade técnica do atendimento ao "Parto/RN" conforme forma de pagamento do atendimento PréNatal e "Parto/RN". Criciúma, 1996.

\begin{tabular}{|c|c|c|c|c|c|}
\hline Variável & $\begin{array}{c}\% \\
\text { crianças } \\
\star\end{array}$ & $\begin{array}{l}\text { Sempre } \\
\text { SUS } †\end{array}$ & $\begin{array}{c}\text { Sempre } \\
\text { Parti- } \\
\text { cular } \ddagger\end{array}$ & $\begin{array}{c}\text { SUS -> } \\
\text { Parti- } \\
\text { cular } \$\end{array}$ & $\begin{array}{l}\text { Parti- } \\
\text { cular } \\
\text {->SUS \| } \\
\text { (p valor I) }\end{array}$ \\
\hline $\begin{array}{l}\text { Colocada para mamar } \\
\text { até } 2 \text { horas após }\end{array}$ & (1997) & & & & $(p=0,8)$ \\
\hline nascimento & $11.5 \%$ & $11.5 \%$ & $11,7 \%$ & $13,7 \%$ & $10,0 \%$ \\
\hline Alojamento conjunto & (2057) & & & & $(p=0,02)$ \\
\hline integral & $35,1 \%$ & $35,2 \%$ & $28,9 \%$ & $44,0 \%$ & 39,7 \\
\hline $\begin{array}{l}\text { Orientação para a mãe } \\
\text { no hospital }\end{array}$ & $\begin{array}{l}(2048) \\
44,6 \%\end{array}$ & $40,0 \%$ & $63.9 \%$ & $45.1 \%$ & $\begin{array}{l}(p<0,001) \\
47.2 \%\end{array}$ \\
\hline Orientação para a mãe & (2048) & & & & $(p<0,001)$ \\
\hline aleitamento & $36,2 \%$ & $32,2 \%$ & $51,6 \%$ & $43,4 \%$ & $38,0 \%$ \\
\hline
\end{tabular}

* Das 2.180 crianças deste estudo $72(3,3 \%)$ não fizeram o Pré-Natal, para outras 48 crianças $(2,2 \%)$ não foi possivel identificar se fizeram o Pré-Natal e para 2 $(0,1 \%)$ crianças que fizeram o Pré-Natal não foi possivel identificar onde o mesmo foi realizado. Portanto, esta análise refere-se a 2.058 crianças.

$\dagger$ Realizaram o Pré-Natal e o "Parto/RN" pelo SUS $(n=1437)$

‡ Realizaram o Pré-Natal e o "Parto/RN" particular/outro tipo de pagamento $(n=307)$

$\S$ Realizaram o Pré-Natal pelo SUS e o "Parto/RN" particular/outro tipo de pagamento $(n=96)$

Realizaram o Pré-Natal particular/outro tipo de pagamento e "Parto/RN" pelo SUS $(n=218)$

I $\mathrm{p}$ valor $=$ Teste do qui-quadrado de Pearson 
Mães com duas ou três situações de risco tiveram menor frequiência de atendimento com qualidade adequada no Pré-Natal em todos os grupos $(p=0,02)$. No entanto, a diferença foi significativa apenas para o grupo "Sempre SUS" $(p=0,02)$

Tabela 11. Análise não ajustada comparando a média de procedimentos de qualidade técnica do Pré-Natal e atendimento ao "Parto/RN" conforme forma de pagamento do atendimento Pré-Natal e "Parto/RN". Criciúma, 1996.

\begin{tabular}{|c|c|c|c|c|c|c|}
\hline Serviço & $\begin{array}{c}\% \\
\text { crianças }\end{array}$ & $\begin{array}{c}\text { Sempre } \\
\text { SUS † }\end{array}$ & $\begin{array}{c}\text { Sempre } \\
\text { Parti- } \\
\text { cular } \neq\end{array}$ & $\begin{array}{c}\text { SUS -> } \\
\text { Parti- } \\
\text { cular } \$\end{array}$ & $\begin{array}{l}\text { Parti- } \\
\text { cular } \\
\text {->SUS || }\end{array}$ & $\begin{array}{c}\text { p valor } \\
\mathbb{T}\end{array}$ \\
\hline $\begin{array}{l}\text { Pré- } \\
\text { Natal } \\
\star \star\end{array}$ & $\begin{array}{r}(2045) \\
7,9\end{array}$ & 7.7 & 8,7 & 8 & 8,1 & $<0,001$ \\
\hline $\begin{array}{l}\text { "Parto/R } \\
\text { N" +† }\end{array}$ & $\begin{array}{r}(2057) \\
0,91\end{array}$ & 0,86 & 1,04 & 1,02 & 0,96 & $=0,001$ \\
\hline Total $\ddagger$ & $\begin{array}{r}(2044) \\
8,8\end{array}$ & 8,6 & 9,8 & 9,1 & 9,1 & $<0,001$ \\
\hline
\end{tabular}

* Das 2.180 crianças deste estudo $72(3,3 \%)$ não fizeram o Pré-Natal, para outras 48 crianças $(2,2 \%)$ não foi possivel identificar se fizeram o Pré-Natal e para 2 $(0,1 \%)$ crianças que fizeram o Pré-Natal não foi possivel identificar onde o mesmo foi realizado. Portanto, esta análise refere-se a 2.058 crianças.

$\dagger$ Realizaram o Pré-Natal e o "Parto/RN" pelo SUS $(n=1437)$

† Realizaram o Pré-Natal e o "Parto/RN" particular/outro tipo de pagamento $(n=307)$

$\S$ Realizaram o Pré-Natal pelo SUS e o "Parto/RN" particular/outro tipo de pagamento $(n=96)$

|| Realizaram o Pré-Natal particular/outro tipo de pagamento e "Parto/RN" pelo SUS $(n=218)$

II $p$ valor $=$ Teste de análise de variância

** 10 procedimentos pesquisados: Verificação da data última menstruação; Determinação do peso; Medida da altura uterina; Medida da pressão arterial; Exame ginecológico especular; Prescrição de ferro; Orientação sobre amamentação; Exame de sangue; Exame das mamas; Orientação sobre vacina anti-tetânica.

†† 3 procedimentos pesquisados: Colocada para mamar até 2 horas após nascimento; 2Alojamento conjunto integral; Orientação para a mãe no hospital. Excluidos 61 crianças devido o entrevistado ignorar a resposta aos três procedimentos.

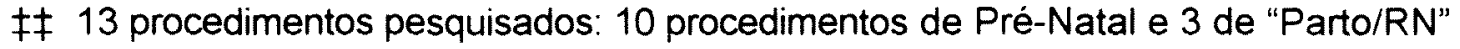
listados acima 


\subsection{Análise do Desfecho (Aleitamento Materno)}

Dentre todas as mulheres atendidas no Pré-Natal, 43,5\% receberam os procedimentos do Pré-Natal relacionados ao aleitamento materno (exame das mamas e orientação sobre a amamentação). Quanto aos procedimentos "Parto/RN" relacionados ao aleitamento materno (tempo de colocação do recém-nascido para mamar após o parto, alojamento conjunto e orientação na maternidade sobre amamentação) $15,7 \%$ receberam dois procedimentos e apenas $2,0 \%$ receberam todos os três

Na tabela 12, verifica-se que três vezes mais usuárias do grupo "Sempre SUS" relataram no Pré-Natal nenhum ou apenas um procedimento relacionado com o aleitamento materno, em comparação com as "Sempre Particular". Não houve diferença entre a forma de pagamento dos serviços e o número de procedimentos "Parto/RN" relativos ao aleitamento materno realizados.

Tabela 12. Procedimentos relacionados ao aleitamento materno e a forma de pagamento do Pré-Natal e "Parto/RN"

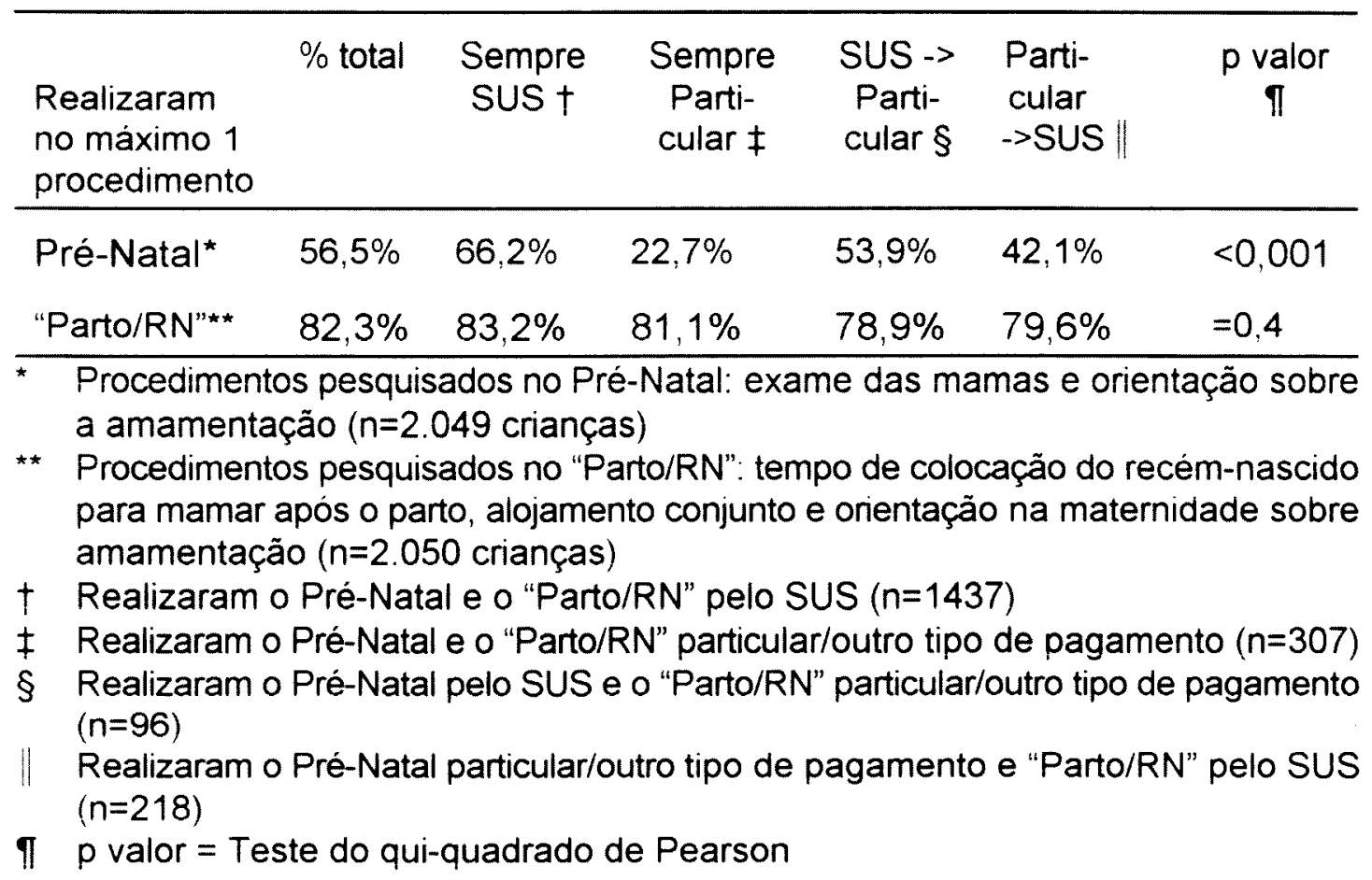


A mediana de duração do aleitamento materno foi de 4,5 meses para as "Sempre SUS"; 4,7 meses paras "SUS->Particular"; 5,7 meses para as "Sempre Particular" e 6,2 meses para as "Particular->SUS" (figura 5). A amamentação por seis meses ou mais apresentou a menor prevalência $(42,0 \%)$ no grupo "Sempre SUS" e a maior no "Particular->SUS" (52,1\%), estando a diferença no limite da significância entre os grupos $(p=0,05)$.

Figura 5. Curva de sobrevivência para o tempo amamentação segundo a forma de pagamento dos serviços Pré-Natal e Parto - Criciúma - 1996

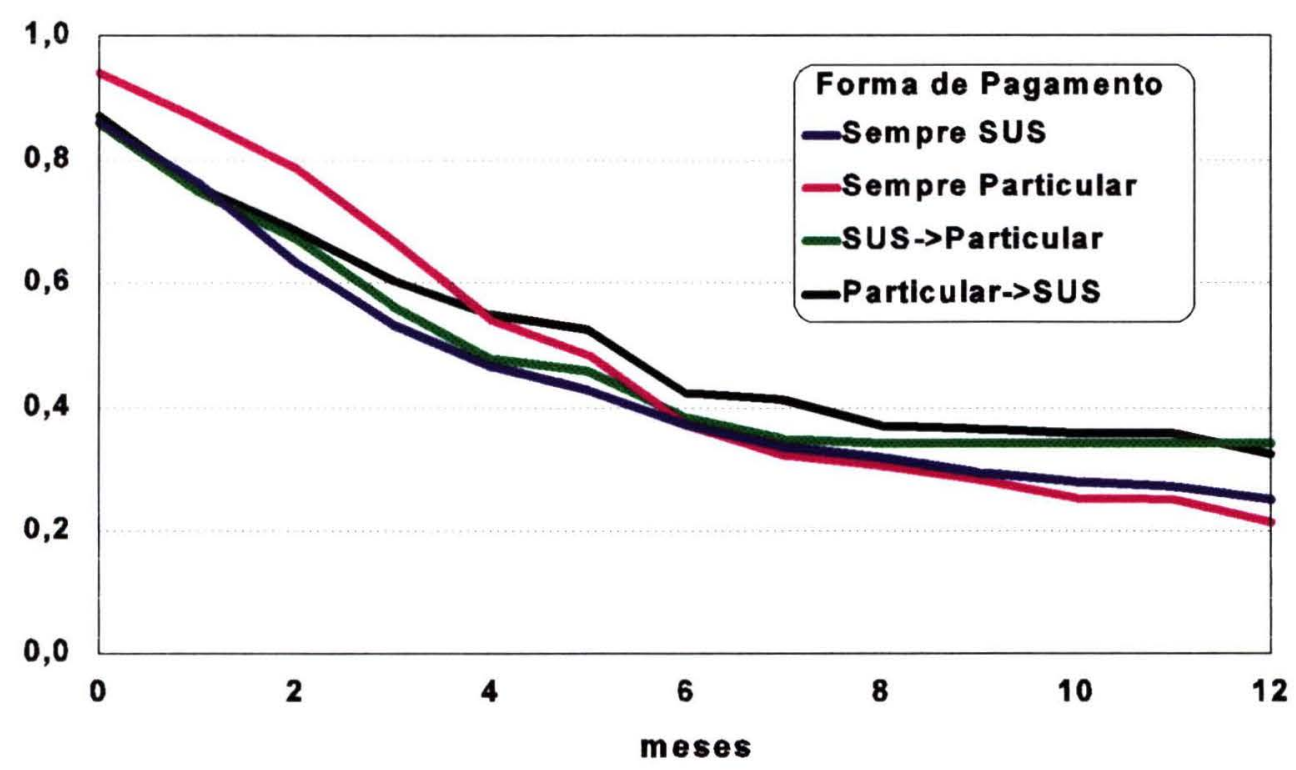

Não foi encontrada diferença significativa na prevalência de aleitamento materno predominante e aleitamento materno exclusivo entre os grupos $(p=0,5$ e $p=0,2$ respectivamente).

A prevalência de introdução da mamadeira antes dos quatro meses de idade foi a maior no grupo "Sempre SUS" $(63,1 \%)$ e menor no grupo "Sempre Particular" (56,3\%), diferença ocorrida no limite da significância $(p=0,05)$.

Na tabela 13, observa-se que, na análise não ajustada para fatores de confusão, em relação às pacientes "Sempre SUS", o grupo "Sempre Particular" apresentou maior chance de amamentar exclusivamente ao seio e de introduzir mais tardiamente a mamadeira. Este grupo apresentou, ainda, maior chance de amamentar por seis meses ou mais. No entanto, ao se ajustar para os fatores de confusão, apenas o grupo "Particular->SUS" manteve a maior 
chance de amamentar por seis meses ou mais. Estes mesmos resultados foram encontrados quando a análise ajustada foi repetida, considerando apenas as mães que iniciaram o Pré-Natal no primeiro trimestre de gestação.

Tabela 13. Análise bruta e ajustada da relação entre a forma de pagamento do serviço Pré-Natal e o padrão alimentar. Criciúma, 1996.

\begin{tabular}{|c|c|c|c|c|}
\hline \multirow{2}{*}{$\begin{array}{l}\text { Variável } \\
L M>=6 \text { meses }\end{array}$} & \multicolumn{2}{|c|}{$\mathrm{RC}=$ não ajustada $(\mathrm{IC})$} & \multicolumn{2}{|c|}{$\mathrm{RC}=$ ajustada $(\mathrm{IC})^{*}$} \\
\hline & & & & \\
\hline Sempre SUS† & 1 & 1 & 1 & 1 \\
\hline Sempre Particular $\$$ & 1,19 & $(0,90-1,56)$ & 0,92 & $(0,65-1,30)$ \\
\hline SUS->Particular§ & 1,11 & $(0,71-1,72)$ & 0,81 & $(0,50-1,32)$ \\
\hline Particular->SUS\| & 1,50 & $(1,11-2,02)$ & 1,48 & $(1,05-2,10)$ \\
\hline \multicolumn{5}{|l|}{ LM exclusivo $>=4$ meses } \\
\hline Sempre SUS† & 1 & 1 & 1 & 1 \\
\hline Sempre Particularł & 2,25 & $(1,03-4,91)$ & 1,43 & $(0,52-3,95)$ \\
\hline SUS->Particular§ & 0,51 & $(0,03-7,86)$ & 0,59 & $(0,07-4,75)$ \\
\hline Particular->SUS\| & 0,88 & $(0,28-2,83)$ & 0,48 & $(0,11-2,20)$ \\
\hline \multicolumn{5}{|l|}{ LM predominante $>=4$ meses } \\
\hline Sempre SUS† & 1 & 1 & 1 & 1 \\
\hline Sempre Particular $\$$ & 1,43 & $(0,83-2,44)$ & 0,91 & $(0,44-1,91)$ \\
\hline SUS->Particular§ & 1,27 & $(0,42-3,86)$ & 0,69 & $(0,22-2,15)$ \\
\hline Particular->SUS\| & 1,29 & $(0,71-2,37)$ & 0,76 & $(0,36-1,60)$ \\
\hline \multicolumn{5}{|l|}{ Mamadeira $>=4$ meses } \\
\hline Sempre SUS† & 1 & 1 & 1 & 1 \\
\hline Sempre Particulart & 1,32 & $(1,03-1,70)$ & 0,81 & $(0,58-1,12)$ \\
\hline SUS->Particular§ & 1,31 & $(0,86-1,99)$ & 0,84 & $(0,53-1,33)$ \\
\hline Particular->SUS\| & 1,31 & $(0,98-1,75)$ & 1,18 & $(0,85-1,64)$ \\
\hline
\end{tabular}

* As variáveis foram ajustadas no modelo hierarquizado pelas seguintes variáveis:

- $L M>=6$ meses: idade da criança, renda familiar total, presença de companheiro, idade da mãe na data do parto, ordem nascimento (linear)

- LM exclusivo >= 4 meses: cor da criança, presença de companheiro, aglomeração no domicilio, idade da mãe na data do parto (linear)

- LM predominante $>=4$ meses: renda familiar total (linear), escolaridade da mãe (linear), aglomeração no domicilio, ordem de nascimento (linear)

- Mamadeira >= 4 meses: idade da criança (linear), renda familiar total (linear), escolaridade da mãe (linear), presença de companheiro, aglomeração no domicilio, tipo de moradia e idade da mãe na data do parto

$\dagger$ Realizaram o Pré-Natal e o "Parto/RN" pelo SUS $(n=1437)$

‡ Realizaram o Pré-Natal e o "Parto/RN" particular/outro tipo de pagamento $(n=307)$

$\S$ Realizaram o Pré-Natal pelo SUS e o "Parto/RN" particular/outro tipo de pagamento $(n=96)$

Realizaram o Pré-Natal particular/outro tipo de pagamento e "Parto/RN" pelo SUS $(n=218)$ 
Visando a identificação dos procedimentos que estariam positivamente associados à amamentação procedeu-se à análise hierarquizada dos mesmos para os diversos fatores de confusão. A análise ajustada de cada procedimento apontou o exame do seio como o único fator associado ao aleitamento materno exclusivo $(R C=2,93 ; \quad I C 95 \% 1,33-6,45)$ e a orientação geral na maternidade como único procedimento associado à introdução tardia da mamadeira ( $R C=1,29$; IC95\% 1,04 - 1,59). Estes valores estiveram bastante próximos aos encontrados na análise não ajustada $(R C=2,81$ e 1,34 respectivamente). A análise ajustada foi repetida considerando apenas as mães que iniciaram o Pré-Natal no primeiro trimestre de gestação. Os resultados foram $\mathrm{RC}=3.29$ (IC95\% 1,30-8,32) para o exame do seio como fator associado ao aleitamento materno exclusivo e RC=1,25 (IC95\% 0,99-1,59) para a orientação geral na maternidade associada à introdução tardia da mamadeira.

A tabela 14 mostra a análise não ajustada e ajustada dos procedimentos relacionados à amamentação realizados no Pré-Natal e "Parto/RN". Na análise não ajustada, o conjunto dos procedimentos realizados no Pré-Natal esteve associado à melhoria do aleitamento materno, não tendo sida encontrada, no entanto, associação entre os procedimentos "Parto/RN" e a amamentação. Na análise ajustada, para cada procedimento realizado no Pré-Natal houve um incremento de 1,97 vezes no aleitamento materno exclusivo e 1,34 vezes no aleitamento predominante. Com relação aos procedimentos "Parto/RN", colocados como variável categórica no modelo, foi encontrada associação apenas entre estes e o retardo da introdução da mamadeira na análise ajustada. Resultados semelhantes foram obtidos na análise dos procedimentos "Parto/RN", colocando-se esta variável no modelo de forma linear ( $R C=1,13 ;$ IC95\% 1,00-1,27).

Procedeu-se novamente à análise ajustada dos procedimentos de PréNatal e "Parto/RN" relacionados à amamentação, considerando-se apenas as mães que iniciaram o Pré-Natal no primeiro trimestre de gestação. Deste modo, apenas os procedimentos de Pré-Natal estiveram associados ao aleitamento materno exclusivo ( $R C=1,94 ;$ IC95\% 1,05-3,60). Ao se coloc ar no modelo o inicio adequado do Pré-Natal ( $1^{\circ}$ trimestre $)$ no modelo de regressão 
logística os resultados foram também semelhantes (RC1,97; IC95\% 1.153.37). Em ambos os casos, deixou de ser significativa a associação entre os procedimentos relacionados ao aleitamento materno do "Parto/RN" e a introdução tardia da mamadeira.

Tabela 14. Análise bruta e ajustada dos procedimentos realizados no Pré-Natal e "Parto/RN" relacionados ao aleitamento materno. Criciúma, 1996.

\begin{tabular}{|c|c|c|c|c|}
\hline \multirow{2}{*}{$\begin{array}{l}\text { Variavel } \\
L M>=6 \text { meses }\end{array}$} & \multicolumn{2}{|c|}{$\mathrm{RC}=$ não ajustada $(\mathrm{IC})$} & \multicolumn{2}{|c|}{$\mathrm{RC}=$ ajustada $(\mathrm{IC})^{*}$} \\
\hline & & & & \\
\hline Pré-Natal† & 1,21 & $(1,08-1,36)$ & -- & -- \\
\hline "Parto/RN" $\ddagger$ & 1,03 & $(0,90-1,17)$ & -- & -- \\
\hline \multicolumn{5}{|l|}{ LM exclusivo $>=4$ meses } \\
\hline Pré-Natal† & 1,88 & $(1,16-3,06)$ & 1,97 & $(1,15-3,37)$ \\
\hline "Parto/RN" $\ddagger$ & 1,09 & $(0,68-1,73)$ & -- & -- \\
\hline \multicolumn{5}{|l|}{ LM predominante $>=4$ meses } \\
\hline Pré-Natal† & 1,52 & $(1,17-1,96)$ & 1,34 & $(1,00-1,79)$ \\
\hline "Parto/RN" $\ddagger$ & 1,01 & $(0,77-1,33)$ & - & - \\
\hline \multicolumn{5}{|l|}{ Mamadeira $>=4$ meses } \\
\hline Pré-Natal† & 1,30 & $(1,17-1,45)$ & -- & -- \\
\hline "Parto/RN" $\ddagger$ & 1,08 & $(0.95-1.22)$ & 1.14 & $(1,01-1,30)$ \\
\hline
\end{tabular}

* As variáveis foram ajustadas no modelo hierarquizado pelas seguintes variáveis:

- $L M>=6$ meses: idade da criança, renda familiar total, presença de companheiro, idade da mãe na data do parto, forma de pagamento do atendimento pre-natal e parto

- LM exclusivo >= 4 meses: cor da criança, presença de companheiro, aglomeração no domicilio, idade da mãe na data do parto (linear)

- LM predominante $>=4$ meses: renda familiar total (linear), escolaridade da mãe (linear), aglomeração no domicilio (linear), ordem de nascimento da criança (linear)

- Mamadeira >= 4 meses: idade da criança, renda familiar total (linear), escolaridade da mãe (linear), presença de companheiro, aglomeração no domicilio, tipo moradia, idade da mãe na data do parto

$\dagger$ Procedimentos pesquisados no Pré-Natal: exame das mamas e orientação sobre a amamentação, variável contínua $(0,1,2)$ ( $n=2.049$ crianças)

‡ Procedimentos pesquisados no "Parto/RN": tempo de colocação do recém-nascido para mamar após o parto, alojamento conjunto e orientação na maternidade sobre amamentação, variável categórica $(0,1,2$ ou 3 procedimentos $)(n=2.050$ crianças $)$ 
Na Tabela 15, pode-se observar os índices kappa de concordância interobservadores. Estes indices, baseados na revisita de cerca de $10 \%$ dos domicilios, foram superiores a 0,77 , com exceção da variável número de consultas de pré-natal (0,55 para o agrupamento de número de consultas de pré-natal adequado e 0,43 para agrupamentos de dois em dois meses).

Tabela 15. Índice Kappa entre as entrevistas e a revisita ( $n=237$ crianças)

\begin{tabular}{lr}
\hline Perguntas (categorias) & Kappa \\
\hline Uso de mamadeira (não usa; já parou; ainda usa) & 0,77 \\
Aleitamento Materno (nunca; já parou; ainda mama) & 0,78 \\
Tempo de aleitamento materno & 0,95 \\
(0 a 3,9 meses; 4 a 5,9; 6 a 11,9; 12 ou mais) & 0,82 \\
Cor (branca/parda/negra)* & 0,87 \\
Consulta pré-natal (fez; não fez; ignorado) & 0,79 \\
Trimestre de início do pré-natal (10; $2^{\text {o; }} 3^{\circ}$ ) & 0,55 \\
Número de consultas de pré-natal (menos que 6; 6 ou mais) & 0,43 \\
\hline Número de consultas de pré-natal (1-2;3-4;5-6;7-8;9-10) &
\end{tabular}




\section{Discussão}

\subsection{Representatividade do estudo}

O presente estudo pôde traçar o perfil das mães com filhos de até três anos da área urbana do município de Criciúma, bem como da qualidade técnica do Pré-Natal e atendimento "Parto/RN", segundo a forma de pagamento dos serviços. Isto foi possivel devido à sua amostra probabilistica e o baixo percentual de perdas do estudo. As perdas nos estratos das amostras foram ligeiramente diferentes $(5,7 \%$ e $2,1 \%)$, mas esta diferença não deve afetar os resultados apresentados.

Houve alto grau de concordância inter-observadores, segundo a análise do índice kappa $^{17}$ (acima de 0,7). O índice mais baixo observado deu-se na variável número de consultas de pré-natal (concordância razoável a boa). Uma vez que o número de consultas pode variar conforme o período da gestação; talvez este achado possa ser explicado pela dificuldade das mães em lembrarem com exatidão o número de consultas.

\subsection{Comparação geral do atendimento Pré-Natal e "Parto/RN"}

O SUS foi responsável pela imensa maioria dos atendimentos Pré-Natal e "Parto/RN" de Criciúma. A freqüência de atendimento ao "Parto/RN" pelo SUS $(81,0 \%)$ foi ainda maior que a de Pré-Natal $(74,5 \%)$. Isto poderia ser explicado pelo menor custo do Pré-Natal particular em relação ao parto pois, além dos honorários médicos, há despesas de hotelaria

Os resultados deste estudo serão comparados a seguir com os apresentados pela Pesquisa Nacional sobre Demografia e Saúde ${ }^{48}$ de 1996 e com estudos desenvolvidos noutra cidade da Região Sul do Brasil: Pelotas/RS.

As mães de Criciúma apresentaram uma alta cobertura de Pré-Natal $(96,6 \%)$, semelhante à registrada na $\operatorname{PNDS}^{48}$ para a região Sul $(93,7 \%)$ e Pelotas/RS em $1997(95,0 \%)^{45}$. A mediana de 7,0 consultas de Pré-Natal em 
Criciúma esteve abaixo das 8,3 consultas da PNDS ${ }^{48}$. Em Pelotas, a média de consultas de Pré-Natal foi $8,2^{45}$, acima do encontrado no presente estudo $(6,7$ consultas). Em Criciúma, o início do Pré-Natal até o terceiro mês foi superior ao de Pelotas ${ }^{45}$ e semelhante ao da Região Sul segundo a $\operatorname{PNDS}^{48}(83,1 \%$. $71,9 \%$ e $79,7 \%$ respectivamente). Os dados apresentados mostram que o municipio de Criciúma apresenta captação mais precoce das gestantes e menor número de consultas que a média da região e também de outro municipio com caracteristicas semelhantes como, por exemplo, Pelotas. No entanto, esta precocidade não se refletiu em maior concentração de consultas de Pré-Natal. Talvez a mediana de 7,0 consultas reflita uma condição de saúde adequada, que não requeira proporcionalmente maior número de controles, $e$ não esteja necessariamente refletindo um controle menos propicio. Deve ainda ser considerado que nem todas as mães com número alto de consultas apresentam complicações. Rezende\&Montenegro ${ }^{43}$, livro de referência na formação de boa parte dos médicos brasileiros, recomenda que a gestante deve iniciar o Pré-Natal assim que suspeite da gravidez e retornar a cada quatro semanas até o sétimo mês; depois cada duas semanas e no nono mês, semanalmente. Assim, dada a facilidade de diagnóstico precoce da gravidez, estas recomendações poderiam resultar facilmente em mais de 15 consultas de Pré-Natal. Por outro lado, o Programa de Assistência Integral à Saúde da Mulher do Ministério da Saúde (PAISM) considera que uma mulher é assistida no Pré-Natal quando comparece a um número de seis consultas durante a gravidez. A maior proporção de médicos por habitante em Pelotas também poderia facilitar ou induzir a um maior número de consultas. Em Criciúma, havia um médico para cada 657 habitantes* enquanto em Pelotas esta proporção era de um médico para cada 260 habitantes $^{12}$.

Em Criciúma, três de cada quatro gestantes utilizaram o setor público para realizar o Pré-Natal, índice bastante semelhante ao encontrado em Pelotas $^{45}$, onde este setor foi responsável por $78,5 \%{ }^{45}$.

Ao analisar os procedimentos de Pré-Natal, tendo como parâmetro o preconizado pela Norma técnica do Ministério da Saúde ${ }^{35}$, verifica-se que tal

\footnotetext{
* Consulta telefônica ao Conselho Regional de Medicina do Estado de Santa Catarina
} 
como em Pelotas $^{45}$, o serviço de Pré-Natal de Criciúma teve frequêencia elevada de verificação da data da última menstruação $(96,9 \%$ para ambos os municipios), da medida da altura uterina (98,3\% e 99,0\% respectivamente) e de medida da pressão arterial $(97,4 \%$ e 99,5\%). Estes procedimentos de PréNatal são desenvolvidos, na prática, pelo pessoal auxiliar de enfermagem. De certa forma isto justificaria a semelhança encontrada em ambos os municípios: são procedimentos que se caracterizam por medidas de cunho individual, da prática cotidiana da enfermagem e bastante consolidadas na prestação de serviços básicos

Encontrou-se freqüência aquém do esperado em orientação sobre a amamentação durante o Pré-Natal (71,3\% e 67,1\% para Criciúma e Pelotas $\left.{ }^{45}\right)$. A freqüência de orientação sobre como cuidar da criança no hospital do parto foi ainda mais baixa: menos da metade das mães a receberam. Estes procedimentos, em relação aos descritos no parágrafo anterior, pressupõem habilidades distintas e/ou participação de outros profissionais da equipe de saúde. Olson ${ }^{42}$, em 1994, descreveu que os médicos, embora acreditem que seja importante um trabalho educativo com seus pacientes, dedicam pouco tempo a esta tarefa por presumirem que estes não querem seus conselhos e, portanto, não os seguirão; referiu ainda, a falta de auto-confiança dos médicos em seus conhecimentos e habilidades na promoção de mudanças comportamentais $^{42}$. Isto talvez explique a menor freqüência de orientação em ambos os municipios.

Em Criciúma, os procedimentos que necessitam maior envolvimento médico (exames ginecológico especular e de mamas e prescrição de ferro) foram realizados com menos freqüência. Sendo norma do Ministério da Saúde $^{35}$ a realização destes procedimentos como rotina para todas as gestantes, esperar-se-ia uma prevalência mais alta dos mesmos. Verifica-se em Criciúma uma menor prevalência de exame ginecológico especular $(51,0 \%)$, em comparação com Pelotas ${ }^{45}(73,2 \%)$. Em relação ao exame das mamas as freqüências foram $50,6 \%$ e $61,3 \%$, respectivamente. A diferença encontrada entre os dois municípios poderia ser explicada pela presença de duas faculdades de medicina em Pelotas, de onde se esperaria propedêtica mais bem estabelecida. Cabe ainda apontar que apenas 50,7\% dos 
atendimentos de Pré-Natal de Pelotas ${ }^{45}$ foram realizados em Postos de Saúde, sendo os demais feitos no Ambulatório da Faculdade de Medicina $(6,0 \%)$, em Ambulatório Hospitalar $(17,8 \%)$, consultórios particulares $(14,7 \%)$ e outros $(11,0 \%)$

\subsection{Eqüidade}

A população de baixa renda apresentou menor probabilidade de receber atendimento Pré-Natal adequado, seja por apresentar maior freqüência de mães que não o fazem, seja por iniciar o Pré-Natal mais tardiamente ou, ainda, por receber atendimentc com menor qualidade técnica. Nas coortes de Pelotas de 1982 e $1993^{12}$, também se observou que as mulheres de baixa renda foram proporcionalmente as que menos procuraram cuidados de Pré-Natal, tiveram menor média de consultas e buscaram assistência médica mais tardiamente. Isto talvez possa ser explicado por dificuldades de acesso: a Pesquisa sobre Padrões de Vida (IBGE ${ }^{50} 1996 / 97$ ) aponta que os mais pobres esperam mais do que o dobro do tempo para serem atendidos.

Entre os dez procedimentos de Pré-Natal pesquisados, apenas a prescrição de ferro foi significativamente maior entre os mais pobres e, ainda assim, apenas 1,2 vezes maior, considerando os quartis extremos. Dentre os demais procedimentos, destacamos os exames ginecológico especular e de mamas. Nestes a população do maior quartil de renda tem 1,5 e 1,9 vezes mais procedimentos, respectivamente, que o primeiro quartil. Estes procedimentos dependem de médico e exigem maior tempo de consulta: a paciente deve tirar a roupa e deitar. Este tempo não foi dedicado principalmente às mais pobres possivelmente porque estas tendem a um menor poder de pressão sobre os serviços de saúde na reivindicação de atendimento de qualidade 5 .

No que concerne ao atendimento ao "Parto/RN", o alojamento conjunto foi mais prevalente para a população de menor renda: foi de 1,2 vezes a diferença entre os quartis extremos. No entanto, as mães mais pobres foram as que menos receberam orientação sobre os cuidados com criança e amamentação (1,5 vezes menos que o último quartil, para ambas as 
orientações). As mães pobres são justamente as menos escolarizadas e com presumivel menor acesso às informações necessárias.

Crianças de famílias com baixa renda são hospitalizadas com mais freqüência ${ }^{9.10}$. As crianças não amamentadas morrem mais por doenças infecciosas $^{57}$ e são internadas 17 vezes mais por pneumonia que as exclusivamente amamentadas ${ }^{26}$. Assim, é importante ressaltar que as práticas de aleitamento materno beneficiariam em especial as crianças cujas mães têm baixa escolaridade e vivem em situações de saneamento precário ${ }^{57}$, tendo sido justamente estas as que receberam menos orientação.

A análise das médias de procedimentos realizados tanto no Pré-Natal como no "Parto/RN" também evidencia a tendência de mães com menor renda receberem menor número de procedimentos. No entanto, há diferenças entre o atendimento ao Pré-Natal e o "Parto/RN": enquanto no primeiro, em média, apenas um em cada cinco procedimentos não foi realizado, no atendimento ao "Parto/RN" deixaram de ser realizados dois dos três procedimentos. Esta diferença poderia ser explicada pelo fato de o atendimento ao "Parto/RN" ser único, enquanto o Pré-Natal é uma seqüência de atividades de controle com procedimentos semelhantes. Assim, os procedimentos "Parto/RN" seriam mais vulneráveis à não realização. Parte desta diferença poderia ainda ser explicada pelo fato de os procedimentos de atendimento Pré-Natal dependerem quase exclusivamente da capacitação do pessoal de enfermagem e do médico no atendimento individual, enquanto os procedimentos de "Parto/RN" dependem também da organização e da estrutura hospitalar.

As gestantes classificadas como de risco, segundo suas características de saúde reprodutiva, tampouco obtiveram a atenção especial necessária à sua situação, tendo recebido menos freqüentemente atendimento adequado. Usando critérios de risco diferentes do presente estudo, Costa ${ }^{12}$ descreveu que, em Pelotas (1993), a média de consultas foi de 8,8 para as de gestantes de baixo risco e 6,8 para as de alto risco. Entre as primeiras, 4,9\% fizeram a primeira consulta após o quinto mês, enquanto para as de alto risco, esta proporção foi de $13,9 \%$.

A Lei dos Cuidados Inversos descrita por Hart (1971) ${ }^{21}$ foi encontrada em Criciúma. conforme exposto acima. Esta situação é compatível com diversos 
outros estudos brasileiros , $, 5,12,48,50,53,54$ nos quais as populações marginalizadas são, sistematicamente, as que menos recebem atendimento dos Serviços de Saúde. Assim, estes serviços ao "invés de corrigir, acentuam os diferenciais, através de uma discriminação contra as mães e crianças mais pobres" (Costa e col. ${ }^{12} 1996$, p.65)

Dentre todas as variáveis mensuradas de qualidade do serviço, o inicio precoce do Pré-Natal dependeria da disponibilidade da gestante em procurá-lo da capacidade de oferta do serviço e ainda do acesso ao mesmo ${ }^{27}$. O número de consultas realizado está certamente associado ao início do Pré-Natal (quanto mais precoce mais consultas), mas também à capacidade do serviço de promover a adesão da gestante ao mesmo. Assim sendo, na análise da qualidade dos serviços, estas duas variáveis devem ser analisadas cautelosamente em virtude de poderem ser determinadas tanto pelos serviços como por motivos associados à gestante. No entanto, os procedimentos mensurados de qualidade técnica do Pré-Natal deveriam ser efetuados já na primeira consulta, dependendo portanto, exclusivamente, dos serviços.

Considerando que as variáveis analisadas foram obtidas por um processo recordatório em entrevista, poderia haver um viés de recordação. Caso isto fosse sistemático em relação às usuárias de menor escolaridade e renda, haveria alteração das análises realizadas. No entanto, os procedimentos mais marcantes para os pacientes, por englobarem invasão da privacidade da cliente (exames ginecológico e de mamas), foram justamente os que apresentaram as maiores diferenças entre os quartis de renda. Outro viés possivel seria uma maior inibição das classes populares em relatar exames de suas partes íntimas, porém as entrevistadoras eram todas mulheres, o que não justificaria um erro sistemático por esta razão.

Em síntese, quanto à qualidade dos serviços prestados em Criciúma, pode-se afirmar que a menor qualidade de atendimento durante as consultas de Pré-Natal está associada aos mais pobres e com maior risco. 


\subsection{Qualidade Técnica da Atenção Prestada conforme a Forma de Pagamento}

\subsubsection{Comparação de indicadores sócio-econômicos, demográficos, ambientais e reprodutivos segundo a forma de pagamento dos Serviços de Saúde}

Todos as variáveis sócio-econômicas, ambientais e de saúde reprodutiva analisadas apontam situação desfavorável para o grupo "Sempre SUS": tem menor renda, menor escolaridade, maior freqüência de mães sem companheiro, piores condições de moradia e aglomeração, maior freqüência de mães muito jovens, maior ordem de nascimento e menor intervalo interpartal.

Chama a atenção a diferente distribuição da idade da criança no momento da entrevista para o total da amostra. As usuárias cujo parto ocorreu no último ano utilizaram com mais freqüência o SUS, bem como mudaram menos a forma de pagamento entre o Pré-Natal e "Parto/RN". Esta situação poderia ser explicada pela intensa crise financeira sofrida pelo municipio no ano da realização da pesquisa (1996) devido à falência das minas de carvão, à concordata na indústria da cerâmica e à forte concorrência das confecções chinesas. Estas eram as três principais fontes de renda da população do município. A melhoria das condições de acesso e atendimento do SUS também poderia provocar maior utilização de seus serviços

Esta pesquisa, no entanto, utiliza dados de renda e escolaridade no momento da entrevista, não podendo analisar se a crise econômica no passado induziu a classe média a buscar o SUS.

\subsubsection{Análise da mudança da forma de pagamento e a medicalização do atendimento ao parto}

O excesso de partos cesarianos e a maior incidência destes nos grupos de melhor condição sócio-econômica tem sido apontado em diversos estudos brasileiros ${ }^{12,15,16,30,53}$. Faúndes ${ }^{15}$ e Lallo ${ }^{30}$ relataram diversos estudos em que as pacientes que fizeram pagamento direto (particular) apresentavam maior 
incidência de cesariana, fato muito similar ao encontrado no presente estudo e em Pelotas $(1993)^{12}$.

Dados de $1986^{15}$ apontam que, no Brasil, três quartos de todas as laqueaduras tubárias foram realizadas por ocasião do último parto. Em Santa Catarina, a proporção de laqueaduras tubárias realizadas por ocasião do último parto foi de $68,6 \%{ }^{15}$.

Neste estudo verificou-se que, além de Criciúma ter um alto índice de cesarianas estas estavam associadas não só à renda familiar como também à mudança da forma de pagamento entre os serviços de Pré-Natal e "Parto/RN".

Especificamente o grupo "SUS->Particular" foi o grupo mais propício para identificar a utilização da medicalização do atendimento ao parto na área do usuário. A força da associação de cesariana e laqueadura tubária entre si e destas com o grupo "SUS->Particular" sugere que esta mudança não foi aleatória. Enquanto as mulheres mais pobres não tiveram opção além do gratuito SUS, as de maior renda poderiam selecionar qualquer serviço. Já as mulheres de renda intermediária teriam que optar pela gratuidade do SUS no Pré-Natal ou no "Parto/RN". O presente estudo, aparentemente, aponta que o grupo "SUS->Particular" escolheu o serviço que the proporcionasse a laqueadura tubária através da cesariana. O local do parto pouco influenciou o risco de laqueadura tubária: ao ser acrescentado o hospital na análise multivariada, o excesso de risco de laqueadura tubária do grupo "SUS>Particular" pouco diminuiu: de 2,63 para 2,21 vezes.

Comportamento semelhante ao poder observado no grupo "SUS>Particular" de conseguir parto medicalizado foi descrito em estudo etnográfico e epidemiológico realizado em Pelotas $/ \mathrm{RS}^{5}$ em 1993, onde este poder se manteve significativo mesmo após ajuste para a educação e a renda.

O grupo "Particular->SUS" optou por um Pré-Natal com maior qualidade e parto com qualidade indiferenciada entre os prestadores. A possibilidade de ser este o motivo dessa escolha foi reforçada pelas características de maior renda e escolaridade deste grupo em relação ao "SUS->Particular". A sua capacidade em conseguir atendimento adequado foi evidenciado na álise das mães que iniciaram o Pré-Natal no primeiro trimestre de gestação: o grupo 
"Particular->SUS" destacou-se pois alcançou 97,3\% de realização de seis consultas ou mais, superando inclusive o grupo "Sempre Particular".

A escolaridade, na análise bruta não esteve associada à laqueadura tubária. No entanto, o ajuste para as outras variáveis sócio-econômicas exacerbou o risco associado ao aumento da renda e revelou um efeito protetor da escolaridade. A complexidade da relação entre nível sócio-econômico e ligadura tubária foi apontada por Faúndes ${ }^{16}$ (1998) em estudo que não encontrou associação entre as condições sócio-econômicas e a prevalência de ligadura tubárea. Os achados deste estudo sugerem que as mulheres de baixa escolaridade utilizam menos a laqueadura tubária devido ao seu custo, enquanto as mulheres com maior escolaridade tendem a escolher outros métodos de planejamento familiar. No presente trabalho foi observado que o parto pelo SUS foi fator de proteção contra a laqueadura tubária, independentemente da forma de pagamento do Pré-Natal.

A associação entre cesariana e laqueadura tubária, especialmente no grupo "SUS->Particular", fere a Lei $n^{\circ} 9.263$ ?, de janeiro de 1996, que disciplinou a questão em seu artigo 10, inciso II, parágrafo segundo: "É vedada a esterilização cirúrgica em mulher durante os periodos de parto ou aborto, exceto nos casos de comprovada necessidade, por cesarianas sucessivas anteriores." Esta lei foi precedida da "Norma brasileira para serviços de planejamento familiar, públicos e privados. Recomendação do Conselho Nacional de Saúde ao Congresso Nacional para elaboração de Lei", aprovada em 02 de junho de 1993. Esta recomendação estabelece em seu artigo $5^{\circ}$, parágrafo primeiro: "é proibido realizar parto cesáreo com o objetivo de realizar laqueadura tubária"

\subsubsection{Comparação da qualidade dos serviços prestados em relação à forma de pagamento}

Ao analisar os quatro grupos de usuários de acordo com a forma de pagamento, observou-se, no presente estudo, que as mães do grupo "Sempre SUS" receberam pior atendimento em praticamente todos os itens do atendimento pré-natal e "Parto/RN" investigados. Gestantes americanas que utilizaram seguro privado também apresentaram maior incidência de Pré-Natal 
adequado em relação às que obtiveram atendimento MEDICAID, pago pelo governo americano ${ }^{27}$, sendo que para as de baixo risco ao entrar no Pré-Natal não foi encontrada diferença de atendimento ${ }^{13}$. Em nosso meio, Costa ${ }^{12}$ também relatou que, para as mães atendidas pelo SUS em Pelotas, o cuidado foi menos adequado.

No que concerne à realização de seis ou mais consultas de Pré-Natal, houve pequena diferença entre o Grupo "Sempre SUS" e o "Sempre Particular" ao serem analisadas apenas as mães que iniciaram o Pré-Natal no primeiro trimestre: $4 \%$. Ao se incluir todas as gestantes a diferença foi de $19 \%$. Estudo norte-americano, conduzido por Kaestner ${ }^{27}$, encontrou o mesmo padrão acima descrito ao analisar o tipo de seguro utilizado para consultas de Pré-Natal e parto. Kaestner sugeriu que esta diferença poderia ser decorrente de viés de seleção: mães mais motivadas e/ou preocupadas com a gestação procurariam com maior antecedência os serviços de saúde. Este autor observa ainda que, caso a diferença fosse devida à oferta inadequada de serviços ou à dificuldade de acesso, as gestantes que iniciaram no primeiro trimestre apresentariam diferencial semelhante ao do conjunto das gestantes.

Quanto à qualidade do atendimento, não houve associação entre renda e a solicitação de exame de sangue e a orientação sobre vacina anti-tetânica. Já as usuárias do SUS tiveram menor solicitação daquele exame e maior orientação sobre a vacina. Esta situação talvez possa ser explicada pela maior oferta de vacinação nos serviços públicos e pela dificuldade destes em solicitar e encaminhar para exames laboratoriais.

Por outro lado, tanto as mães mais pobres quanto as usuárias do SUS receberam maior prescrição de ferro. A prescrição de ferro é rotina determinada pelo Ministério da Saúde ${ }^{35}$ a todas as gestantes, independentemente do nível sérico de hemoglobina.

No tocante a outros itens de qualidade dos serviços, constatou-se que a freqüência de verificação da data da última menstruação, a realização de exame ginecológico e de mamas foi menor nos Postos de Saúde de Criciúma que nos outros locais, à semelhança de Pelotas em $1997^{45}$. Por outro lado, enquanto as mães de Criciúma que tiveram atendimento particular recek aram mais orientação sobre amamentação (87,5\%), em Pelotas os outros serviços 
orientaram de forma semelhante aos Postos de Saúde $(68,4 \%$ e $65,8 \%$ respectivamente). Esta proporção foi semelhante ao grupo "Sempre SUS" em Criciúma $(67,4 \%)$. Assim este estudo mostrou que o grupo "Sempre Particular" se destacou na variável orientação sobre amamentação.

Deve ser lembrado a mudança de gestão ocorrida entre o período da pesquisa e a situação atual. Em 1996 a gestão era Estadual e, em 2.000 Criciúma apresenta-se como um dos 22 municípios catarinenses com Gestão Plena de Sistema Municipal, estando os demais municípios (268) em Gestão Plena da Atenção Básica ${ }^{36}$. Além disso no ano 2.000, 19 equipes do Programa Saúde da Familia (PSF) cobriam $25,6 \%$ da população e o Programa de Agentes Comunitários de Saúde (PACS), implantado em agosto de 1999 , cobria $15,3 \%{ }^{37}$. Foi, ainda, ampliado em 10 o número de Unidades Básicas, além do horário de funcionamento de duas Unidades Referenciais de Saúde (para 24 horas) e implantado um serviço de Pronto Socorro Infantil 24 horas. Assim, as estratégias de melhoria da atenção devem levar em consideração esta nova situação.

Limitação da presente pesquisa, em estabelecer quais os profissionais que prestaram os serviços, não nos permitiu avaliar se diferentes profissionais atenderam os pacientes do SUS e Particular ou, se um mesmo profissional atendeu de forma desigual esses dois públicos. As diferenças de qualidade, dentro de um mesmo serviço, devido a diferentes formas de pagamento deveriam ser objeto de novos estudos, tendo em vista aspectos éticos e políticos

\subsection{Desfecho (Aleitamento Materno)}

Os estudos observacionais retrospectivos estão sujeitos a viéses de recordação. No entanto, a análise das curvas de sobrevivência para o aleitamento materno com as proporções de aleitamento no momento da entrevista foram bastante similares, havendo diferença apenas aos dois e doze meses. Tendo sido utilizado como ponto de corte, para a duração do aleitamento, a idade de seis meses, essa diferença não deve afetar os resultados apresentados. 
A mediana nacional de amamentação segundo a PNDS 1996 foi de 7.0 meses $^{48}$, uma duração superior à observada em Criciúma (4,8 meses) e em Pelotas 1993 (4,0 meses) ${ }^{22}$.Tal como neste último estudo, em Criciúma os grupos de mais alta renda familiar total apresentaram maior mediana de amamentação no sexto mês de vida. Tendo em vista que as crianças de familias pobres são as que mais necessitam do aleitamento e as que menos o recebem nos primeiros meses de vida ${ }^{22}$, os presentes resultados sugerem que as estratégias de incremento da amamentação devam ser dirigidas prioritariamente às familias de baixa renda

Os procedimentos relacionados com a amamentação foram realizados com menor freqüência para o grupo "Sempre SUS" em relação a todos os outros grupos. No entanto, este atendimento menos adequado não se refletiu em diferenças na amamentação por parte de seus usuários em relação aos demais grupos. O grupo "Particular->SUS" apresentou um comportamento paradoxal: recebeu atendimento pior em relação aos procedimentos relacionados ao aleitamento materno do que o grupo "Sempre Particular" e foi o único que apresentou associação significativa com o aleitamento materno por seis meses ou mais após o ajuste para os fatores de confusão. Seria interessante que estudos posteriores investigassem melhor as características das mães do grupo "Particular->SUS" em relação ao aleitamento materno para esclarecer se seu perfil diferenciado é que as leva a amamentar por mais tempo ou não.

A análise dos efeitos de cada procedimento em separado, em relação aleitamento materno, mostrou que a maioria não tem efeito sobre este.

A análise do conjunto dos procedimentos relacionados ao aleitamento materno realizados durante o Pré-Natal, mostrou efeito positivo sobre o aleitamento materno exclusivo e predominante. O efeito do exame das mamas e a orientação sobre amamentação no Pré-Natal foi chamativo uma vez que mães com os dois procedimentos teriam uma chance quatro vezes maior de amamentar exclusivamente até os quatro meses, cabendo ao primeiro, na análise em separado dos procedimentos, uma chance de 2,9 vezes. Infelizmente, menos da metade das mães foi beneficiada com estes procedimentos. Ressalve-se a possibilidade de viés de informação: mães que 
amamentaram podem recordar as orientações recebidas de forma diferenciada das que não amamentaram. Já o exame do seio, possivelmente, não seria tão sensivel a este viés. É importante ressaltar que a Razão de Produtos Cruzados tende a exagerar o Risco Relativo de eventos freqüentes. No entanto, tendo em vista que o aleitamento materno exclusivo em Criciúma foi relativamente raro (apenas $8,1 \%$ ), esta estimativa está provavelmente muito próxima da realidade

O conjunto dos procedimentos relacionados ao aleitamento materno realizados no "Parto/RN", mostrou uma associação de baixa magnitude com a introdução tardia da mamadeira. É importante lembrar, no entanto, que apenas 2,0\% das mães receberam os três procedimentos pesquisados (tempo de colocação do recém-nascido para mamar após o parto menor ou igual a duas horas, alojamento conjunto e orientação na maternidade sobre amamentação). Caso utilizássemos neste estudo o ponto de corte recomendado nos "Dez Passos para o Sucesso do Aleitamento Materno" da Iniciativa Hospital Amigo da Criança ${ }^{31}$, verificariamos que apenas 1,8\% de crianças foram colocadas para mamar na primeira meia hora de vida. Com este critério, somente sete crianças $(0,3 \%)$ teriam recebido os três procedimentos de "Parto/RN" avaliados. Certamente a falta destes procedimentos contribuiu para que $61,1 \%$ das mães introduzissem a mamadeira antes do quarto mês de vida, procedimento que favorece a mortalidade infantil ${ }^{18,52,55}$ e as hospitalizações, principalmente por pneumonia ${ }^{26}$.

O ajuste, na análise multivariada, para o inicio do Pré-Natal no primeiro trimestre tornou não significativa a associação entre os procedimentos relacionados ao aleitamento materno do "Parto/RN" e a introdução tardia da mamadeira. Esta mudança pode ser oriunda de características intrínsecas destas mães que, ao iniciar precocemente o controle, já apresentam motivação ou preocupação com a saúde 27,46 .

A situação encontrada em Criciúma foi coerente com um estudo multicêntrico $0^{6.32 .56}$ que identificou a fragilidade da educação em saúde ao não ser capaz de demonstrar sucesso em um programa preventivo e de apoio que visava a melhoria dos desfechos da gestação e da satisfação e/ou bem-estar materno. Nesses trabalhos os autores observaram que as orientações ladas em curto espaço de tempo (três meses) foram pouco efetivas na modificação 
de comportamentos. Estes seriam conseqüência de experiências acumuladas por muito tempo e estariam fortemente influenciados pelo ambiente presente e o passado. Outro aspecto a ser lembrado é a tendência dos profissionais de saúde em "obrigar" a mãe a amamentar ${ }^{58}$, sem dar o devido apoio (a amamentação é um processo complicado e que demanda aprendizado') e, por vezes, ignorando as questões relacionais e culturais que permeiam este ato. 


\section{Resumo dos principais resultados:}

\subsection{Quanto à cobertura dos serviços de Pré-Natal e parto/assistência ao} recém nascido:

- os serviços de Pré-Natal tiveram alta cobertura em Criciúma;

- o parto hospitalar foi universal.

\subsection{Quanto à eqüidade:}

- as gestantes com menor renda e as com "Risco de saúde reprodutiva" receberam atendimento menos adequado:

- houve carência de procedimentos médicos no Pré-Natal, mais relevante nas classes de menor renda;

- o atendimento ao parto foi inadequado para todas as classes de renda.

\subsection{Avaliação da qualidade dos serviços oferecidos segundo forma de} pagamento do prestador do serviço:

- o SUS foi, de fato, o serviço que atende a população de baixa renda e com maior risco reprodutivo

- O atendimento SUS apresentou qualidade menos adequada, principalmente quanto aos procedimentos médicos utilizados como indicadores de qualidade, com destaque para o exame ginecológico especular e de mamas;

- a utilização de diferente forma de pagamento do parto, em relação ao PréNatal, não foi aleatória, havendo indícios que o grupo "SUS->Particular" mudou por interesse no planejamento familiar através da laqueadura tubária:

- o atendimento ao parto pelo SUS foi fator de proteção contra a cesariana:

- o grupo "Particular->SUS" apresentou maior propensão ao parto normal, preocupação com a saúde da criança e tendência a resultados positivos superando as deficiências dos serviços ofertados; 


\subsection{Avaliação da qualidade e o aleitamento materno:}

- os procedimentos relativos ao incentivo ao aleitamento materno no geral foram pouco realizados, sendo consistentes com o baixo indice de amamentação no município;

- gestantes que tiveram suas mamas examinadas e receberam orientação sobre amamentação no Pré-Natal apresentaram uma chance quatro vezes maior de amamentar exclusivamente ao seio até o quarto mês de vida em relação às mães que não receberam estes procedimentos, refletindo uma relação médico-paciente de maior qualidade; 


\section{Recomendações:}

- utilizar indicadores de qualidade da atenção como o exame ginecológico e de mamas:

- devem-se buscar estratégias para captar mais precocemente as gestantes de menor renda;

- utilizar enfoque de risco: as mais pobres e gestantes com risco devem receber atenção diferenciada (discriminação positiva);

- retreinar os médicos quanto à importância de seus procedimentos de PréNatal, especialmente com relação ao exame ginecológico e de mamas;

- maior divulgação da Lei 9.264 que regula o planejamento familiar entre os médicos;

- melhorar a qualidade de atendimento pelo SUS especialmente no que concerne à atenção médica durante o Pré-Natal;

- universalizar o alojamento conjunto, a colocação da criança para mamar logo após o parto e a orientação para a mãe durante o internamento, sobre os cuidados com a criança (Hospital Amigo da Criança);

- reciclar os médicos quanto à importância de seus procedimentos de prénatal, estimulando a realização de procedimentos simples como o exame das mamas e a orientação da amamentação a fim de alterar a qualidade da atenção e da relação médico-paciente, visando resultados mais efetivos

- discussão destes resultados nos Conselhos Populares de Saúde, Conselho Municipal de Saúde e com os programas que mais intensamente atingem a população de menor poder aquisitivo, em especial o PSF, PACS e Pastoral da Criança. 


\section{Bibliografia:}

I Almeida JAG. Amamentação: um hibrido natureza-cultura Rio de Janeiro: Fiocruz; 1999.

2 Armitage $P$, Berry $G$. Statistical methods in medical research. 2 ed. Oxford: Blackwell; 1987.

3. Barros FC, Halpern R, Victora CG, Teixeira AMB, Béria JU. Promoção da amamentação em localidade urbana da região Sul do Brasil: estudo de intervenção randomizado. Rev Saúde Pública 1994; 28(4):277-83

4. Barros FC, Semer TC, Tonioli Filho S, Tomasi E, Victora CG. 1995. The impact of lactation centres on breastfeeding patterns, morbidity and growth: a birth cohort study. Acta Paediatr 1995; 84(11):1221-6.

5. Béhague DP, Victora CG, Barros FC. Consumer demand for caesarean section deliveries in Brazil: informed decision-making, patient choice or social inequality? [artigo não publicado].

6. Belizan JM, Barros F, Langer A, Farnot U, Victora C, Villar J. Impact of health education during pregnancy on behavior and utilization of health resources Am. J. Obstet. Gynecol 1995; 173(3 Pt 1): 894-99

7. Brasil. Lei $n^{\circ} 9.263$, de 12 de janeiro de 1996. Regula o parágrafo 7 do artigo 226 da constituição federal, que trata do planejamento familiar, estabelece penalidades e da outras providencias. Diário Oficial da República Federativa do Brasil, Brasilia, 15 jan 1996. Seção I, pt1, p. 6009.

8. Centers for Disease Control \& Prevention (CDC), World Health Organization. Epi Info 6. A Word processing, Database and Statistics Program for Public Health [programa de computador]. Version 6.02. Atlanta: WHO; 1994

9. César JA Victora CG, Barros FC, Ramos FA Albernaz EP, Oliveira LM, Halpern R, Breitenbach A, Stone MH, Fracalossi V. Hospitalizações em menores de um ano pertencentes a duas coortes de base populacional no Sul do Brasil: tendências e diferenciais. Cad Saúde Públ 1996; 12 (supl.1):67-71.

10. César JA, Victora CG, Santos IS, Barros FC, Albernaz EP, Oliveira LM, Flores JA, Horta BL, Weiderpass E, Halpern R. Hospitalização por pneumonia: influência de fatores socioeconômicos e gestacionais em uma coorte de crianças no Sul do Brasil. Rev Saúde Pública 1997; 31(1):53-61

11. César JA, Victora CG, Barros FC, Santos IS, Flores JA. Impact of breast feeding on admission for pneumonia during postneonatal period in Brazil: nested case-control study. BMJ 1999; 318:1316-20. 
12. Costa JSD, Victora CG, Barros FC. Halpern R. Horta BL, Manzolli P. Assistência médica materno-infantil em duas coortes de base populacional no Sul do Brasil: tendências e diferenciais Cad Saúde Públ 1996; 12 (supl. 1):59-66

13. Dobie S, Hart LG, Fordyce M, Andrilla CHA, Rosemblatt RA. Obstetric care and payment source: do low-risk Medicaid women get less care? Am J Public Health 1998: 88(1):51-56.

14. Donabedian A. La investigación sobre la calidad de la atención médica. Salud Publica Mex 1986;28:324-327.

15. Faúndes A Cecatti JG. A operação cesárea no Brasil. Incidência, tendências, causas, conseqüências e propostas de ação. Cad Saúde Públ $1991 ; 7(2): 150-173$

16. Faúndes A, Costa RG, Pádua KS, Perdigão AM. Associação entre prevalência de laqueadura tubária e características sócio-demográficas de mulheres e seus companheiros no Estado de São Paulo, Brasil Cad Saúde Públ 1998; 14 (supl. 1): 49-57.

17. Fleiss JL. Statistical methods for rates and proportions. 2nd ed. New York: John Wiley \& Sons; 1981

18. Fuchs SC, Victora CG, Fachel J. Modelo hierarquizado: uma proposta de modelagem aplicada à investigação de fatores de risco para diarréia grave. Rev. Saúde Pública 1996; 30 (2): 168-78

19. Goodine LA, Fried PA. Infant feeding practices: pre- and postnatal factors affecting choice of method and the duration of breastfeeding. Can J Public Health 1984; 75 : 439-444.

20. Haas JS, Udvarhelyi S, Epstein AM. The effect of health coverage for uninsured pregnant women on maternal health and the use of cesarean section. JAMA 1993;270(1):61-4

21. HART JT. The inverse care law. Lancet 1971; Feb: 405-12

22. Horta BL, Olinto MTA, Victora CG, Barros FC, Guimarães PRV. Amamentação e padrões alimentares em crianças de duas coortes de base populacional no Sul do Brasil: tendências e diferenciais. Cad Saúde Públ 1996; 12 (supl. 1):43-48.

23. IBGE (Fundação Instituto Brasileiro de Geografia e Estatística). Contagem da população 1996. Rio de Janeiro: IBGE; 1997.

24. IPEA (Instituto de Pesquisa Econômica Aplicada). Crescimento, desigualdade e pobreza: o impacto da estabilização. Brasília: IPEA: 1996. (IPEA - Carta de Conjuntura, 62). 
25. IPEA (Instituto de Pesquisa Econômica Aplicada). A evolução recente do bem-estar social, da pobreza e da desigualdade. Brasilia: IPEA; 1997. (IPEA - Carta de Conjuntura, 71)

26 Jacobs J. Prenatal care key to breast-feeding. Can Med Assoc J 1995: $152(8): 1188-9$

27. Kaestner R. Health insurance, the quantity and quality of prenatal care. and infant health. Inquiry 1999:36:162-175.

28. Kirkwood BR. Essentials of medical statistics. London: Blackwell Science Ltd; 1999

29. Krieger JW, Connell FA, LoGerfo JP. Medicaid prenatal care: a comparison of use and outcomes in fee-for-service and managed care. Am J Public Health $1992 ; 82: 185-190$

30 Lallo D, Perucci CA, Bertollini R, Mallone S. Cesarean section rates by type of maternity unit and level of obstetric care: an area-based study in Central Italy. Prev Med 1996; 25:178-185.

31. Lamounier JA. Experiência iniciativa Hospital Amigo da Criança. Res Ass Med Brasil 1998; 44(4):319-24.

32. Langer A, Farnot U, Garcia C, Barros F, Victora C, Belizan JM, Villar J. The latim american trial of psychosocial support during pregnancy: effects on mother's wellbeing and satisfaction. Soc Sci Med 1996; 42(11): 1589-97.

33. Latham MC. Breast feeding reduces morbidity [Editorial].BMJ 1999; 318:1303-4.

34. Mackenbach JP, Gunning-Schepers LJ. How should interventions to reduce inequalities in health be evaluated? J Epidemiol Community Health 1997; 51:359-364.

35. Ministério da Saúde. Assistência pré-natal. $2^{a}$ ed. Brasilia: Centro de Documentação do Ministério da Saúde; 1988

36. Ministério da Saúde. Condição de gestão por Municípios. [site on line]. Disponivel em <URL:http://www.saude.gov.br/descen/sc.htm> [2000 nov 11]

37. Ministério da Saúde. DATASUS Sistema de Informações Hospitalares do SUS (SIH/SUS). [banco de dados on line]. Disponivel em <URL:http://www datasus.gov br> [2000 nov 11]

38. Neumann NA, Victora CG, Halpern $R$, Guimarães PRV, Cesar JA Desempenho da Pastoral da Crianca na promoção de açčes de sobrevivência infantil e na educação em saúde em Criciúma, uma cidade do sul do Brasil. Pam Am J Public Health 1999; 5(6):400-10 
39. Neumann NA Victora CG, Halpern R, Guimarães PRV. Cesar JA. A Pastoral da Criança em Criciúma, Santa Catarina, Brasil: cobertura e características sócio-demográficas das familias participantes. Cad Saude Públ 1999;15(3):543-552

40. Neumann NA. Tanaka OY, Szarfarc SC, Guimarães PRV, Victora CG. Prevalência e fatores de risco para anemia no Sul do Brasil. Rev. Saúde Pública 2000: 34(1):56-63

41. Olinto MT, Victora CG, Barros FC, Tomasi E. Determinantes da desnutrição infantil em uma população de baixa renda: um modelo de análise hierarquizado. Cad. Saúde Públ 1993; 9 (supl.1): 14-27.

42. Olson CM. Promoting positive nutritional practices during pregnancy and lactation. Am J Clin Nutr 1994; 59(suppl):525S-31S

43 Rezende J, Montenegro CAB. Obstetricia Fundamental $4^{a}$ ed. Rio de Janeiro: Guanabara Koogan; 1984.

44. Rothman KJ, Greenland S. Modern Epidemiology. 2 ed. Philadelphia: Lippincott-Raven Publishers; 1998.

45. Santos IS, Baroni RC, Minotto I, Klumb AG. As mães e os serviços de acompanhamento pré-natal: critérios para a escolha de postos de saúde em Pelotas, RS. Rev Saúde Pública 2000 [no prelo].

46. Swigonski NL, Skinner CS, Wolinsky FD. Prenatal health behaviors as predictors of breast-feeding, injury, and vaccination. Arch Pediatr Adolesc Med 1995; 149:380-385

47 Silva RMR, Saboia AL, Cervini RA. Crianças e adolescentes: indicadores sociais. Rio de Janeiro: IBGE (Fundação Instituto Brasileiro de Geografia e Estatistica); 1992. v.1

48 Sociedade Civil Bem-Estar Familiar no Brasil (BENFAM). Pesquisa Nacional sobre Demografia e Saúde 1996. Relatório Preliminar. Rio de Janeiro: BENFAM: 1996

49. SPSS (Statistical Package for the Social Sciences). Release 6.1, standard version [programa de computador]. Chicago: SPSS inc; 1994.

50. Travassos C, Viacava F, Fernandes C, Almeida CM. Desigualdades geográficas e sociais na utilização de serviços de saúde no Brasil. Ciência e Saúde Coletiva 2000; $5(1): 133-149$.

51. UNICEF, IBGE. Municipios brasileiros: crianças e suas condições de sobrevivência. Censo Demográfico 1991. Fundo das Nações Unidas para a Infância - UNICEF e Fundação Instituto Brasileiro de Geogratıa e Estatística - FIGBE. Brasilia; 1994. 
52. Victora CG et al. Evidence for protection by breast-fedding against infant deaths from infectious diseases in Brazil. Lancet 1987; aug 8:319-322.

53. Victora CG, Barros FC, Vaughan JP. Epidemiologia da desigualdade $2^{\mathrm{a}}$ ed. São Paulo: Hucitec; 1989.

54. Victora CG, Barros FC, César J, Horta B, Lima SM et al. Saúde das crianças dos Estados do Ceará, Rio Grande do Norte e Sergipe, Brasil: descrição de uma metodologia para diagnósticos comunitários. Rev Saúde Pública 1991; 25 (3): 218-25.

55. Victora CG, Fuchs SC, Kirkwood BR, Lombardi C. Barros FC. Breastfeeding, nutritional status, and other prognostic factors for dehydration among young children with diarrhoea in Brazil. Bull World Health Organ 1992; 70 (4): $467-475$

56. Villar J, Farnot U, Barros F, Victora C, Langer A, Belizan JM. A randomized trial of psychosocial support during high-risk pregnancies. $\mathbf{N}$ Engl J Med 1992; $327(18): 1266-71$

57. WHO Collaborative Study Team on the Role of Breastfeeding on the Prevention of Infant Mortality. Effect of breastfeeding on infant and child mortality due to infectious diseases in less developed countries: a pooled analysis. Lancet 2000; 355:451-55.

58. Winnicott DW. Os bebês e suas mães São Paulo: Martins Fontes; 1999 A amamentação como forma de comunicação;p.19-27. 


\section{ESTUDO SOBRE SAÚDE DAS CRIANÇAS MENORES DE 3 ANOS EM CRICIÚMA- 1996}

$\mathbf{N o}$
numqes

1. NUMMERO DA FOLHA DE CONGLOMERADO:

2. ENTREVISTADOR:

SUPERVISOR:

ENTREVISTA SUPERVISIONADA: ( ) Sim

(2) Não

3. SETOR:

4. BAIRRO:

5 DIA DA SEMANA:
(1) Dom
(2) Seg
(3) Ter (4) Qua
(5) Qull
(6) Sex (7) Sab

6. TENTATIVAS: 12

(1) Sim entrevistada

$2^{2}-3^{3}$

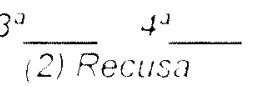

(8) NSA

(2) Sim. marcou para outro dia

(4) Náo ausente

Faço parte do grupo que esta estudando a saude das cranças pequenas

Meu nome

de Criciuma

Gostana ve saber se tem crança menor de 3 anos de idade nesta casa?

(1) $\mathrm{s} / \mathrm{m}$

(2) nào

NÄO ESQUEÇA DE ANOTAR NAS FOLHAS DE CONGLOMERADO

- HORA DA ENTREVISTA

8 vome dame.

9 NUMERO DA CRIANÇA (COMEÇAR PELA MAIS NOVA)

10 Como e onome da cranca

(ONDE CONSTAR <CRIANCYA>, SUBSTITUIR PELO NOME,

11 SEXO: (1) Masculino $\quad$ (2) Feminino

12 Quem esta cudando <CRIANCA > a maior parte do tempo 110 ultmo mes?
1 pessoa
$2^{3}$ pessoa
(01) Mãe
(02) $\mathrm{Pa}$
(04) Funcionaria da creche
(05) amiga / vizinha $<15$ anos
(06) Empregadababa $<15$ anos
(06) amiga fizmha $>=15$ anos
(07) Empregadababa $>=15$ anos
(08) irmã(o) / parente < 15 anos
(09) irmã(o) / parente $>=15$ anos
(88) NSA
(99) $1 G N$

- (03) Avo

(1) Outro

13 A senhora tem certidăo de nascimento e caderneta de saude? A Sra poderia me trazer?

14 DATA DE NASCIMENTO

SE NÄO TEM REGISTRO $\overline{D A} \overline{D A T} \bar{A}$ DE NASCIMENTO PERGUNTAR:

Qual a data de hascmento de <CRIANÇA> (anversáno)?

A DATA DE NASCIMENTO FOI:
(1) vista no registro/caderneta
(2) Só informada
(9)/GN

nucria

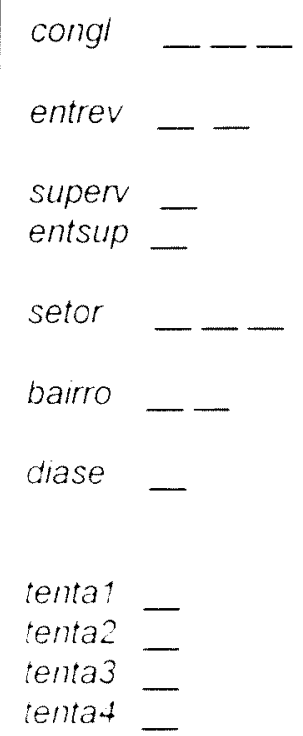

hor

culda1

cuida2

$d n$

confdn 
15 TEM CADERNETA DE SAÚdE
(1) $\operatorname{Sim}$, visto
(2) Sim, não visto
(3) Tinha mas perdeu
(4) Nunca teve
(9) IGN

16 Durante a gravidez de <CRIANÇA> a Sra fez alguma consulta pré-natal?
(1) $\operatorname{Sim}$
(2) Não $\rightarrow \# 22$

SE SIM:

17 Em que mês da gravidez de <CRIANÇA> a Sra fez a primeira consulta de pré-natal _ $(01=$ primeiro mês, $88=N S A, 99=/ G N)$

18 Quantas consultas de pré-natal a Sra fez na gravidez de <CRIANÇA>?

_ $(8=$ não se aplica $)$

19 Durante as consultas de pré-natal o médico ou a enfermeira alguma vez?

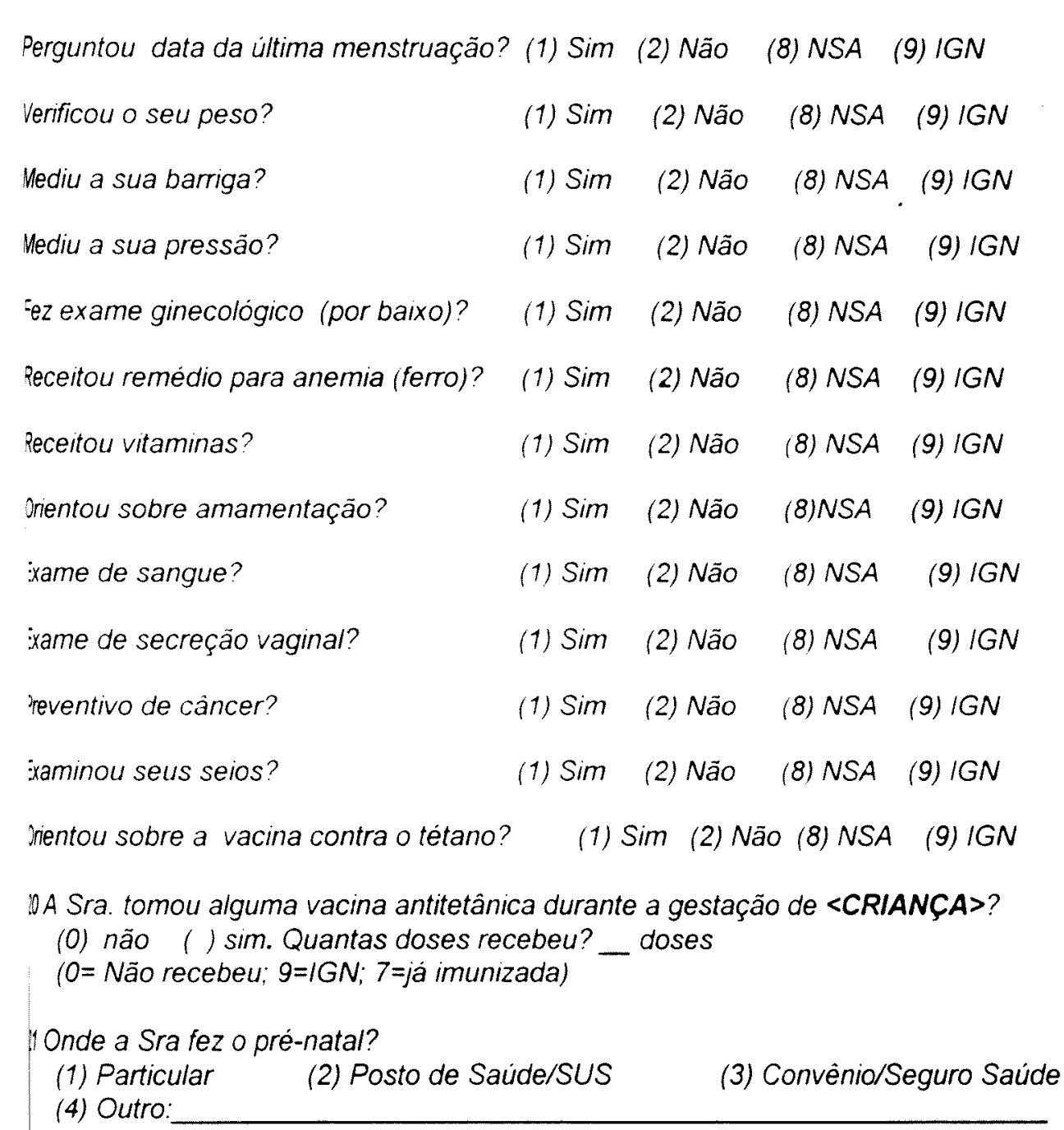

Inentou sobre a vacina contra o tétano?

(1) $\operatorname{Sim}$

(2) Não (8) NSA

(9) IGN

DA Sra. tomou alguma vacina antitetânica durante a gestação de <CRIANÇA>?
(0) não () sim. Quantas doses recebeu? doses

$(0=$ Não recebeu; $9=1 G N ; 7=j a ́$ imunizada)

I Onde a Sra fez o pré-natal?
(1) Particular
(2) Posto de Saúde/SUS
(3) Convènio/Seguro Saúde
(4) Outro:

Em que hospital foi o parto de <CRIANCAA>?
(1) São José
(2) São João
(3) Outro:

cadern

conspre

numcos

b O parto de <CRIANÇA> foi normal ou cesária?
(1) Normal
(2) Cesárea
(9) IGN
(3) outro

- - - $\quad(9.99=1 G N)$
(1) Confirmado
(2)Só informado
(9) IGN

ultmen -
prepes -
medbar -
medpre -
exginec -
reman -
recvit -
orama -
exsan -
exvag -
ponfpn -
precan -
exseio -
vactet -
doste 
25 Quanto tempo depois de nascida <CRIANÇA> foi colocada no seio para mamar? _ _ horas _. minutos

$26 \mathrm{Na}$ maternidade <CRIANÇA > ficou o tempo todo com a mãe?
(1) Não / berçário
(2) Sim / alojamento conjunto

27 No hospital depois do parto de <CRIANÇA> a Sra recebeu alguma orientação sobre como cuidar da criança?
(1) $\mathrm{Sim}$
(2) Não

SE SIM: Qual?
(1) amamentação
(2) umbigo
(3) higiene
(4) cólicas
(5) vacinas
( ) outro

280 parto foi particular ou pelo INPS?
(1) Particular
(2) Pelo SUSIINPS
(3)convênio/seguro saúde
(4) outro

19 A Sra teve filhos ou filhas antes de <CRIANÇA>?
Quantos? $100=$ Nenhum $\rightarrow \# 33$ )
Algum deles nasceu morto?

(1) $\operatorname{sim}$ (2) näo $\rightarrow$ \#31

\section{SE SIM:}

A Sra. lembra com quantos meses de gestação ocorreu a perda? nascidos mortos (28 semanas ou mais de gestação; $1000 \mathrm{~g}$ ou mais)

\section{NASCIDOS VIVOS ANTES ( $0=$ NENHUM; $7=$ FILHO ÚNICO ; $9=$ IGNORADO)}

Dos filhos que a Sra teve antes de <CRIANÇA>, quantos estão vivos?

SE NÜMERO DE FILHOS DIFERENTE DO NÚMERO DE NASCIDOS VIVOS:
idade da morte 1
idade da morte2
- anos meses
idade da morte3
_

$(8888=$ NSA $)$

\section{ETEM IRMĀS OU IRMÃOS MAIS VELHOS}

12 Qual a data de nascimento do irmão (ou irmã) que nasceu antes de
$<$ CRIANCA > ?
$(08 / 08 / 08=N S A ; 09 / 09 / 09=/ G N)$
A Sra ficou grávida depois d
<CRIANCA>?
(1) $\operatorname{Sim}$
(2) Não $\rightarrow \# 36$

SE SIM: Quantas vezes: $(8=N S A)$

Algum deles nasceu morto ? (1) sim (2)não $\rightarrow \# 35$

\section{SE SIM}

A Sra. lembra com quantos meses de gestação ocomeu a perda? nascido mortos (28 semanas ou mais de gestação: $1000 \mathrm{~g}$ ou mais)
_
Dos filhos que a Sra teve depois de <CRIANCA>, quantos estão vivos? SE NÚMERO DE FILHOS NASCIDOS DEPOIS DIFERENTE DO NUUMERO DE NASCIDOS VIVOS NASCIDOS DEPOIS:
idade da morte anos meses $(88.88=N S A)$

fora eu vou fazer algumas perguntas sobre o que <CRIANÇA> gosta de comer

Ontem <CRIANÇA> se alimentou como sempre?
(1) $\operatorname{Sim}$
(2) Näo
(9) IGN

SE NÃO: Quando foi o último dia que <CRIANCCA> se alimentou como sempre? $\ldots \ldots$ _ $(I G N=01 / 01, N S A=88 / 88)$

temmam

alomae

orient

qual1

qual2

qual3

qual4

parpag

filan

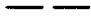

nmoant

temoan

tevian

vivant

moran 1

moran2

moran 3

$--$

dnfian

gradep

graqua

mordep

namode

navide

nvidep

alimen

alisem 
37 Por favor diga-me tudo que <CRIANÇA> comeu neste dia?

RECORDATÓRIO ALIMENTAR - 24 HORAS

\begin{tabular}{|c|c|c|c|c|c|c|c|c|c|}
\hline Alimento & Acordar ' & Manhã & Almoço & Tarde & Janta & Dormir & Madrugada & & \\
\hline$L M$ & & & & & & & & & \\
\hline & & & & & & & & $I m$ & - - \\
\hline LVaca & & & & & & & & & \\
\hline & & & & & & & & vac & - \\
\hline$\angle P O$ & & & & & & & & & \\
\hline & & & & & & & & po & - \\
\hline Café & & & & & & & & caf & - \\
\hline Agua & & & & & & & & sat & \\
\hline Chà & & & & & & & & cha & \\
\hline Suco & & & & & & & & & \\
\hline Pão & & & & & & & & & \\
\hline Bolacha & & & & & & & & & -- \\
\hline logurte & & & & & & & & & \\
\hline Mingau & & & & & & & & $\min a$ & \\
\hline Caldo & & & & & & & & cal & \\
\hline Frutas & & & & & & & & & \\
\hline (qual?) & & & & & & & & fru & \\
\hline Ovo & & & & & & & & & -- \\
\hline Arroz & & & & & & & & & - \\
\hline Feijão & & & & & & & & $a r r$ & -- \\
\hline $\begin{array}{l}\text { Legume/ } \\
\text { verdura }\end{array}$ & & & & & & & & $\operatorname{leg}$ & $\begin{array}{l}-- \\
--\end{array}$ \\
\hline Massa & & & & & & & & mass & \\
\hline $\begin{array}{l}\text { Batatal } \\
\text { Aipim }\end{array}$ & & & & & & & & & \\
\hline $\begin{array}{l}\text { Farinha } \\
\text { nandioca }\end{array}$ & & & & & & & & fman & \\
\hline Carne & & & & & & & & carn & \\
\hline $\begin{array}{l}\text { Engros- } \\
\text { sante }\end{array}$ & & & & & & & & engr & \\
\hline Outro1 & & & & & & & & out1 & \\
\hline Outro2 & & & & & & & & out2 & \\
\hline ใefeições & & & & & & & & & \\
\hline & & & & & & & & refei & \\
\hline
\end{tabular}


38 Desde $<D I A$ DA SEMANA > passada a $<$ CRIANCCA> comeu algum destes alimentos que eu vou the dizer?
- figado
(1) $\operatorname{Sim}$
(2) Não
- cenoura
(1) $\operatorname{sim}$
(2) Não
- batata-doce
(1) $\operatorname{sim}$
(2) Não
- espinafre
(1) $\operatorname{Sim}$
(2) Não
- abobora
(1) $\mathrm{Sim}$
(2) Não
- melão
(1) $\mathrm{Sim}$
(2) Não
- brócoli
(1) $\mathrm{Sim}$
(2) Não
- pêssego
(1) $\mathrm{Sim}$
(2) Não
- gema de ovo
(1) $\mathrm{Sim}$
(2) Não
- laranja
(1) $\mathrm{Sim}$
(2) Não
- maça
(1) $\operatorname{Sim}$
(2) Não
- couve
(1) $\mathrm{Sim}$
- abacate
(2) Não
(1) $\mathrm{Sim}$
- manga
(1) $\mathrm{Sim}$
(2) Não
- banana
(1) $\mathrm{Sim}$
- pó de folhas verdes
(1) $\mathrm{Sim}$
(2) Não
(2) Não
(mandioca. aipim, batata doce. outras)
- farelo de arroz ou de trigo (1) Sim
(2) Não
(2) Não

\section{APLICAR APENAS PARA CRIANCAS MENORES DE 1 ANO:}

39 Agora eu vou the dizer uma lista de liquidos e alimentos e peço que a Sra. me diga se ja começou a dar para <CRIANÇA>.

Quando eu digo começou eu quero saber se $\langle$ CRIANCCA> recebe(eu) este ilquido ou ailmento todos os dias. ou quase todos os dias da semana.

Se a Sra. já começou a dar. eu quero saber quando começou.

Lette de vaca/saquinho:

Lette empó

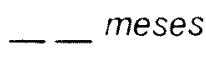

Cha:

Suco:

Papa de frutas/fruta amassada.

Papa salgada (leg/ver)

Mingau.

logurte.

Pãolbolacha:

Ovo (gema).

Ovo (clara):

Carne

Caldo de feijão.

Feijão (grão):

Farinha de mandioca

Arroz:

Massa:

Farelo de arroz:

Farelo de trigo:

Pó folhas verdes.

Pó casca de ovo.

Sementes (melancia/abóbora):

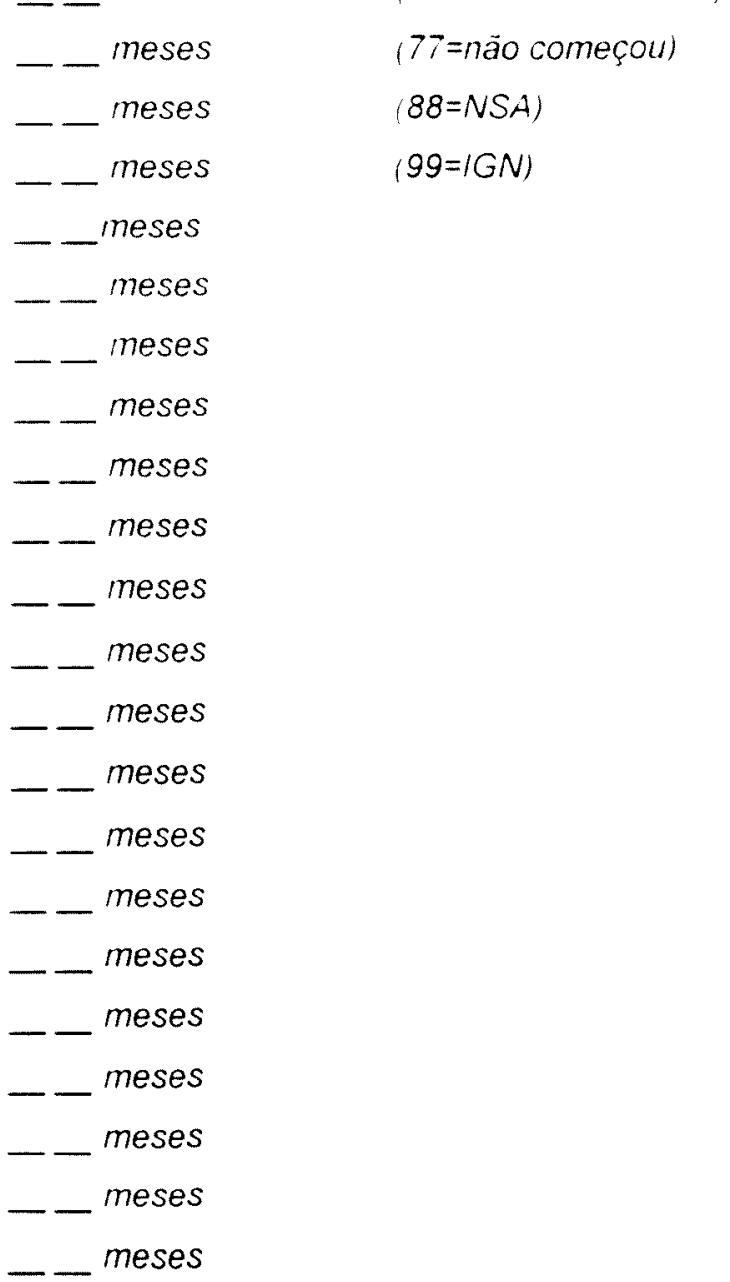

figad

cenou

batado

espin

$a b o b$

melao

broc

pesseg

gema

laran

maca

couve

abac

manga

banan

pofol

far

$\begin{array}{ll}\text { iniva } & - \\ \text { inipo } & - \\ \text { inich } & - \\ \text { inisu } & - \\ \text { inifru } & - \\ \text { inileg } & - \\ \text { inimin } & - \\ \text { iniog } & - \\ \text { inipao } & - \\ \text { inovo } & - \\ \text { inicla } & - \\ \text { inicar } & - \\ \text { inical } & - \\ \text { inifej } & - \\ \text { inifman } \\ \text { iniarr } \\ \text { inimas } \\ \text { inifara } \\ \text { inifatri } \\ \text { inifove } \\ \text { inicaov } \\ \text { iniseme }\end{array}$ 
40 Tem alguma outra comida que ele(a) já recebeu e que eu não faleı agora?

Outro1

Outro2

- _meses

Outro3 meses

(nunca tomou $=88$ meses: ignorado $=99$ meses) meses

$41<$ CRIANCA> chegou a usar mamadeira?
(1) Não $\rightarrow \# 43$

(2) Sim. ja parou. Ate que idade usou mamadeira?

meses

(3) Sim. ainda usa. Quantas vezes usou a mamadeira desde ontem a esta hora? - - vezes

SE SIM:

42 Quando comecon? _ _ meses__ dias

SE NO RECORDATORIO A MÃE NĀO CITOU LEITE MATERNO, PERGUNTAR; SE JÁ FOI CITADO ASSINALE A OPÇÃO 1 NA PROXIMA PERGUNTA.

43 CCRIANÇA chegowa mamar no perto?
1) Nunca mamou
(2) Sim. anda mama $\rightarrow \$ 46$
3) Sim a barou Ate que dave mamou
anos
_ dias
$838.88=$ NSA. $9.99 .99=$ (GN)

\section{SE NUNCA MAMOU:}

44 Porque năc chegou a mamar?

(01) Māe năo qus

\section{RAZÕES $1^{\circ}$}

(02) Ele não quis

(04) Não tinha leite

(06) Mãe doente

(05) Ele to adotado

(07) Prematuro/doente

(09) Dor rachadura ou infeccão no seio

() Outro.
$2^{3}$

(99) IGN

(88) NSA

(08) Alguem aconselhou

pqnma2 inout1

inout2

inout3

idmad

fremad

commad

mam

temoma

\section{CASO NÁO MAME MAIS NO PEITO}

45 Eu gostana que a Sra me contasse wido o que estava acontecendo na epco em que ele(a) parou de mamar e porque a Sra acha que ele(a) näo mamou mars?

\section{SE AINDA MAMA:}

65 Ate que idade pretende dar o perto?

_ _ meses ou outro

( $77=$ enquanto a criança quiser: $78=$ enquanto tiver leite)

7 Esta tendo alguma dificuldade agora para dar de mamar?
(1) $\operatorname{Sim}$
2) Não
8) NSA
(9) IGN

SE SIM: Qual? 


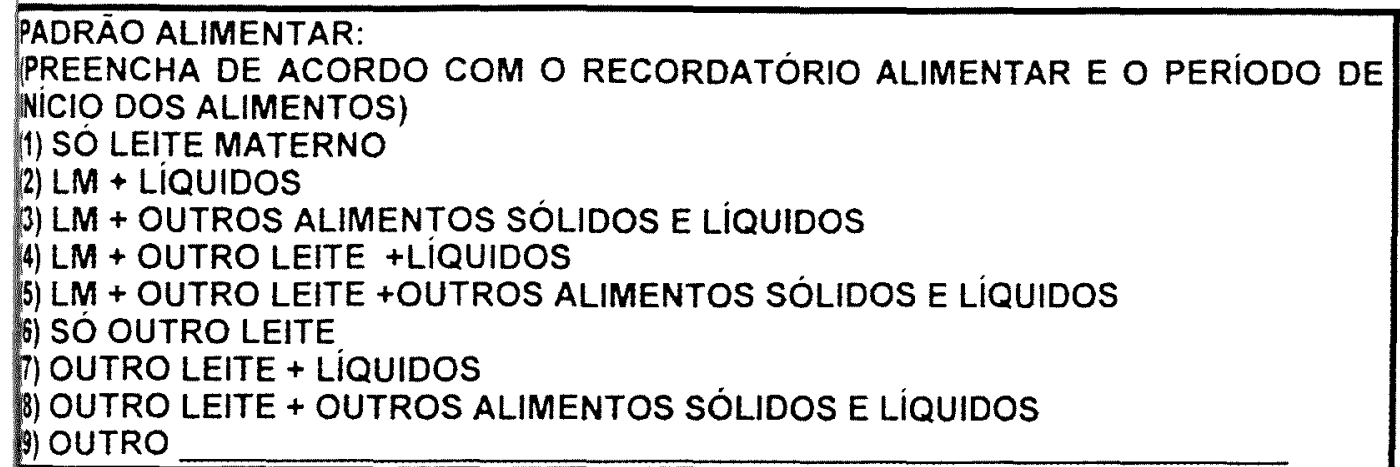
1) O dia todo
(2) de vez em quando
(3) so para dormir
4) outro
(8) NSA
(9) IGN

SE SIM: Toda a norte ou so para dormir?
(1) a lloite toda
(2) so para dormir (3) outro (8) NSA (9) IGN

bora eu gostaria de saber a sua opiniảo sobre alguns assuntos gerais de crianças.

- A Sra ja ouviu falar em cozmha altemativa ou alternativas almentares como a multimistura de farelo. po de folhas verdes escuras, po de sementes. casca de ovo?
(1) $\mathrm{sim}$
(2) năo $\rightarrow \# 62$

\section{SE SIM}

Quem the falou?

(1) Pastoral da Criança/Lider/lgreja (2)Agente de Saude

(3) médico. enfermeira ou outra pessoa da equipe de saude
(4) rádio. TV
(5) parente
(6) vizinha

(7) outro:

Vá experimentou este tipo de alimentaçăo? (1) sim

(2) nāo

$\rightarrow \# 59$

(8) NSA

nchubc

qnpacr

ancocr

bicdic

bicdia

bicnoc

bicnac

alalim

SE SIM:

A Sra gostou deste tipo de alimento? (1) sim

(2) năo

(8) NSA

alaliq

alalex Por que? 
57 Já fez alguma recelta com estes alimentos em casa? (1) sim

58 Nos últimos 3 dias, a Sra. fez ou comeu algum alimento alternativo?
(1) $\operatorname{sim}$
(2) não
(8) NSA

59 E <CRIANCA > já experimentou algum alimento alternativo?
(1) $\mathrm{sim}$
(2) não
(8) NSA

alafez

SE SIM

60 A <CRIANCA> gostou deste tipo de alimento? (1) sim (2) não

(8) NSA

crigo

Por que?

61 Nos ultimos 3 dias, <CRIANCA> comeu algum alimento alternativo?

$\begin{array}{lll}\text { (1) } \mathrm{sim} & \text { (2) não } & \text { (8) NSA }\end{array}$

criali

Agora vou fazer algumas perguntas, sobre como está a saúde da $\langle C R I A N C ̧ A\rangle$

$62<C R I A N C A>$ leve diarréia desde ontem a esta hora?
(1) $\mathrm{Sim}$
(2) Não

$63<$ CRIANÇA> teve diarreia desde <DIA DA SEMANA> de duas semanas atrás?
(1) $\mathrm{Sim}$
(2) Não $\rightarrow$ \#2
(9) IGN

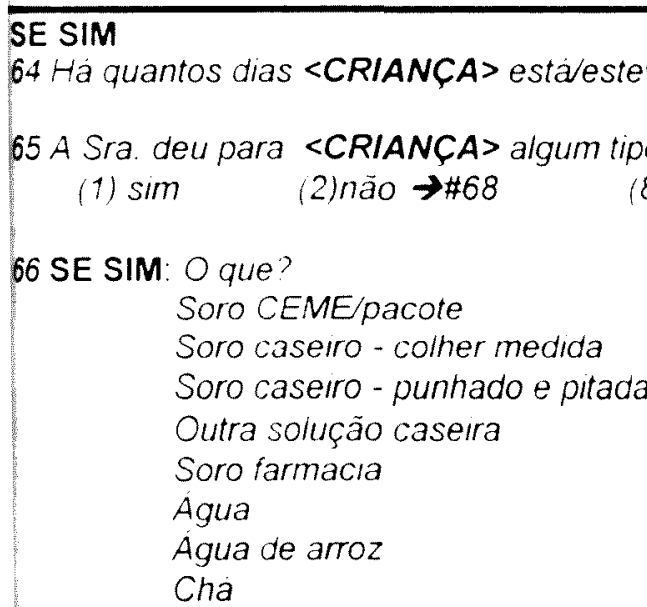

\section{SE USOU SORO}

67 Quem indicou?
(1) familiares
(2) Lider/Pastoral
(3) farmacia
(4) Agente Comun. Saúde
(5) médico
membro da equipe de saúde
(8) NSA
(9) IGN
(7) outro

$(88=N S A: 99=\mid G N)$

cripor

alalec

18 Usou algum tipo de remedio para tratar a diarreia?

(1) $\operatorname{sim}(2)$ não $\rightarrow \# 70$

remdia

E USOU REMÉDIO: QUal?

Remédio caseiro: Qual1?

Qual2?

Remedio farmácia: Qual 1? Qual 2?

9 Quem indicou?
(1) familiares
(2) Lider/Pastoral
(3) farmácia
(4) Agente Comun. Saude

(5) médico
(6) vizinha

membro da equipe de saude

(8) NSA

(9) IGN

diaho

diar14

qndiar

trat

ceme

scolhi

spita

soutr

farm

trag

agarr

cha

sqind

cha

cha2

trem1

trem2

- -

-

reqind 
70 Durante a diarréia a Sra. ofereceu:

(2) menos água do que o costume

(1) mais água do que o costume

(3) normal

(9) IGN

71 Durante a diarréia a senhora ofereceu: (1) mais vezes comida do que o costume
(2) menos vezes comida do que o costume
(3) normal
(9) IGN

72 Desde que nasceu <CRIANÇA teve alguma vez, diarréia que durasse 2 semanas ou mais sem parar?

(1) $\mathrm{Sim}$

(2) Não

(9) IGN

73 <CRIANÇA > teve tosse desde <DIA DA SEMANA> passada?
(1) $\operatorname{Sim}$
(2) Não
(9) IGN

\section{SE TEVE TOSSE:}

Estava com respiração dificil?

Estava com canseira/falta de ar?

Estava com o nariz entupido?

Estava com ronqueira/catarro?

Estava com nariz escorrendo?

Tinha febre?

$\begin{array}{llll}\text { (1) } \operatorname{Sim} & \text { (2) Não } & \text { (8) } N S A & \text { (9) } I G N \\ \text { (1) } \operatorname{Sim} & \text { (2) Não } & \text { (8) } N S A & \text { (9) } I G N \\ \text { (1) } \operatorname{Sim} & \text { (2) Não } & \text { (8) NSA } & \text { (9) } I G N \\ \text { (1) } \operatorname{Sim} & \text { (2) Não } & \text { (8) NSA } & \text { (9) } I G N \\ \text { (1) } \operatorname{Sim} & \text { (2) Não } & \text { (8) NSA } & \text { (9) } I G N \\ \text { (1) } \operatorname{Sim} & \text { (2) Não } & \text { (8) NSA } & \text { (9) } I G N\end{array}$

SE SIM: Como mediu? (1) termômetro

(2) mão (3) Não mediu

(8) NSA

(9) IGN (4) Outro

$74<$ CRIANÇA $>$ já teve chia no peito alguma vez?

(1) $\operatorname{Sim}$ (2) Não $\rightarrow$ \#9

SE SIM:

15 Com que idade <CRIANÇA> teve chia pela primeira vez? - - meses

$(88=N S A)$

16 Tinha falta de ar ou canseira junto com a chia ? (1) Sim (2)Não (8)NSA (9)/GN

17 Quantas vezes <CRIANÇA> teve chia nos ultimos 3 meses? _ vezes (näo teve $=00: \overline{88}=\overline{N S A}: 99=1 \mathrm{GN}$ )

18 Alguma vez que teve chia. precisou fazer inalação/cheirinho?
(1) $\operatorname{Sim}$
(2) Não
(8) NSA
(9) /GN

19 Desde que nasceu. <CRIANCA > teve pontadalpneumonia?

(1) $\operatorname{Sim}$ (2) Não $\rightarrow \# 84$

\section{E SIM:}

Q Quantas vezes? - $(8=$ NSA: $9=1 G N)$

1 Quem disse que era pontada? $1^{a}$ vez _ $2^{a}$ vez $~ 3^{a}$ vez $\ldots 4^{a} v e z$
(1) médico
(2) mảe ou pai da criança
(3) parente
(8) NSA
(4) vizinha
( ) Outro
(9) IGN

2 Onde recebeu tratamento? $1^{a} v e z \quad 2^{a} v e z \quad 3^{a} v e z$
(1) Casa
(2) Hospital
(8) NSA
(9) IGN
(3) Posto de Saúde ou Ambulatório
( ) outro

I CCRIANCA> fez chapa de pulmão alguma vez? (1) Sim (2) Não

KCRIANÇA teve dor de ouvido no ultimo mès? $\quad$ (1) Sim (2) Não $\rightarrow \# 88$ SIM:

$\begin{array}{lllll}\text { Saia pús do ouvido? } & \text { (1) } \operatorname{Sim} & \text { (2) Não } & \text { (8) NSA } & \text { (9) IGN }\end{array}$

Quem disse que era problema de ouvido?
(1) médico
(2) mãe ou pai da criança
(3) parente
(8) NSA
(4) vizinha
( ) Outro
(9) IGN

Onde recebeu tratamento?
(1) casa
(2)hospital
(3) posto ou ambulatónio
(4) farmácia
(5)outro
(8) NSA
(9) IGN

$\begin{array}{ll}\text { respdi } & - \\ \text { faltar } & - \\ \text { nariz } & - \\ \text { catarr } & - \\ \text { naries } \\ \text { febre }\end{array}$

medfeb

chia

d1chi

canchi

vezchi

nebuli

pontad

verpon

$\operatorname{diag} 1 p$

$\operatorname{diag} 2 p$

$\operatorname{diag} 3 p$

diag $4 p$

trat1p

trat $2 p$

$\operatorname{trat} 3 p$

trat $4 p$

nxpulm

ouvido

pusouv

diaouv 
QCRIANÇA> foi internada em hospital desde <MÊS > do ano passado?
(O) Não
( ) Sim. Quantas vezes:
(9) Não sabe

FOOI HOSPITALIZADA: Qual o motivo?
Diarréia _ vezes ( $0=$ não fol: $9=$ =não sabe: $8=$ NSA)
Pneumonia/pontada _ vezes
Acidente _ vezes
Outro:

$<$ CRIANCA $>$ foi pesada nos últimos 3 meses?
(0) Não $\rightarrow \# 92$
( ) Sim quantas vezes
(9) IGN

SE SIM:

Onde?
(1) Posto de Saude _ vezes
(3) Pastoral da Criança _ vezes
(5) hospital
(6) outro
(2) em casa - vezes
(4) farmacia _ vezes

(8) NSA

(A Sra lembra quanto $<C R I A N C ̧ A>$ pesou na uiltima vez?
(1) Sim. quanto
(2) Não
(8) NSA

( CCRIANCCA> Consultou com médico hos íltumos très meses?
(1) $\mathrm{Sim}$
(2) Não
(9) IGN

SE SIM: Qual o motivo?
Diarréia
(1) $\operatorname{Sim}$
(2) Não
Infecçäo respiratoira
(1) $\mathrm{Sim}$
(2) Não
Problema de pele
(1) $\mathrm{Sim}$
(2) Não

Outro

<CRIANCCA > esta cadastrada ou inscrita em algum programa para receber
damento?
(1) Não
(2) Posto de Saude
(3) AFASC

loutro

(9) IGN

KCRIANCA > foi para a creche ou maternal alguma vez?
(1) $\mathrm{Sim}$
(2) Não $\rightarrow \# 97$
(9) ignorado
SE SIM: Com que idade começou? _anos _ _meses
$(8.88=$ NSA $)$

CRIANCA > continua frequentando a creche? (1) $\operatorname{Sim}$ (2) Não

(8) NSA

SE NÄO: Com que idade parou? - anos $\overline{(7.77=\text { continua; } 8.88=N S A)}$

Wuantas horas por dia <CRIANCA> fica(va) na creche? horas $(88=N S A)$

bque a Sra acha de uma criança de um inès que mama no peito e recebe chá todos os dias?
1) Bom
(2) Ruim
(3) Não faz diferença
(9) IGN/não sabe
1) Outro:

He que idade a Sra acha que uma criança deveria mamar somente no peito sem receber água, chá, sucos ou outros alimentos?

- meses

Na sua opinião, até que idade uma criança devena mamar no peito? _

H partir de que idade a Sra acha que uma criança deveria começar a receber: leite de vaca/saquinho leite em pó

suco

Papa de frutas/amassada

Papa salgada(legiverd) inter

hosdia

hospne

hosaci

hosout

peso3

pespos

pescas

pespas

pesfar

peshos

pesout

lempes

lemqua

- - -

consu3

condia

conira

conpel

conout

progra

creche

creini

-

-

-

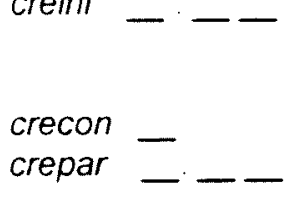

crehor

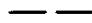

alemix

aleiex

oplei

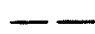

oplv

oplpo

opsu

opfru

$-$ 
101 A Sra saberia me dizer as vacinas que uma criança deveria receber no primeiro ano de vida?

$\begin{array}{lll}\quad \text { (NÄO CITAR) } & \text { (1) } \mathrm{Sim} & \text { (2) Não } \\ \text { Triplice/DPT } & \text { (1) } \mathrm{Sim} & \text { (2) Não } \\ \text { Tétano } & \text { (1) } \mathrm{Sim} & \text { (2) Não } \\ \text { Difteria/crupe } & \text { (1) } \mathrm{Sim} & \text { (2) Não } \\ \text { Coqueluche/tosse comprida } & \text { (1) } \mathrm{Sim} & \text { (2) Näo } \\ \text { Sabin/Pólio/Paralisia/Gotas } & \text { (1) } \mathrm{Sim} & \text { (2) Não } \\ \text { Sarampo } & \text { (1) } \mathrm{Sim} & \text { (2) Não } \\ \text { BCG/Tuberculose } & \text { (1) } \mathrm{Sim} & \text { (2) Não } \\ \text { Hepatite } & \end{array}$

102 Agora eu vou dizer algumas vacinas e gostaria que a senhora me dissesse quantas doses uma criança deve receber durante o $1^{\circ}$ ano de vida?

(DOSES DE ROTINA - NĀO CONSIDERAR AS DOSES DE CAMPANHA)

\begin{tabular}{|l|l|}
\hline Vacina & doses \\
\hline Triplice ou DPT & \\
\hline SABIN/Contra paralisia infantil & \\
\hline Antisarampo & \\
\hline BCG/contra tuberculose & \\
\hline Hepatite & \\
\hline
\end{tabular}

$(70 u$ mais $=7: 1 G N=9)$

sdpt -
stet -
sdift -
scoq -
spol -
ssaram -
sbcg -
shep -

dosdpt

dospol

dossar

dosbcg

doshep

SE A MÄE NĀO TINHA A CADERNETA DE SAUUDE, PERGUNTAR:

103 A Sra já viu esta caderneta? (mostrar a caderneta de saúde)
(1) $\operatorname{Sim}$
(2) Não $\rightarrow \# 108$

\section{OBSERVAR SE O PESO ESTA ANOTADO NA CURVA DA CADERNETA DE SAÚDE OU DO CARTẢO DA CRIANÇA:}

\section{SE SIM}

104 Pode me dizer para que serve esta parte da caderneta?
(MOSTRAR A PAGINA 12 OU 14)
(1) llăo sabe
(2) Peso
(3) Desenvolvimento da criança
$(8=N S A)$
(4) crescimento
(5) desnutriçăo ( ) outro.

\section{SE RESPONDEU CORRETAMENTE}

105 Este cartão mostra o peso de uma criança no seu primeiro ano de vida. A Sra acha que a criança esta bem? (cartão 1)
(1) $\mathrm{Sim}$
(2) $\mathrm{NăO}$
(3) Mais ou menos
$18=N S A: 9=(G N)$
( ) Outro:

06 E esta outra criança, esta bem? (cartão 2)
(1) $\mathrm{Sim}$
() Outro:
(2) Não (3) Maıs ou menos
$(8=N S A ; 9=1 G N)$

pescur

carvi

07 Qual destas crianças a Sra acha que está doente agora? (cartão 3 e 4)
(1) criança do cartão 3
(3) as duas
(2) criança do cartão 4
() Outro
(4) nenhuma
$(8=N S A ; 9=1 G N)$

cart3

08 O que a Sra. acha de uma mulher grávida que fuma durante a gestação.
(1) bom
(2) $\mathrm{mal}$
(3) nảo faz diferença
(9) IGN/näo sabe

19 Uma criança que nasce em hospital ou maternidade e está bem. deve ficar o tempo todo com a mäe ou ir a notte para o berçario?

(1) Com a mãe

(2) No berçário

(3) Com a mãe se parto normal e berçario se cesárea

(9) $1 G N /$ não sabe

() outro 
110 O que a mãe deve fazer quando uma criança está com diarréia? (NĀO CITAR)
(01) levar ao médico / Posto de Saúde
(02) procurar o agente de saúde
(03) dar bastante liquidos
(04) remédio/chá caseiro
(05) remédio farmácia
(06) suspender a alimentação
(07) insistir com a alimentação
(08) não modificar dieta

(09) procurar a Lider/Past. da Criança

(10) dar soro

(11) benzer

(12) não sabe

(13) esperar passar / nada

( ) outro

\section{SE A MÃE NĀO CITAR ALIMENTAÇĀO OU COMIDA, PERGUNTAR:}

E quanto a alimentação (comida) de uma criança com diarréia, o que a mãe deve fazer?
(1) suspender a alimentação
(2) oferece mais comida
(3) oferece menos comida
(4) não modificar a oferta de comida
( ) outro

(SE A MÄE CITOU ALIMENTAÇĀO NA

QUESTĀO ANTERIOR, CODIFICAR COM 8)

111 Que tipos de soro para tratar a diarréla a Sra. conhece?
(01) soro CEME/pacote
(02) soro farmácia
(03) soro com cereais (água de arroz)
(04) nenhum
( ) Outro
(05) soro caseiro - pitado e punhado
(06) soro caseiro com colher-medida
(07) outra solução caseira

fazdi1

fazdi2

fazdi3

fazdi4

fazal

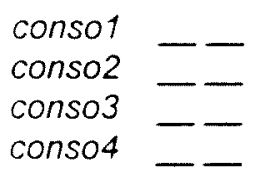

12 A senhora tern colher-medida de plástico, como esta. para fazer soro caseiro? Posso ver?
(1) sim, visto
(2) $\operatorname{sim}$, näo visto
(4) sim, emprestado
(5) nunca teve
(3) sim, tinha mas perdeu
(6) não conhece

colmed

\section{SE SIM}
13 Quem deu
(1) Pastoral da Criançallgreja
(2) Posto de Saúde
(3) Agente Comunitário
(4) Parente/ComadreNizimha
(5) Farmacêutico
Outro

114 Como a Sra acha que <CRIANÇA> está crescendo?
(1) Bem
(2) Näo muito bem (mais ou menos)
(3) $\mathrm{Mal}$
(4) IGN/não sabe

115 Por que?

(01) fez referéncia ao peso

(02) fez referência à altura

103) fez referência às linhas da curva da caderneta de saúde

(04) tem saúde

(05) Porque a Lider da Pastoral disse

(06) Porque o Agente Comunitário de Saúde disse

(07) Porque o médico disse

(08) Porque a enfermeira disse

) Outro 
OBSERVE SE A CRIANÇA FAZ AS ATIVIDADES REFERENTES À SUA FAIXA ETÁRIA, FAIXA ETÁRIA ANTERIOR À SUA IDADE E FAIXA ETÁRIA POSTERIOR A SUA IDADE. SE NÄO CONSEGUIR OBSERVAR, PERGUNTE PARA A MÃE.

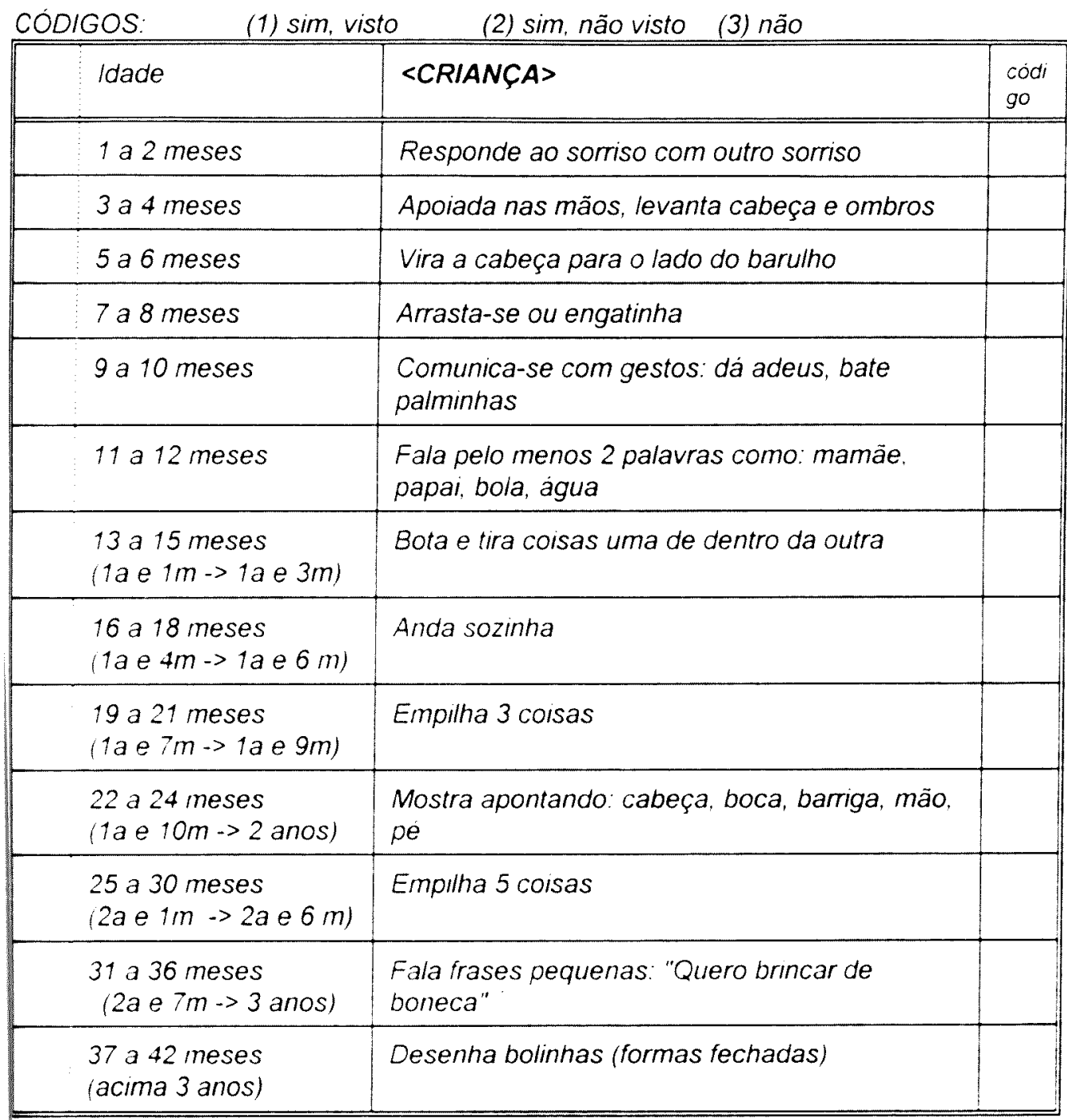

\section{Agora vamos conversar sobre a Sra.}

16. Em que municipio a Sra. nasceu?

Estado

117 Há quanto tempo a Sra. mora neste bairro? anos

"18 SE MUDOU HÁ MENOS DE 5 ANOS: Morava antes na cidade ou no interior?
(1) cidade / urbana
(2) interior/rural
(8) NSA

119 E em Criciuma. a senhora mora há quanto tempo? anos
20 A Sra. fuma?
(1) $\operatorname{sim}$
(2) กão
SE SIM: Quantos cigarros por dia: (88) NSA anos (já completou?) 
122 Quaıs são as pessoas que moram na casa?
Pai
(1) Não
(2) Sim, biológico
(3) Sim, adotivo
Mãe biológica (1) Não
(2) Sim biológica
(3) Sim. adotiva

irmãos da <CRIANÇA

Outros: (nimero)

\section{- (numero)}

maebio $=$
filnum
outnum $=-$

SE A MAE NĀO CITOU ESPOSO OU COMPANHEIRO, PERGUNTAR:

123 A Sra tem esposo ou companheiro?
(1) $\operatorname{Sim}$
(2) Não

\section{SE TEM ESPOSO OU COMPANHEIRO}

\section{A quanto tempo vive com ele? _ _ anos}

E casada com ele?
(1) Sim. no civil
(3) ambos (religioso e civil)
(2) $\mathrm{Sim}$ no religioso
(5) outro.

\section{(4) Não}

125 A senhora sabe ler e escrever? E seu companheiro?
Mãe.
(1) $\mathrm{Sim}$
(2) Não
Companhero.
(1) $\mathrm{Sim}$
(2) Não
(3) Só assina
(3) Só assina

126 Ale que serie a Sra estudou na escola? (completou?) E seu companheiro?
Máe
Companhemo
_ serie do _erie do grau

127 A centrora estudou nos iltimos 12 meses?
(1) Sm
(2) Näo
(9) Näo sabe//GN
(3) Outra

in8 4 senhora trabahou nos ultmos 12 meses?
(1) Sim. rrabalhou fora
(2) Sim trabalhou em casa para fora
(3) NaO $\rightarrow+131$
(9) Não sabe/ IGN
4) Outra

\section{SE TRABALHOU}

129 Quantos meses mabalhou? - - meses
Quantos dias por semana? - dias
Quantas horas por dia?

Quantas horas por dia? _- horas

130 Que tipo de trabalho fez?
(01) costurema
(02) vendedora com carteira assinada
(03) vendedora autonoma
(04) empregada domestica
105) diarista
(06) professora primario
(07) professora ginasio/segundo grau
( ) outro

131 No mès passado. quanto ganharam as pessoas que trabalharam?

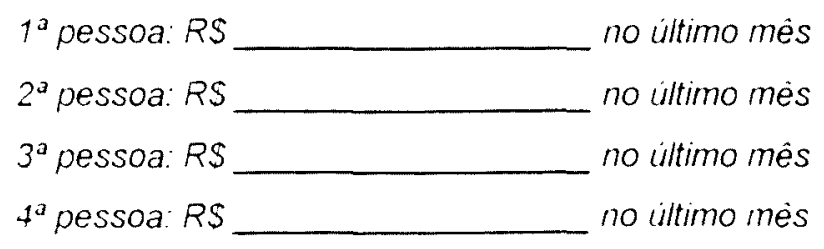

\section{(NĀO PREENCHER} CENTAVOS “,00")

132 A familia tem outra renda? RS

no último mès

tiptrab - -

renda1 renda2 renda3 renda4 orend 
133 O terreno da casa em que a Sra mora é
(1) Próprio
(2) Alugado
(3) Emprestado
(4) Posselocupação
(5) Outro

terren

134 TIPO DE CASA: (OBSERVAR,SE NECESSÁRIO PERGUNTAR)
(1) Tijolos $\mathrm{c} /$ reboco
(2) Tijolo S/ reboco
(3) Apartamento
(4) Madeira regular
(5) Madeira irregular
(6) Papelão, plástico ou lata
() Outro:

135 TIPO DE PISO: (OBSERVAR,SE NECESSÁRIO PERGUNTAR)
(1) Terra
(2) Cimento
(3) Madeira
(4) Forração
(6) Lajota(cerâmica)
(7) Tijolo

( ) Outro

136 Quantas peças da casa usam para dormir?

137 Tem água encanada em casa?
(1) Sim, dentro de casa
(2) Sim. no quintal
(3) Não

38 De onde vem a agua usada para beber?
(1) Rede públicalCASAN
(2) Poço
(3) agua mineral

() Outro:

39 Tem banheiro em casa?
(1) $\mathrm{sim}$
(2) privada
(3) não tem
(1) Outro

SE SIM: O vaso sanitario tem descarga? (1) $\operatorname{sim}$ (2) não

40 Na sua casa tem?
Radio?
(1) $\operatorname{Sin}$
(2) Não
(3) Não funciona
Televisão?
(1) $\mathrm{Sim}$
(2) Não
(3) Não funciona
Geladeira?
(1) $\operatorname{Sin}$
(2) Não
(3) Não funciona
Liquidificador
(1) $\mathrm{Sim}$
(2) Não
(3) Não funciona
Fogão a gas?
(1) $\mathrm{Sim}$
(2) Não
(3) Não funciona
Video cassete?
(1) $\mathrm{Sim}$
(2) Não
(3) Não funciona

11 A Sra está grávida?
(1) $\operatorname{Sim} \rightarrow \# 145$
(2) Não
(9) /GN

42 A Sra deseja engravidar?
(1) $\mathrm{Sim} \rightarrow \# 145$
(2) Não
(3) Não sabe/ näo pensou misso
(8) NSA
(9) /GN
( ) Outro

13 A Sra está fazendo alguma coisa para não engravidar?
(1) $\mathrm{Sim}$
(2) Não
(8) NSA
(9) IGN

piso

aguaen

fonte

privad

vaso

radio

iv

gelad

Liqui

fogao

video

gravid

degrav

naengr

tro
(04) DIU
(07) Vasectornia
(10) Aleitamento
(06) Tabelinha
(12) Billings/muco cervical
(09) Não menstruou
(99)/GN
(88) NSA
ESIM:
8) Coito interrompido
b) Não tem parceiro 
145 A Sra sabe o que é método naturai para evitar filhos?
(1) $\operatorname{Sim} \rightarrow \# 146$
(2) Não
(LER O ENUNCIADO ABAIXO)

conmet

Metodos naturais são métodos em que o casal evita ter relaçōes em determinados dias como forma da mulher não ficar grávida.

146 A Sra conhece algum método natural para não engravidar? Quais?
(01) Coito interrompido
(02) Tabelinha
(03) Aleitamento
(04) Billings/muco cervical
(05) temperatura basal
(77) camisinha/pilula
(06) não conhece
( ) outro

qalmet

palmet
(1) $\sin$
(2) não
(8) NSA

\section{SE SIM:}

148 Quem ihe ensinou?
(1) Pastoral da CriançalLider/lgreja
2) Curso de noivos
(5)Agente de Saúde
(3) medico enfermeira ou outra pessoa da equipe de saude
4) radio ( ) outro

\section{Agora nós vamos conversar sobre religiāo:}
149 A Sra. tem religlão?
(01) $n$ ão $\rightarrow \# 154$
(05) Testemunha de Jeova
(02) Católico
(06) Batista
103) Luterano
(07) Metodista
(04) Assembleia de Deus
(08) Espirita

150 No mès passado a senthora panticipou de alguma missa. culto ou cerimóna religiosa?
(00) näo
( ) smlm Quantas vezes:
(88) NSA

$-$

cultme

outrel
151 4 Sra participa ou faz parte de algum movmento ou atividade de sua religiăo?
(1) Não
(2) Sim Qual?

152 Na sua opiniäo quem deve educar uma criança na fé ou religião?
(1) mäe
1 ) outro
(2) paı
(3) familiavem casa
(4) na igreja/catequista

153 A partir de que idade uma criança deve ser educada para a fé/religião? _ anos _ _ meses (se durante gestação= 77.77: quando falar=66.66)

154 A senhora ja ouviu falar nos Agentes Comunitarios de Saúde?
(1) $\sin$
(2) não
$\rightarrow \# 161$

SE SIM

\section{Foi visitada por eles:}
(1) $\mathrm{sim}$
(2) não $\rightarrow$ \$61
(9) IGN

156 Durante a gestaçăo de <CRIANCA> a senhora já era acompanhada pelo agente comunitario de saude?

$$
\text { (1) } \operatorname{sim} \quad \text { (2) năo }
$$

157 No primeiro mês depois que <CRIANÇA $>$ nasceu. a senhora recebeu visita do Agente Comunitário de Saude?
(1) $\mathrm{Sim}$
(2) Não $\rightarrow \# 159$ 


\title{
SE SIM:
}

158 Conversaram sobre aleitamento materno?

conale
(1) $\sin$
(2) Não
(8)NSA

159 Nos últimos três meses a senhora recebeu alguma visita de Agente Comunitário de Saude? (1) $\mathrm{Sim}$

(2) Não

(8)NSA

160 A senhora está satisfeita com o visitas trabalho do Agente Comunitário de Saúde? (1) Sim. Porque.

(2) Näo. Porque:

161. A senhora já ouviu falar na Pastoral da Criança?
(1) $\mathrm{sim}$
(2) não $\rightarrow$ \#173

\begin{abstract}
162 A Sra sabe o que faz a Pastoral da Criança? (1) Sim (2)Não $\rightarrow$ \#167 (9)/GN
SE SIM: O que ela faz? (1) pesa

(3) ensma alternativas alimentares

(5) faz visitas l outros

(2) ensina cuidar das crianças

(4)ensina remédios caseiros
\end{abstract}

163 Participa ou ja participou?
(4) sim. anda participa
(2) sm. mas náo particıpa mais

(3) numca participou

PERGUNTAR SEMPRE: Porque

\section{SE PARTICIPA OU PARTICIPOU: A quanto tompo deixou de participar da Pastoral}

64 Quanto tempo anos meses

65 Le quars atividades a senhora participa/participou na Pastoral da Criança.

tipeso (a) reumöes/aulasicursos (3) vistias

outro

66 Quars mars gosta. (1) peso

(2) reumỏes/aulasicursos

(3) visitas

i outro

67 Fol vistada pela Lider Comumitarla
(1) $\mathrm{s} / \mathrm{m}$
(2) $n$ ăo $\rightarrow \# 173$

68 Curante a gestaçăo de <CRIANÇA> a senhora ja era acompanhada pela Lider da Pastoral da Crança?
(1) $\mathrm{sim}$
(2) กão

19 No primeiro mès depois que <CRIANÇA> nasceu. a senhora recebeu visita da Lider da Pastoral da Criança?

(1) $\operatorname{Sim} \quad$ (2) Não

SIM:

¿Conversaram sobre aleitamento materno? $\begin{array}{lll}\text { (1) } \operatorname{Sim} & \text { (2) Não } & \text { (8)NSA }\end{array}$

1 Nos últimos très meses a senhora recebeu alguma visita da Lider da Pastoral da
Crança?
(1) $\mathrm{Sim}$
(2) Não (8)NSA

2 A senhora esta satisfeita com o visitas/trabalho da Lider da Pastoral da Criança?

(1) Sim. Porque

(2) Não. Porque vis3ag

satagc

pqsata

fapasc

sapfaz

oqfazp

- -

parti

partpa

partem

$-1$

qativ

agost

vislid

gespas

naspsc

-

alepst

vis 3 me

satpa1

satpa2 
173 NA CADERNETA DE SAÚDE (PÁGINA 16) VERIFICAR E ANOTAR A DATA DAS DOSES DE VACINAS

\begin{tabular}{|c|c|c|c|c|c|}
\hline VACINA & $\begin{array}{c}\text { Antipólio - } \\
\text { Sabin } \\
\text { (gotas) } \\
\end{array}$ & $\begin{array}{c}\text { Triplice-DPT } \\
\text { (nádegas) }\end{array}$ & $\begin{array}{c}\text { Anti- } \\
\text { Sarampo }\end{array}$ & $\begin{array}{c}B C G \\
\text { (ver cicatriz } \\
\text { no ombro) }\end{array}$ & Hepatite \\
\hline $1^{2}$ dose & $1 /$ & 11 & $1 /$ & $/$ & $/$ \\
\hline $2^{2}$ dose & 11 & 1 & 1 & 1 & 1 \\
\hline $3^{2}$ dose & 11 & $t$ & 1 & 1 & 1 \\
\hline Reforço & 1 & 1 & 1 & 1 & 1 \\
\hline
\end{tabular}

174 NA CADERNETA DE SAÚdE (PÁGINA 11) COPIAR DATA OU IDADE, PESOS e ESTATURAS DA CRIANÇA

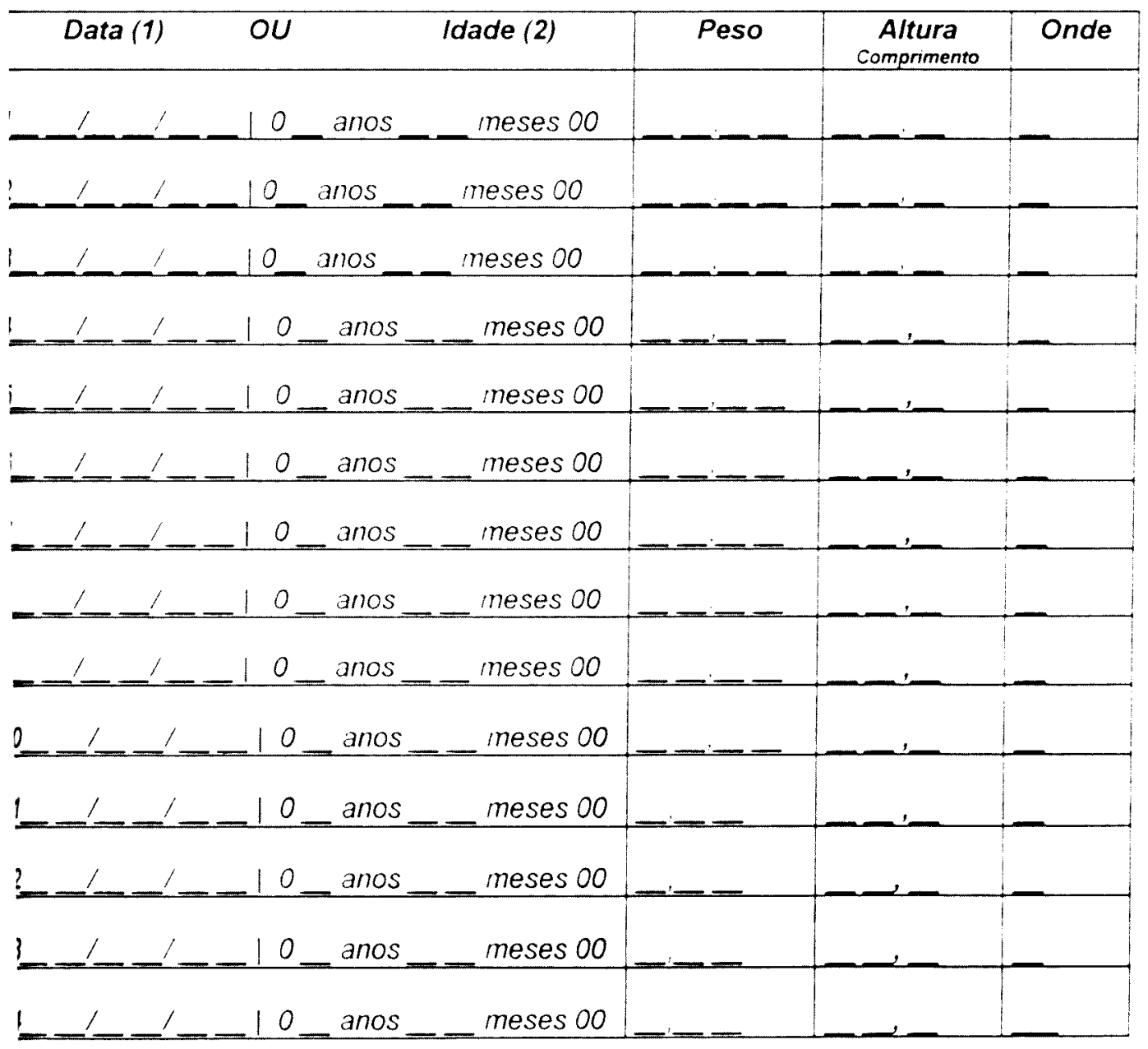

\section{códigos:}

Onde: (1) Posto de saude

(2) Em casa

(3) Pastoral da criança

(4) agente comunitário

() Outro. 
6 Onde (mais) a criança foi pesada para que possamos procurar esta informação?
(1) a criança não foi pesada (desconsiderar o peso ao nascer)
(2) foi pesada mas não teve seu peso anotado
(3) a mãe não tem anotação mas esta foi feita.

\title{
ANOTAÇĀO FOI FEITA - NĀO CODIFICAR ESTA QUESTĀO \\ 7 Aonde?
(1) no hospital
(2) Posto de Saúde
(3) Pastoral da Criança :SCRIÇÃO DO LOCAL:
}
(a) Aonde DATA:
LOCAL
(b) Aonde
DATA:
$-1-1$

\begin{abstract}
LOCAL
\end{abstract}
(c) Aonde _ DATA

LOCAL

\section{O PESO FOI ANOTADO PELA PASTORAL, PERGUNTAR O NOME DA LIDER.}

\section{SERVAR}

'8 COR DA PELE DA CRIANCAA (SE NECESSÁRIO PERGUNTAR):
(1) Branca
(2) Parda
(3) Preta
(4) Outra

\section{CICATRIZ DA BCG}
(1) $\operatorname{sim}$
(2) não

o Peso Kg

1 Comprimento $\mathrm{cm}$

\section{Hemoglobina:}

3 Data da entrevista _ _

\section{GRADECER A MÃE PELA SUA COLABORAÇÃO!}




\section{MANUAL DE INSTRUÇÕES}

\section{INSTRUÇÕES GERAIS}

Formule as perguntas exatamente como estão escritas, sem enunciar as opções de resposta. Se necessário, explicar suscintamente a pergunta (conforme instruções especificas) e, em último caso, enunciar todas as opçōes, tendo o cuidado de não induzir a resposta.

Onde constar <CRIANÇA> substitua pelo nome da criança. Por exemplo: Quando <CRIANÇA> começou a tomar leite do peito? DIGA: Quando Márcio (se for este o nome) começou a tomar leite do peito?

Caso a criança não esteja presente. pergunte à mãe por ela.

Sempre que houver dúvida, escreva por extenso a resposta dada pela informante. Quando uma resposta parecer pouco confiável, anote-a e faça um comentário sobre sua má qualidade.

Não deixe respostas em branco. Observe a aplicação dos códigos especiais:

- Ignorado ou IGN: código 9. 99 ou 999... = resposta desconhecida do informante, não sabe ou informação muito pouco confiável. Use a resposta "ignorado" somente em último caso. Abrevia-se IGN.

- Não se aplica ou NSA: codigo 8, 88 ou $888 \ldots$.. = quando a pergunta näo pode ser aplicada para aquele caso. Quando houver instruções para pular de uma pergunta para outra mais adiante, utiliza-se o código 8 ou $88 \ldots$ nas perguntas que não forem aplicáveis. O simbolo \#\# indica pular para pergunta. Por exemplo: \#33 indica pular para a pergunta 33 .

- código "0" não deve ser aplicado como sinônimo de "não", a não ser quando isto esteja especificado claramente nas opções da pergunta. Deve-se considerá-lo normalmente em seu significado numérico. Assim, 00 meses e 02 dias $=2$ dias; 00 dias $=$ menos que 24 horas, 00 meses $=$ menos de 30 dias.

Para 0 uso de outros códigos, siga as instruções que constam abaixo de cada pergunta. As instruções em LETRAS MAIÚSCULA não devem ser perguntadas às mães pois servem apenas para orientar $O$ entrevistador. Já as frases em negrito e em 
minúsculas devem ser lidas exatamente como estäo, pols servem para introauzır um novo assunto.

Utilizar lápis grafite e borracha para preencher o questionário. Atenção especial deve ser dada para a escrita e legibilidade dos números.

O pronome de tratamento (tu ou senhora) ficará a critério da entrevistadora e seu uso dependerá das circunstâncias de cada entrevista. Na dúvida, use sempre senhora.

Apresentação da entrevistadora ao informante: porte SEMPRE seu crachá. Em caso de perda ou estravio comunique aos supervisores que providenciarão um novo. Apresente-se como sendo integrante do grupo que esta estudando a saúde das crianças pequenas de Criciuma. Se necessário, mostre a carta de apresentação. Pergunte se tem criança com menos de três (3) anos morando naquela casa e se a mãe está em casa. Diga que gostaria de falar com ela. Em caso de uma mesma familia ter 2 crianças menores de 3 anos, deverá ser preenchido um questionário para cada criança.

Mãe ausente: caso a mãe não esteja, pergunte aos parentes ou vizinhos qual o melhor horário para encontrá-la. Caso a mãe não more com a criança. pergunte pela pessoa responsável e aplique o questionário a esta pessoa. Nos casos em que a criança passa a maior parte do tempo com um responsável pela criança que não a mãe, ou seja, com um "substituto", e a mãe não se encontre em casa, o questionário pode ser aplicado a esta pessoa. Se houver necessidade de complementar a entrevista com informações da mãe, deve-se voltar a casa e formular à mãe somente as perguntas que o "substituto" não soube responder

Caso não encontre a criança no endereço principal, procure obter informações de como encontrá-la ou localizá-la. Depois de esgotadas essas tentativas, comunique aos supervisores que tentarāo nova busca.

Recusas: muitas recusas são temporárias, isto é, o entrevistador chegou em um momento não muito propicio, mas ao retornar mais tarde, é provável que consiga realizar a entrevista. Não desista antes de três tentativas em horários diferentes. Tente "trocar" a visita com outra entrevistadora, que talvez tenha mais sorte que você.

Casas vazias (desabitadas): onde dois vizinhos diferentes informam que "não mora ninguém" devem ser ignoradas. Na folha de conglomerados anota-se "casa vazia".

Casas com moradores ausentes: se os moradores estão temporariamente ausentes, sugerimos que se pergunte a dois vizinhos diferentes se existem crianças pequenas naquela casa. Se ambos informarem que não, anota-se o endereç na folha de conglomerado e marca-se "zero" na coluna da criança. Se os vizinhos informarem que há criança, ou se estiverem em dúvida, a entrevistadora deverá retornar duas vezes 
ou mais neste domicilio nos horários referidos pelos vizinhos como mais prováveis de serem encontrados os moradores. Depois de esgotadas essas tentativas considerar como morador ausente e informar ao seu supervisor, não esquecendo de registrá-la na folha de conglomerado.

Deixar claro à informante, no início da entrevista, que as suas respostas serão completamente sigilosas.

Diário de trabalho de campo: mantenha, para seu controle, um diário de trabalho de campo, anotando quais crianças visitou, se foram ou não realizadas as entrevistas. Caso não tenham sido, anote o motivo e seu plano para retornar e visitá-la (voltar no emprego do pai, da mãe ou em endereço secundário). Não confie na memória. São muitas crianças e confusōes só atrapalharão seu próprio trabalho.

Codificação: no final do dia de trabalho faça a codificação das questões, utilizando a coluna da direita do formulário. Codifique apenas as questões "fechadas", isto é, aquelas cujas respostas são do tipo múltipla escolha e quando näo tiver dúvidas quanto a que código usar. Caso tenha dúvidas, deixe a questão em branco. As questões abertas - aquelas que devem ser respondidas por extenso - serão codificadas posteriormente.

Cálculos: caso seja necessário algum cálculo, não o faça durante a entrevista porque isso geralmente resulta em erro. Faça-o no momento da codificação. Por exemplo, se o salário for indicado sob a forma de pagamento diário ou semanal, anotálo por extenso e não tentar a multiplicação para obter o valor mensal. Isto deve ser feito por ocasião da codificação.

Não anote nada além dos códigos na coluna da direita. Reserve este espaço somente para a codificação. Use números LEGIVEIS, bem desenhados. Um lembrete importante, use somente lápis tanto para a entrevista, como para a codificação.

Devolva o questionário preenchido na manhã do dia seguinte à entrevista. 


\section{INSTRUÇÕES ESPECIFICAS}

Ao receber os questionários, verifique se as páginas estão completas, ou seja, se os questionários possuem todas as folhas. Trace seu itinerário de visitas no início do dia, em acordo com seu supervisor

PERG.1 Número do questionário: esta questão será preenchida pelos coordenadores da pesquisa.

Número da folha de conglomerado: anote o número da folha de conglomerado no espaço correspondente. Não esquecer de anotar o endereço completo no questionário.

PERG.2 Entrevistadora: preencha com seu nome. E o código referente ao seu número. Anote aqui o seu nome:

e Código:

Supervisora: Anote o nome de sua supervisora.

Entrevista supervisionada: visa saber se na hora da entrevista esta era supervisionada ou não pelo supervisor do trabalho de campo.

PERG.3 Setor: anotar o número do setor correspondente.

PERG.4 Bairro: deverá ser preenchido conforme o bairro onde os dados estão sendo colhidos e o endereço completo. * O endereço tem que ser anotado detalhadamente no questionário. Na folha de conglomerados pode ir só o número do questionário, mas não esquecer o endereço no questionário pois a visita para coleta de sangue depende deste endereço e se houver algum problema maior na codificação voce também necessitará utilizar este endereço.

PERG.5 Dia da semana: marcar o dia da semana correspondente.

PERG.6 Tentativas: destina-se a anotação do número de visitas necessárias para localizar cada mãe e criança.

Comunique à supervisora caso ocorram problemas com a localização. Se você conseguiu entrevistar a mãe na primeira tentativa, anote a opção 1 (Sim, entrevistada) e nas demais alternativas marcar a opção 8 (NSA).

Se por exemplo na primeira tentativa a mãe marcou para outro dia a entrevista, marque na primeira tentativa a opção 2 (Sim, marcou para outro dia) e na segunda visita no dia marcado pela mãe, você conseguiu realizar a entrevista, marque na segunda tentativa a opção 1 (Sim, entrevistada) e nas demais alternativas 8 (NSA).

APRESENTAÇÃO: logo após a PERG.6, apresente-se de forma clara e breve, lendo à apresentação existente no questionário. 
Se houver criança menor de 3 anos no domicilio, aplique o questionário completo. Se não houver, aplique apenas as perguntas da Folha de Conglomerado, conforme instruções abaixo:

\section{INSTRUÇÃO PARA PREENCHIMENTO DA FOLHA DE CONGLOMERADO:}

1. Bairro, setor, entrevistador, código do entrevistador: seguir as mesmas instruções utilizadas no questionário.

2. Nome e endereço: nome da pessoa que prestou informação, rua e número da casa.

PERG.7 Hora da entrevista: registrar a hora em que a entrevista teve início.

PERG.8 Nome da mãe: anotar o nome completo da mãe por extenso (sem abreviar), de forma legivel, preferentemente em letra de forma.

No caso de não ter sido a mãe quem respondeu o questionário, anotar tambèm o nome da pessoa responsável pelas informaçōes.

Procure chamar a mãe ou responsável pelo nome.

PERG.9 Número da criança: em familias que tiverem mais de uma criança menor de 3 anos, a mais nova será a $n^{\circ} 1$ e a seguinte será a $n^{\circ} 2$.

Se houver apenas uma criança seu n será 1 . O número 1 deverá ser sempre da criança de menor idade, ou seja, a mais nova.

PERG.10 Nome da criança: anotar o nome completo da criança por extenso (sem abreviar), de forma legivel, em letra de forma e deste momento em diante, onde constar $<$ CRIANÇA $>$, substituir pelo nome

PERG.11 Sexo: definir o sexo da criança pelo nome ou pela aparência pode, algumas vezes, provocar engano.

Por exemplo uma criança de nome Juraci com cabelos compridos tornaria bastante dificil afirmar a que sexo pertence. A cor da roupa pode enganar. Em caso de dúvida pergunte a mãe se é menino ou menina.

PERG.12 Quem cuida...?: Identificar quem tomou conta da criança a maior parte do dia no último mês; entender que "cuida da criança" diz respeito aquela pessoa que é responsável pela alimentação, pelo sono e pelo cuidado com as roupas. Em caso de dúvida, anote por extenso.

Caso a mãe e outra pessoa cuidem da criança exatamente a mesma proporção de tempo, considere a mãe como responsável, codificando com 1 (Mãe) na $1^{\text {a }}$ pessoa e na $2^{\circ}$ pessoa o código referente a esta pessoa. Se parente/vizinho receber remuneração para cuidar da criança, considere como "empregada". Perguntar também a 
idade da pessoa que cuida caso parente, amiga, vizinha, empregada ou babá para saber se é maior de 15 anos ou menor de 15 anos.

Caso não se encontre a mãe ou responsável, pergunte a que horas pode voltar para encontrá-la. Caso a mãe ou responsável cuide a criança sozinha, codifique 8 (NSA) na variável "cuida2".

PERG.13 Tem Certidão de nascimento: perguntar à mãe se ela tem a certidão de nascimento ou caderneta de saúde e pedir para trazer.

PERG.14 Data de nascimento da criança. anotar a data de nascimento e caso a mãe não tenha o documento, perguntar pela data de aniversário e quantos anos a criança fez no último aniversário.

Certidão de nascimento, confirmação: confirmar a idade com algum documento, de preferência a certidão de nascimento. Se não estiver disponivel, pedir a caderneta de saúde ou carteira de vacinas. Em caso de discordância com a informação fornecida pela mãe, perguntar a esta sobre a diferença. Caso a discordância permaneça, codificar com a idade fornecida pelo documento. Em ambos os casos anotar a data de nascimento e ler em voz alta para a mãe.

PERG.15 Tem caderneta de saúde: Marcar a informação dada pela mãe. Quando a caderneta de saúde foi vista codificar a questão 103 como $8=$ NSA.

PERG.16 Consulta pré-natal: considerar consulta do parto, como consulta de prénatal, somente se a mãe compareceu a consulta como rotina pré-natal, sem saber que já ficaria hospitalizada. Näo considerar grupos de gestante como consultas. SE NÃO: pular para a questão \# 22.

PERG.17 Em que mês fez a primeira consulta pré-natal? Se a mãe não souber dizer com quantos meses estava, aceitar o nome do mês em que iniciou e anotar na margem do questionário, fazendo a conta no momento da codificação.

Marcar 01 se iniciou o pré-natal antes de completar um mês. Não contar como consulta pré-natal aquela em que apenas foi feito o diagnóstico de gravidez.

PERG.18 Quantas consultas pré-natal? Anotar quantas vezes a mãe consultou. Se a mäe responder por exemplo, entre 5 e 6 consultas insistir para obter o número mais provável de consultas.

PERG.19 Esta questão refere-se a qualidade do pré-natal. Perguntar exatamente como está escrito e anotar a resposta da mãe.

PERG.20 Se fez vacina anti-tetânica, quantas doses: a vacina é normalmente feita no braço. Se já havia sido imunizada em gestação anterior há dez anos ou menos, responder com a opção 7 (já imunizada). Aplicar esta questão mesmo que a mãe não tenha sido orientada sobre a vacina contra o tétano durante a gestação.

PERG.21 Onde fez pré-natal: marcar o local referido pela mãe. Caso seja outro local anotar detalhadamente. Onde constar posto de saúde entender unidade básica de saúde ou referencial de saúde e também posto de puericultura. Particular caso tenha 
pago consulta e conveniado caso possua algum convênio. Quando a mãe referir consultório, saber se foi particular ou com convênio.

PERG.22 Hospital do parto: marcar a opção referida pela mãe. Caso outro hospital, por exemplo de outra cidade, anotar detalhadamente.

PERG.23 Parto: marcar a resposta da mãe sobre o tipo de parto referente a criança em questão. Caso a mãe refira que o parto foi a fórceps ou a ferro, assinalar parto normal. Se obtiver outra resposta, marque outro e escreva por extenso $\circ$ que a mãe disse.

PERG.24 Peso: perguntar para a mãe o peso de nascimento da criança e anotar, após olhar a caderneta de saúde ou cartão do hospital para confirmar o peso.

PERG.25 Queremos saber quantos minutos ou horas depois de nascida a criança mamou no peito. Tentar aproximar com a mãe quantas horas e minutos. Se não for possivel, perguntar a que hora a criança nasceu e quanto tempo depois ela foi mamar pela primeira vez, anotar por extenso e depois fazer os cálculos. Na hora de codificar usar o código 77:77para a criança que não chegou a mamar ou nunca mamou; e 78:78para crianças que mamaram com mais de 99 horas depois do nascimento.

PERG.26 Alojamento conjunto: visa saber se na maternidade a criança ficou com a mãe $\circ$ tempo todo após o nascimento. Se a criança era levada a noite para o bercário, ou se ficou na incubadora por algum tempo, considerar não/bercário.

PERG.27 Visa saber se a mãe recebeu alguma orientação para cuidados da criança, do umbigo, sobre amamentação, vacinas. Não importa se foi o obstetra, o pediatra, o enfermeiro, medico, anestesista, auxiliar etc. Queremos saber se recebeu e se sim qual foi a orientação. Anotar detalhadamente o referido pela mãe.

PERG.28 Parto particular ou não: visa saber se o parto foi pago, feito por convênio ou foi gratuito, pelo SUSIINPS ou outro.

PERG.29 Filhos antes: nessa questão deverá ser anotado o número de filhos nascidos mortos e nascidos vivos que a mãe teve antes desta criança em estudo.

Caso a mãe cite aborto, este não deve ser considerado na contagem dos filhos.

Considerar como natimorto (nascido morto) aqueles que tenham 28 semanas ou mais de gestação (mais ou menos 7 meses) ou peso igual ou superior a 1000 gramas. Se algum for gemelar (gêmeos) anotar na margem. Se não teve filhos antes pular para pergunta \#33. Se Sim: fazer a pergunta 30.

PERG.30 Mãe lembra da perda: queremos saber com quantos meses ocorreu a perda,

Considerar como natimorto (nascido morto) aqueles que tenham 28 semanas ou mais de gestação (mais ou menos 7 meses) ou peso igual ou superior a 1000 gramas. Se algum for gemelar (gêmeos) anotar na margem. 
NASCIDOS VIVOS ANTES: sempre codificar, independentemente do pulo da questão 29. O número de nascidos vivos antes é a diferença entre o número de filhos antes (perg. 29) e o número de perdas/nascidos mortos (perg. 30). Ex. se a mãe refere que teve 3 filhos antes da <criança> e que 1 nasceu morto, o número de nascidos vivos é 2; se teve 3 filhos antes e nenhum nasceu morto, o número de nascidos vivos antes é 3 .

\section{PERG.31 Quantos estão vivos: SE NÚMERO DE FILHOS DIFERENTE DO NÚMERO} DE NASCIDOS VIVOS queremos saber se algum filho morreu antes da crianca em estudo. É necessário comparar o número de nascidos vivos antes com quantos estão vivos (perg. 31). Ex. se a mãe refere que teve 4 filhos e 3 estão vivos perguntar pelo filho que falta e anotar a idade da morte do mesmo.

PERG.32 Data de nascimento do(a) irmão(ã) mais velho(a): somente fazer esta pergunta a mães que tenham filhos mais velhos do que a criança em estudo. Quando a criança for primogenita (primeiro filho) codificar com 08/08/00. Esta pergunta visa saber o intervalo entre o nascimento da <criança> e o filho anterior. No caso de gêmeos, perguntar pelo parto anterior.

PERG.33 Gravidez depois do nascimento da criança: nessa questão deverá ser anotado o número de filhos nascidos mortos e nascidos vivos que a mãe teve depois do nascimento da criança em estudo

Considerar como natimorto (nascido morto) aqueles que tenham 28 semanas ou mais de gestação (+ ou - 7 meses) ou peso igual ou superior a 1000 gramas. Se algum for gemelar (gêmeos) anotar na margem. Se sim: saber quantas vezes e perguntar se algum deles nasceu morto, Se sim: fazer a questão \# 34. Se não: pular para a \#35.

PERG.34 Mãe lembra da perda: queremos saber com quantos meses ocorreu a perda, Considerar como natimorto (nascido morto) aqueles que tenham 28 semanas ou mais de gestação (mais ou menos 7 meses) ou peso igual ou superior a 1000 gramas. Se algum for gemelar (gêmeos) anotar na margem.

NASCIDOS VIVOS DEPOIS: sempre codificar, independentemente do pulo. O número de nascidos vivos depois é a diferença entre o número de filhos depois (perg. 33 ) e o número de perdas/nascidos mortos.

PERG. 35 Quantos estão vivos : esta questão visa saber quantos estão vivos. Caso tenha havido alguma morte, procurar saber a idade da criança e anotar por extenso ao lado; na codificação anotar em meses. Por exemplo: se a criança tinha 1 ano e 9 meses. Anote por extenso e depois em casa faça o cálculo que dará 21 meses.

PERG.36 Ontem se alimentou como sempre ? pergunte se no dia anterior a criança se alimentou como sempre. Estamos preocupados principalmente com a diminuição do apetite por causa de doenças.

Eventualmente a criança pode ter estado muito "enjoada" ou ter passado o dia em outra casa que não a sua e isso ter modificado seu apetite. Alterações jo apetite, como por exemplo pelo calor, que não forem muito importantes não precisam ser levadas em conta. Caso a resposta seja afirmativa, passe direto para o recordatório alimentar das últimas 24 horas. 
SE NĀO: quando foi o último dia que se alimentou como sempre? Esta questăo só se aplica caso a criança não tenha se alimentado como habitualmente no dia anterior. Anote então quando foi o último dia que a criança se alimentou como de costume, direcionando as questões do recordatório alimentar para este dia.

Use os seguintes códigos especiais, 01/01 (IGN) se a mãe ou responsável não souber responder e 88/88 (NSA) se a criança tiver se alimentado normalmente no dia anterior.

PERG.37 RECORDATÓRIO ALIMENTAR (24 horas): o recordatório alimentar deverá corresponder às 24 horas anteriores a entrevista.

Por exemplo, se a entrevista está iniciando às $13 \mathrm{~h} 30$ (este horário corresponde ao inicio da tarde), perguntar à mãe tudo o que a criança tomou desde o dia anterior após o almoço até o almoço do dia da entrevista (inclusive).

A entrevistadora deverá marcar em cima da tabela com uma flecha o periodo de inicio do recordatório, para que não haja confusão quanto ao término do mesmo. Anotar sempre que possivel o horário da refeição.

Se a mãe desconhece as refeições do dia anterior (por exemplo, a criança passou o dia na casa de outra pessoa), perguntar com relação há dois dias atrás. Caso a criança faça suas refeiçōes em creche ou similares, và à creche, de preferência no mesmo dia, e faça o recordatório do periodo em que a criança esteve ali, com a responsável pela alimentação das crianças e obtenha da mãe as informações referentes ao periodo em que a criança ficou em casa.

A descrição dos alimentos consumidos pela criança deverá ser feita de acordo com cada periodo correspondente do dia. Caso a <CRIANÇA> não tenha recebido o alimento codifique 00 .

Durante o recordatório a entrevistadora deve enfatizar o periodo do dia ao qual ela está se referindo naquele momento. Por exemplo: "diga-me o que a criança comeu ontem à tarde".

Caso a entrevistada responda que a criança mama "toda hora" tente precisar o número de mamadas em cada periodo, inclusive durante a noite.

No caso da criança não ser amamentada exclusivamente, anote o alimento realmente INGERIDO, o que a criança realmente comeu. Isto é, não considere caso a mãe tenha oferecido um determinado alimento que a criança não tenha aceitado (não tenha ingerido nada).

Número de refeições: o último código da folha do recordatório alimentar refere-se ao número total de refeições feitas pela criança durante as 24 horas. Considere um intervalo de 45 minutos para cada refeição, ou seja se a criança tomou uma mamadeira e comeu um pedaço de maçã, juntas considerar isto como uma refeição, mas se outra criança as 8 hs da manhã tomou uma mamadeira de leite e 9 hs comeu um pedaço de fruta, serão consideradas duas refeições, pois houve um intervalo superior a 45 minutos entre ambas. Chá, café e água, quando consumidos isoladamente não são considerados como refeição.

Mamadeira incompleta: Refere-se ao uso de mamadeira com intervalo de 45 minutos ou mais. Por exemplo a Mãe preparou uma mamadeira de $200 \mathrm{ml}$ para a criança, mas ela só ingeriu $100 \mathrm{ml}$ e dormiu, após 46 minutos, ao acordar ela deu para a crianca o restante, considera-se duas mamadeiras; e marque em leite de vaca ou pó dependendo do tipo de leite.

Agua, chás,: Quer se saber quantas vezes a crianca tomou nas 24 horas. Neste caso não se aplica o intervá-lo de 45 minutos. 
Leite materno: Quando a criança der duas mamadas com intervalo menor de 45 minutos, em refeição considerar apenas uma, mas na codificação do número de mamadas as duas deverão ser computadas.

Leite de vaca: considere leite de saquinho, de tambo, leiteiro ou caixinha.

Café: algumas mães misturam café na mamadeira de seus filhos ou até mesmo dão café puro as crianças. Quando a entrevistada descrever a preparação da mamadeira, pergunte se ela mistura "alguma coisa". Caso misture café com leite, anote separadamente o café e o leite.

Suco: quer saber quantas vezes a mãe ofereceu suco a criança nas últimas 24 horas, considerar qualquer tipo de suco (frutas).

Pão: considere quando a mãe referiu pão caseiro ou de padaria.

Bolacha: considere quando a mãe deu para a criança e esta ingeriu, não importa se doce ou salgada.

logurte: Considere quando oferecido para a criança, danoninhos etc.

Mingau: Caso seja preparado para a criança leite misturado com algum tipo de farinha que seja consistente a ponto de não ser oferecido pela mamadeira, considere como mingau.

Caldo: considere que a mãe fez uma sopa e deu oferecendo a parte liquida. Exemplo de caldos que podem aparecer: Caldo de Ameixa, Caldo de Feijao, de verduras.

Frutas: Caso a criança receba apenas o suco de frutas, anote em suco. Anote se receber a parte semi-sólida em forma de papa, anote como fruta e procure anotar o nome da fruta usada. Algumas frutas que podem ser citadas: banana, maçã, mamão, laranja, abacate, pera, manga, morango, abacaxi...

Ovo: Considere o que a mãe deu a criança, não importa se a criança comeu apenas parte da clara ou gema, anotar que a criança ingeriu ovo;

Arroz: considere quando ela referir arroz. Caso a mãe tenha dado água de arroz para a criança, não considere neste item, marque em outros apenas o caldo.

Feijāo: considere tanto quando a mãe ofereceu a parte sólida como também

Legumes e verduras: $O$ que poderemos encontrar são alguns vegetais verdes e amarelos como: repolho, couve, abóbora, chuchu, espinafre, brócole, tomate, cebola, cenoura, beterraba. Esmagadas ou batidas no liquidificador, e que a criança tenha realmente comido.

Massa: considere quando oferecido o produto, anotar quantas vezes a criança comeu.

Batata e aipim: considere papa de batata ou de aipim, se a mãe preparou um purê ou simplesmente amassou a batata pura ou o aipim e ofereceu a criança separadamente ou misturado a outro alimento.

Farinha de mandioca: caso a mãe tenha referido ou utilizado para alguma preparação, como por exemplo engrossar o caldo do feijāo.

Carne: Só anotar como carne quando realmente a criança comeu. Por exemplo quando a mãe passou no liquidificador a carne e realmente a criança comeu. Não considerar quando apenas oferecido apenas o caldo de carne.

Engrossante: caso a mãe ofereça leite com algum tipo de engrossante, procure anotar o nome. Podem aparecer mucilon, aveia, maizena, etc.

Outro 1 e 2: Anotar qualquer tipo de preparação diferente das que foram descritas anteriormente e quantas vezes a crianca comeu.

Sopas: quando a mäe referir sopa, tente identificar que tipo de sopa. Se sopa de legumes e carne, anotar em legumes e carne, näo esquecendo de se certificar 
que a criança comeu a carne. Se sopa de galinha ou canja, perguntar se levou arroz na preparação; anotar em arroz e carne, não esquecendo de se certificar que a criança comeu a carne. Se algum outro tipo de sopa como sopa de farinha de milho ou fubá, anotar em outros

PERG.38 Comeu algum destes alimentos na última semana: estas questões visam saber se a criança ingeriu, comeu algum destes alimentos na última semana, ou seja, no periodo de sete dias atrás. Importa saber se ela ingeriu pelo menos uma vez o alimento na semana que passou.

Ao perguntar, substitua <DIA DA SEMANA> pelo dia da entrevista. Por exemplo: se a entrevista está sendo realizada numa terça-feira, a pergunta ficaria: Desde terça-feira da semana passada a $<$ CRIANÇA> comeu algum destes alimentos que eu vou the dizer?

PERG.39 Começou a ingerir alimentos: APLICAR APENAS PARA CRIANCAS MENORES DE 1 ANO (11 meses e 29 dias). As questões a seguir visam saber quando a criança iniciou a ingerir tais alimentos regularmente.

Considera-se como regularmente o alimento oferecido pelo menos duas vezes em dias diferentes dentro de uma semana, desconsiderando os alimentos oferecidos esporadicamente.

Se a criança nunca recebeu regularmente o alimento citado para a mãe, completar com o código 77 (nāo começou). Se a criança nāo come mais o alimento, mesmo assim perguntar para a mảe com que idade começou a comer e anotar a resposta.

Devem ser anotados os meses de vida que a criança tinha quando recebeu pela primeira vez os diversos alimentos. Evite arredondamentos por parte da mãe: quando for no $1^{\circ}$ dia (menos de 24 horas), ou menos de 1 mês (30 dias) codificar como 00. Quando a criança não começou a ingerir o alimento, codifique 77. Quando a criança for maior de 1 ano, não aplicar a questão e codificar com 88 (NSA).

Considere "papa salgada" preparações de papas com ovos, arroz, feijão, mingau, legumes/verduras, massa, batata/aipim, cenoura/beterraba, carne, ou outro tipo de preparação que não leve açúcar.

PERG.40 Após perguntar para a mãe sobre a introdução dos alimentos presentes no questionário, pergunte para a mãe se a criança recebeu algum outro alimento que não foi citado, anotando em Outro o nome do alimento como também a idade em que começou a recebè-lo. Atenção, no questionário consta 88 (nunca tomou), está errado. Considere na codifcação 77 (não começou).

PERG.41 Criança chegou a usar mamadeira: queremos saber se a criança algum dia usou mamadeira. SE SIM já parou: saber até que idade usou mamadeira. Se a criança usou mas já não o faz, marcar a opção 2 (Já parou), e perguntar "Quando parou usar mamadeira?" e anotar detalhadamente a idade da criança em meses.

Se a criança ainda usa mamadeira, anotar 88 (NSA). Se opçāo 3, ainda usa perguntar quantas vezes a criança usou mamadeira: desde de ontem, ou dia anterior no mesmo horário. Queremos saber quantas vezes ela usou a mamadeira nas últimas 24 horas e fazer a questão \# 42. Se não, opção 1: pular para \# 43. 
PERG. 42 Quando começou: aplica-se caso a mãe tenha respondido positivamente a op̧̧ão 2.

PERG.43 Leite materno: se no recordatório alimentar a mãe citar leite materno ou leite de peito, assinalar a opção 2 (Sim, ainda mama), responder "até que idade mamou" com 88888 (NSA) e pular para a questão \# 46.

Se a mãe não citou leite materno, perguntar "<CRIANÇA> chegou a mamar no peito?" Responder "Sim, ainda mama" quando a criança mamar no peito todos os dias, mesmo que a mãe informe que "mama mas não sai leite".

Se a criança mamar de vez em quando, mas não todos os dias, ou já parou de mamar responder com a opção 3 (Sim, já parou) e perguntar "Até que idade mamou?", anotando a idade em que parou de mamar, não aceitando respostas arredondadas como "dois meses" sem perguntar à mãe: foi aos dois meses mesmo ou alguns dias antes ou depois ? Procurar saber quantos dias somente se a criança for menor de 4 meses.

Perguntar se a <criança> foi colocada ao seio para mamar visando identificar as crianças que foram desmamadas nos primeiros dias de vida. Se a criança realmente nunca mamou responder "até que idade mamou" com 88888 (NSA) e aplicar o quadro abaixo no questionário \# 45.

PERG. 44 Por que não chegou a mamar: esta pergunta visa saber o motivo da criança näo ter chegado a mamar, anotando as duas principais razöes para a criança nunca ter sido amamentada.

Se a mãe citar mais de dois motivos, codifique os dois motivos mais importantes e escreva em baixo do questionário, os demais motivos e pule para a pergunta \#48.

PERG.45 História do desmame: esta pergunta aplica-se apenas às crianças ABAIXO DE 12 MESES que foram amamentadas mas já pararam de mamar.

É de fundamental importância saber quais foram os motivos que levaram a mãe a interromper $O$ aleitamento. Faça a pergunta para a mãe e deixe que ela conte sua história livremente, sem fazer interrupçōes. Caso a mãe dê uma resposta suscinta, estimule-a a falar mais, repetindo sua resposta na forma de pergunta.

Exemplo 1: Mãe: "parou de mamar porque eu não tinha leite"; Entrevistadora: "Por que a Sra não tinha leite?"; Mãe: "não tinha leite porque ele não pegava o peito"; Entrevistadora: "E por que ele não pegava o peito?"; Mãe: "Não pegava o peito porque meu leite era fraco"; Entrevistadora: "E porque acha que seu leite era fraco?"... e assim sucessivamente ate esgotar as respostas.

É muito importante que a entrevistadora não induza a resposta para a mãe, como no próximo exemplo (que não deve ser feito). Exemplo 2: Mãe: "<CRIANÇA> parou de mamar porque meu leite era fraco". Entrevistadora: "A Sra. acha que seu leite era fraco porque ele chorava muito?". Neste exemplo a tendência da mãe poderá ser de concordar com a entrevistadora, o que pode levar a falsos resultados.

Quando a mãe terminar de contar sua história, escreva-a detalkiadamente, com as palavras da mãe. Não codifique esta questão.

Atenção: Procurar detalhar mais as respostas, explorar mais a questão. 
PERG.46 Até quando pretende dar o peito? Visa saber até quando a mãe pretende amamentar. A resposta pode ser em meses ou mais vaga, tal como: "até quando ele quiser" = usar código 77"; até quando tiver leite" = usar código 78.

Caso a mãe dê outras respostas vagas tais como "até quando sustentar", tente perceber se a mãe já está determinada a interromper o aleitamento em uma determinada data (exemplo: vai trabalhar aos 8 meses e acha que a partir de então seu leite não sustentará: anote 8 meses). Caso isso não ocorra, anote a resposta dada, com as palavras da mãe, no espaço destinado a "outro".

PERG.47 Está tendo alguma dificuldade agora para dar de mamar? Visa saber se a mãe, no momento, está tendo algum tipo de dificuldade ou problema com a amamentação.

Caso a resposta seja afirmativa, faça a próxima pergunta. Caso a resposta seja negativa, vá para a PERG. \#48.

SE SIM: Qual? Aplica-se apenas para as mães que estão tendo dificuldades em amamentar, isto é, que responderam afirmativamente a pergunta \# 47. Perguntar qual o tipo de dificuldade que estão tendo e anotar detalhadamente a resposta, na ordem que as dificuldades forem citadas. Deixe a mãe falar livremente, sem interrompêla.

\section{PADRÃO ALIMENTAR:}

Esta questão não deve ser feita à mãe, mas sim respondida pela entrevistadora de acordo com as informações obtidas no recordatório alimentar e periodo de inicio dos alimentos (perguntas \# 37 e \# 39).

Assinale o padrão alimentar da criança, isto é:

(1) se a criança é amamentada exclusivamente ao seio;

(2) se é amamentada mas recebe também outros liquidos como água, chás ou sucos;

(3) se só recebe leite materno, outros alimentos sólidos e liquidos;

(4) se é amamentada, recebe também outros tipos de leite (leite de vaca ou em pó) e outros alimentos liquidos;

(5) se é amamentada, recebe outros tipos de leite e outros alimentos sólidos e líquidos;

(6) se só recebe leite de vaca ou outro tipo de leite;

(7) se recebe leite de vaca ou outro leite, mais outros líquidos;

(8) se recebe leite de vaca ou outro leite, mais outros alimentos sólidos e liquidos;

(9) outra situação (que não se encaixe nas anteriores), deve ser anotada por extenso. Não codifique este item.

PERG.48 Chupa bico: visa saber se a criança fica com o bico na boca e suga. Não basta apenas ficar como mesmo atado a roupa, só no berço ou carrinho. SE SIM: vá para a pergunta \#50. 
PERG.49 Parou ou nunca chupou? Aplica-se caso a mãe tenha respondido negativamente a pergunta anterior.

Se a criança chupou mas já não o faz, marcar a opção 1 (Já parou), e perguntar "Quando parou de chupar bico?" e anotar detalhadamente a idade da criança em anos, meses e dias.

Se a criança ainda chupa bico, anotar 88888 (NSA). Se a criança nunca chupou, ou seja, mesmo tendo a mãe ou outra pessoa oferecido a chupeta, não chegou a chupar ou o fez por menos de 24 horas marcar a opção 2 (nunca chupou) - neste caso pular para a pergunta \#53.

\section{\#50 à \#52 - APLICA-SE APENAS PARA QUEM CHUPA OU JÁ CHUPOU BICO}

PERG.50 Qual era a idade da criança quando começou a chupar bico? Aplica-se para crianças que chupam ou já chuparam bico.

Começar a chupar significa sugar efetivamente ("pegar mesmo"). Não esqueça de anotar detalhadamente a data, em anos e meses, não aceitando respostas arredondadas. Se nunca chupou usar código 8888 (NSA).

PERG.51 Ele(a) usa(va) bico de dia? Fazer a pergunta e esperar a resposta da mãe. Caso responda "Às vezes", considere como sim e pergunte para a mãe se a criança chupava bico todo o tempo ou só de vez enquando ou só para dormir

PERG.52 Ele(a) usa(va) bico de noite? Seguir as mesmas orientações da questão anterior.

PERG.53 Cozinha alternativa ou alternativas alimentares: queremos saber se a mãe tem conhecimento sobre alimentação alternativa como multimistura, farelo de arroz, farelo de trigo, fubá, pó de folha de aipim ou outras folhas verdes escuras, pó de sementes ou sementes torradas, pó de casca de ovo etc.

SE NĀO: pular para \#62.

PERG.54 Quem Ihe falou? Queremos saber se a mãe lembra ou sabe quem lhe falou sobre cozinha alternativa.

Considere a opção 1 se a mãe referiu Pastoral da Criança, Lider, Agente(s) ou mulher(es) da Igreja; opção 2 se foi o agente de saúde vinculado à Unidade de Saúde (Posto de Saúde); opção 3: médico, enfermeira ou outra pessoa da equipe de saúde que não o agente comunitário de saúde; opção 4: se ouviu no rádio; opção 7 : outro - escreva por extenso a resposta dada pela mãe.

PERG.55 Já experimentou...? Se a mãe já teve oportunidade de experimentar este tipo de alimentação. SE NÃO: pular para a pergunta \#59.

PERG.56 Se gostou...? Visa saber se a mãe gostou do alimento que expeimentou e porque. Anote tanto porque sim como porque não. Deixar a mãe falar livremente e anotar exatamente o que a mãe falou. 
PERG.57 Fez alguma receita: procurar saber se ela já fez alguma receita com estes alimentos alternativos em casa.

PERG.58 Nos últimos 3 dias ela fez ou comeu: Também queremos saber se nos úitimos 3 dias ela fez ou comeu algum alimento alternativo.

PERG.59 Criança já experimentou...? Se a criança já teve oportunidade de experimentar este tipo de alimentação. SE NÃO: pular para a pergunta \#62.

PERG.60 Se gostou...? Visa saber se a criança gostou do alimento que experimentou e porque. Tanto porque sim como porque não. Deixar a mãe falar livremente e anotar exatamente o que a mãe falou.

PERG.61 Nos últimos 3 dias criança comeu: Também queremos saber se nos últimos 3 dias a criança comeu algum alimento alternativo.

PERG.62 Se teve diarréia desde ontem: nesta questão o critério de diarréia será definido a partir dio número de vezes que a criança fez cocô nas últimas 24 horas e de sua consistência

(a) Para crianças de até 5 meses e 29 dias: aumento no número de evacuaçōes acompanhado de um amolecimento na sua consistência que deixam a mãe preocupada

(b) Para crianças com 6 meses ou mais: três ou mais evacuaçōes de consistência amolecida (liquida) dentro de um periodo de 24 horas.

Não deve ser considerada como diarréia, quando a criança apresentar fezes moles e freqüentes devido ao uso de laxantes, e que estava com as fezes normais antes de recebê-lo.

Se teve diarréia ontem. considerar SIM, e se sim considerar a quetão 63 como SIM.

PERG.63 <CRIANÇA> teve diarréia desde <DIA DA SEMANA> de duas semanas atrás? Especifique o dia da semana retrasada. Por exemplo, se a entrevista estiver sendo realizada em uma segunda- feira, pergunte "desde segunda-feira de duas semanas atrás/retrasada?".

Utilizar os mesmos criterios de diarréia da pergunta anterior. Considerar diarréia ocorrida nas últimas duas semanas, mesmo que já tenha terminado.

SE NÃO: se a criança näo teve diarréia pular para a pergunta \#72.

PERG.64 Há quantos dias? Aplica-se apenas para as crianças que tiveram diarréia dentro das duas semanas anteriores a entrevista.

Pergunte quando iniciou a diarréia e anote o número de dias decorridos até a data da entrevista. Caso a criança tenha tido mais de um episódio de diarréia na última quinzena, anote o último.

A entrevistadora não deverá fazer a conta no momento da entrevista; deverá anotar como a mäe referir. Por exemplo: domingo passado, quarta-feira da outra semana, etc. Só por ocasiāo da codificação a entrevistadora verificará a época exata de inicio. 
PERG. 65 A sra. deu para <criança> algum tipo de liquido para tratar a diarréia? Quer saber se foi dado algum líquido especificamente para tratar a diarréia. Se a resposta for não vá para a pergunta \#68.

PERG.66 O quê? Anotar os líquidos utilizados, sem induzir. A criança pode ter utilizado mais de um tipo de soro ou líquido durante a diarréia e todos devem ser marcados e no restante codificar com 2 (Não).

Se a mãe respondeu anteriormente que não utilizou líquido para tratar a diarréia, codificar com 8 (NSA), todas as opções desta pergunta.

PERG.67 Se usou soro - quem indicou: para aquelas crianças que utilizaram soro, perguntar quem indicou.

A opção 5 (outro membro da equipe de saúde) inclui respostas como enfermeiras, auxiliar de enfermagem, etc. Considerar farmácia, somente quando o mesmo prescreveu o soro, e não quando apenas o vendeu. Cuidar quando a mãe diz agente, tentar especificar se é agente da Pastoral da Criança ou da equipe de saúde,ou PSF (programa de saúde familiar).

PERG 68 Se usou remédio: perguntar qual e anotar como remédio de farmácia os industrializados ou os preparados em farmácia. Como remédios caseiros considerar os feitos em casa ou artesanais.

PERG.69 Se usou remédio - quem indicou: para aquelas crianças que utilizaram remédio, perguntar quem receitou.

A opção 5 (outro membro da equipe de saúde) inclui respostas como enfermeiras, auxiliares de enfermagem, etc. Considerar farmácia, somente quando o mesmo forneceu e nāo apenas quando o vendeu. Cuidar quando a mãe diz agente. tentar especificar se é agente da Pastoral da Criança ou da equipe de saúde.

PERG. 70 e 71 Durante a diarréia a Sra. ofereceu: nestas perguntas entender que ofereceu é diferente de tomou ou comeu.

Não queremos saber se a criança tomou ou comeu mais ou menos durante a diarréia. Queremos saber se a mäe ofereceu mais, menos ou normal.

PERG.72 Diarréia persistente: perguntar para a mãe se desde que a criança nasceu, teve alguma vez diarréia que durasse 2 semanas ou mais, sem interrupção.

Considerar interrupção se a diarréia parou por dois dias consecutivos ou mais. Se a criança no intervalo de 2 semanas teve dois ou mais episódios de diarréia, não considerar e assinalar a opção 2 (Não). Por exemplo: a criança teve diarréia durante 10 dias e três dias depois teve novamente diarréia por mais oito dias - foram dois episódios menores de 14 dias, portanto assinalar opção 2 (Não).

Não se esqueça de que o critério de diarréia, três ou mais evacuações de consistência amolecida dentro de um periodo de 24 horas, não vale para crianças com idade abaixo de 6 meses, neste caso utilizar o critério da mãe sobre se a criar ça teve ou não diarréia conforme instruçōes da pergunta $\# 62$. 
PERG.73 Teve tosse desde <DIA DA SEMANA> passada? Ao perguntar, substitua $<$ DIA DA SEMANA > pelo dia da entrevista.

Por exemplo: se a entrevista está sendo realizada numa terca-feira, a pergunta ficaria: Teve tosse desde terça-feira da semana passada?

Nesta questão interessa saber se a criança teve tosse mesmo, não considere engasgadas na mamada ou ao tomar água ou chá, mas tosse provocada por algum problema respiratório que a mãe tenha observado acontecer mais de uma vez por dia.

SE NÄO teve tosse, vá para \#74.

SE TEVE TOSSE, fazer as seguintes perguntas:

Estava com a respiração dificil? Visa captar a percepção subjetiva da mãe quanto alterações do fluxo aéreo da criança (sibilos, estridor, ronco, etc).

Estava com canseira ou falta de ar? As crianças apresentavam dificuldade de respirar, com aumento da freqüência respiratória.

Estava com o nariz entupido? Visa captar a presença de obstrução nasal, coriza ou secreção purulerita.

Estava com ronqueira/catarro? Visa saber se a mãe percebeu ronco ou secreção, como catarro.

Tinha febre? Visa saber a percepção da mãe sobre a elevação anormal de temperatura na criança. Independe de medição com termômetro. Se a mãe responder que "o médico disse que tinha", considere "sim". SE SIM: perguntar se mediu com termômetro. Caso tenha usado outro método para conferir a temperatura, anotar em outro.

PERG.74 <CRIANÇA> já teve chia no peito alguma vez? Visa saber se desde que nasceu a criança alguma vez teve por algum motivo, uma alteração do fluxo aéreo, apresentando sibilos ("miado").

SE NĀO: pular para a pergunta \#79.

PERG.75 Com que idade <CRIANÇA> teve chia pela primeira vez? Procure obter esta resposta da forma mais completa possivel, não aceitando respostas arredondadas, perguntando a idade em meses e dias em que a criança teve chia pela primeira vez.

Se ela não teve chia, codificar com 88 (NSA).

PERG.76 Tinha falta de ar ou canseira junto com o chia ? Interessa saber se junto com a chia a criança apresentava dificuldade respiratória, se isto ocorreu na maioria das vezes, marcar a opção 1 (Sim).

PERG.77 Quantas vezes <CRIANÇA> já teve chia ? Ou seja quantos episódios de chia a criança apresentou desde os últimos 3 meses ou nascimento, caso a criança tenha menos de 3 meses, não interessando saber a gravidade do(s) mesmo(s) ou o seu tempo de duração.

PERG.78 Alguma vez que teve chia, precisou fazer inalação/cheirinho (nebulização)? Somente considere como Sim a resposta se a mesma fol feita por ordem médica.

Portanto se a mãe responder que precisou fazer inalação, perguntar "O médico mandou fazer a nebulização (inalaçao ou cheirinho)?" Se a mãe responder que 
em um dos episódios de chia a criança foi ao médico e o mesmo mandou fazer nebulização marcar a opção 1 (Sim), mesmo que nas outras vezes a criança não tenha feito nebulização ou que a mãe tenha feito sem indicação médica. Se a criança teve chia e fez nebulização (inalaçao ou cheirinho) porque a mãe ou outra pessoa achavam necessário, sem ter ocorrido indicação médica anterior, marcar a opção 2 (Não).

PERG.79 Desde que nasceu <CRIANÇA> teve pontada? Interessa saber se a criança já teve pneumonia (pontada).

SE NÃO TEVE PONTADA: pular para a questão \#84.

PERG.80 Quantas vezes? Ou seja quantos episódios de pneumonia/pontada a criança apresentou desde o nascimento.

PERG.81 Quem disse que era pontada? Perguntar para a mãe, quem disse que a criança tinha pneumonia.

Se ela teve mais de uma vez, anotar para cada vez, quem disse, mesmo que tenha sido sempre a mesma pessoa. Por exemplo, a criança desde que nasceu teve pneumonia duas vezes e em ambas o médico foi quem disse que a criança tinha pontada, neste caso anotar em $1^{\mathbf{a}}$ vez a opçäo 1 (médico) e em $2^{\mathbf{a}}$ vez o mesmo código, e em $3^{a}$ e $4^{a}$ vez codificar com 8 (NSA). Se alguma vez a pessoa que disse que a criança estava com pontada não for nenhuma das existentes nas opções, escrever em outro e deixar em branco o espaço correspondente a vez, para posterior codificação.

PERG.82 Onde recebeu tratamento? Anotar o local em que a criança fez o tratamento, ou seja, onde fez aplicação das injeções na maioria dos dias.

Se a criança teve pontada mais de uma vez, anotar para cada vez o local em que foi feito o tratamento. Por exemplo: a criança teve pontada duas vezes, na primeira vez 0 tratamento foi feito em casa e na segunda vez, foi necessário hospitalizar para fazer o tratamento - anotar em $1^{\mathbf{a}}$ vez a opção 1 (Casa) e em $2^{\mathbf{a}}$ vez a opção 2 (Hospital) e em $3^{\mathrm{a}}$ e $4^{\mathrm{a}}$ vez a opção 8 (NSA).

PERG.83 <CRIANÇA> fez chapa de pulmão alguma vez? Interessa saber se a criança fez alguma vez uma chapa de pulmão (raio X), não interessando saber o motivo do pedido da mesma, como também o seu resultado.

PERG.84 <CRIANÇA> teve dor de ouvido no último mês? Nesta pergunta interessa saber se a criança teve dor de ouvido, não interessando saber o motivo da mesma.

SE NÃOTEVE: pular para a questão \# 88.

PERG.85 Saía pús do ouvido? Se a criança teve mais de um episódio de dor de ouvido anotar se um destes, saía pus (secreção) do ouvido, não interessa a cor da mesma.

PERG.86 Quem disse que era problema de ouvido? Interessa saber quem foi que disse para a mãe que a criança estava com problema de ouvido. 
PERG.87 Onde recebeu tratamento? Perguntar para a mãe, pelo local onde foi feito 0 diagnóstico e posterior acompanhamento.

Se a criança foi no consultório médico marcar a opção 3 (Ambulatório, posto), mas se o médico foi na casa da criança, marcar 1 (Casa).

PERG.88 Já foi internada em hospital? (Excluir parto) Quer saber se a criança foi hospitalizada no último ano ou últimos 12 meses e o número de vezes que isto ocnrreu.

Considere hospitalizada a criança que, após 24 horas ou mais de alta do parto, retorna ao hospital permanecendo aí por mais de 24 horas. Caso a criança tenha tido alta após o parto e retornado ao hospital pelo menos no mesmo dia, não considere como internação. Se a criança foi hospitalizada para fazer exames ou ser reidratada, perguntar se ficou mais de 24 horas.

SE SIM: perguntar qual o motivo e anotar o número de vezes, caso outro motivo anotar por extenso. Se a criança não foi hospitalizada ou foi por menos de 24 horas, codifique com 00 e vá para a questão \#89.

PERG.89 Pesou nos últimos 3 meses: referir o mês correspondente a 3 meses atrás e perguntar quantas vezes.

SE NĀO: pular para a pergunta \#92.

PERG.90 Onde? Anotar o local referido pela mãe e o número de vezes. Caso a mãe tenha pesado em mais de um local diferente, marcar cada um e o número de vezes.

PERG.91 Quanto pesou? Queremos saber se a mãe lembra do último peso da criança.

PERG.92 Consultou médico nos últimos 3 meses: se necessário referir o mês correspondente a 3 meses atrás. SE SIM: anotar qual o motivo. Ex. se a mãe referiu febre perguntar o motivo e anotar

PERG.93 Programa de alimento: visa saber se a criança está recebendo alimento de alguma instituição para ser consumido em casa. Não considere alimentação fornecida na creche para a criança comer na mesma como inscrição em programa de alimento.

SE SIM: anote qual a instituição que está dando o alimento para a criança.

PERG.94 <Criança> já foi a creche ou maternal alguma vez? Considere "sim" se a criança chegou a freqüentar creche, maternal, escolinha, "mäe crecheira" ou outra instituição que dê assistência à criança pequena na ausência da mãe.

SE NÃO: pule para a pergunta \#97.

SE SIM (freqüentou alguma das instituições já citadas): Pergunte com que idade a criança começou a freqüentar e procure obter a resposta da forma mais completa possivel, anotando a idade em anos e meses em que a criança iniciou a freqüentar a instituiçāo.

PERG.95 Continua freqüentando a creche: anotar se a criança continua freqüentando a creche, caso a criança tenha freqüentado creche ou similares mas já 
não o faça, pergunte com que idade a criança parou de ir a creche, procurando colher a informação da forma mais detalhada possivel.

PERG.96 Quantas horas por dia <CRIANÇA> fica(va) na creche ? Esta pergunta deverá ser feita tanto para crianças que ainda frequentam como frequentaram a creche.

PERG.97 Criança de 1 mês que mama e recebe chá: marcar a opinião da mãe sem influenciá-la. SE OUTRO: anotar detalhadamente.

PERG.98 Mamar somente no peito: visa saber a opinião da mãe sobre amamentação exclusiva. Procurar obter resposta precisa sem arredondamentos.

Anotar em meses: caso a mãe refira 1 ano e meio, anotar por extenso e deixar para fazer as contas na hora da codificação em casa. Codificar 77 quando a resposta for - não sabe.

PERG 99 Opinião da mãe: queremos saber a opinião da mãe sobre a idade de desmame, ou seja, até que idade ela acha que uma criança deveria mamar no peito. Reforçar que é a opinião dela a este respeito.

PERG. 100 A partir de que idade ... Visa saber qual a idade, na opinião da mãe, que a criança deve começar a receber os alimentos citados abaixo.

Citar um por um e anotar. Caso a mãe refira 1 ano e meio, anotar por extenso e deixar para fazer as contas na hora da codificação em casa. Caso a mãe refira por exemplo no leite da mãe ou leite materno, "quando nasce" ou "no mesmo dia que nasce" codificar 00; 99 para ignorado ou não sabe; 77 para não deve receber ou nunca.

PERG.101 Conhecimento de vacinas: visa saber se a mãe sabe quais as vacinas que a criança deve receber. Não citar as opçōes.

PERG. 102 Número de doses da vacina: visa saber se a mäe sabe quantas doses de vacinas que a criança deve receber no primeiro ano de vida como rotina. Citar as vacinas. As doses das campanhas de imunização não devem ser consideradas.

\section{SE A MÃE NĀO TINHA A CADERNETA DE SAÜDE, PERGUNTAR :}

PERG.103 Reconhecimento da caderneta de saúde: nesta questão vamos mostrar para mäe a caderneta de saúde. SE NÃO: pular para a questão \#108. Case a mãe tenha trazido a caderneta quando pedida na perg. 15 , codificar 8 , observar a curva na caderneta e seguir com a perg. 104.

Anotação na Curva de Peso: observar na caderneta de saúde ou cartão da criança se os pesos foram marcados na curva. Marcar as opçōes.

PERG.104 Mostrar a página 12 ou 14 da caderneta e anotar a resposta.

SE RESPONDEU CORRETAMENTE: considerar como respostas corretas (Z) peso, (3) desenvolvimento da criança, (4) crescimento e (5) desnutrição. Se a mãe não sabe ou referir altura da criança, não aplicar as questões 105 à 107. Caso a mãe dê outra 
resposta anote por extenso e aplique as questões. Antes de codificar, discuta com a sua supervisora sobre a resposta dada pela mãe ou informante.

PERG. 105 Mostrar cartão 1; anotar a resposta.

PERG. 106 Mostrar cartão 2 : anotar a resposta.

PERG. 107 Mostrar cartão 3 e 4 : anotar a resposta.

PERG.108 Fumo na gestação: visa saber a opinião da mãe sobre fumo na gestação.

PERG.109 Alojamento conjunto: opinião da mãe sobre alojamento conjunto.

PERG.110 Diarréia - o que fazer: aplicar a questão e não citar as opções. Deixar a mãe falar livremente e depois anotar detalhadamente. Anotar todas as alternativas que a mãe referir. No final perguntar apenas uma vez "algo mais?". SE A MÃE NÄO CITAR ALIMENTAÇĀO OU COMIDA, PERGUNTAR: E quanto a alimentaçāo (comida) de uma criança com diarréia, o que a mãe deve fazer? Nesta questão queremos saber a opinião da mãe sobre a alimentação da criança durante a diarréia. Se a mảe citou alimentação na questão anterior, codificar com 8 (NSA). Caso a mãe refira apenas líquidos quando perguntada sobre a alimentação, repetir a pergunta tal qual esta escrita.

PERG.111 Tipos de soro: fazer a questão e não citar. Anotar todas as alternativas que a mãe referir. No final perguntar apenas uma vez "algo mais?"

PERG.112 Colher medida: visa saber se a mãe tem a colher medida.

SE NUNCA TEVE: pular para a questão \#114.

PERG113. Quem deu: de quem ela ganhou a colher medida.

Considere a opção 1 se a mãe referiu Pastoral da Criança, Lider, agente(s) ou mulher(es) da Igreja: opção 2: médico, enfermeira ou outra pessoa da equipe de saúde que não o agente comunitário de saúde; opção 3: se foi o agente de saúde vinculado à Unidade de Saúde (Posto de Saúde); opção 4: parente; comadre; vizinha opção 5: farmaceutico; outro - escreva por extenso a resposta dada pela mãe.

PERG.114 Como acha que a criança esta crescendo? marcar o que a mãe referir e perguntar o porquê.

PERG.115 Por que? Deixar a mãe falar livremente. Caso o referido pela mãe não se encaixe em nenhuma opção anotar em outro. Codificar esta questão com os códigos referidos no questionário.

OBSERVE SE A CRIANÇA FAZ A ATIVIDADE REFERENTE A SUA FAIXA ETÁRIA, FAIXA ETÁRIA SUPERIOR A SUA IDADE E FAIXA ETÁRIA POSTERIOR A SUA IDADE. SE NĀO CONSEGUIR OBSERVAR PERGUNTE A MÃE.

Utilize os códigos abaixo para completar o quadro de desnvolvimento.

Desenvolvimento: identificar na tabela de desenvolvimento a idade da criança e observar se ela faz a atividade prevista. Observar se a criança realiza as atividades 
previstas para a faixa etária imediatamente anterior, a faixa etária atual e a faixa etária posterior a que se encontra a criança. Caso não consiga observar, pergunte para a mãe se a criança faz as referidas atividades. Assinalar sim visto se voce observou a criança realizar a atividade. Assinalar (2) sim, não visto se a mãe ou informante referiu que a criança realiza a atividade.

PERG.116 Onde nasceu? Anotar por extenso o nome do municipio e o estado. Na codificação do municipio: Criciúma $=01$, Içara $=03$, Urussanga $=08$, Orleans $=09$, Meleiro $=13$, Maracaja $=14$, Tubarão $=17$; se surgirem outros municipios deixe em branco para posterior codificação. Na codificação de estado: Santa Catarina = SC, Paraná $=$ PR, São Paulo $=$ SP, Rio Grande do Sul = RS.

PERG.117 Há quanto tempo mora no bairro: anotar detalhadamente em anos completos. Evitar cálculos na hora. Por exemplo se a mãe referir 1 ano, 11 meses e 29 dias considerar 1 ano.

PERG.118 Se mudou há menos de 5 anos: interessa saber se morava no interior (zona rural) ou na cidade (área urbana).

PERG.119 Tempo de moradia em Criciúma: anotar em anos completos. Por exemplo se a mãe referir 1 ano, 11 meses e 29 dias, considerar 1 ano.

PERG.120 A Sra. fuma? Saber se a mãe da criança fuma.

SE SIM: anotar o número de cigarros diários. Se a mãe referir número de carteiras, anotar e na hora da codificação anotar em número de cigarros, lembrando que cada carteira tem 20 cigarros.

PERG. 121 Idade da mãe: anotar em anos completos. Por exemplo: se a mãe vai fazer 26 anos amanhã, sua idade é 25 anos completos.

Se outra pessoa que não a mãe da criança estiver respondendo o questionário, pergunte e anote a idade da mãe biológica ou adotiva em anos completos.

PERG.122 Moram na casa: Considerar a familia como sendo constituida por todos aqueles que dormem na casa e fazem regularmente pelo menos uma refeição juntos. Pai biológico é o pai da criança.

A casa da criança è aquela onde ela dorme, mesmo que ela fique durante o dia em outra casa (por exemplo na casa dos avós). Se a criança mora na casa dos avós, no mesmo terreno da casa dos pais, considerar como sendo uma só familia, incluindo todas as pessoas que moram nas duas casas, inclusive em relação a renda.

Se a casa onda a criança mora com os avós fica em outro terreno, considerar como sendo a casa da criança aquela onde ela reside com os avós. Em outros anotar todas as outras pessoas que moram na casa, além de pais e irmãos. Não considerar como moradores da casa pessoas que estiverem temporariamente residindo no domicilio, como por exemplo avó que vem passear um tempo ou ajudar a cuidar do neto/neta. Quando tem irmãos da criança os Outros codificar como 00.

\section{SE A MÃE NÃO CITOU ESPOSO OU COMPANHEIRO, PERGUNTAR:}


PERG.123 Se tem esposo ou companheiro: visa saber se o esposo ou companheiro mora na mesma casa.

SE NÃO: pule para a questão \#125.

PERG.124 Há quanto tempo: em anos e meses completos. Por exemplo se a mãe referir 1 ano, 11 meses e 29 dias, só então considerar 2 anos, menos do que isto considerar 1 ano.

Tipo de união: visa saber se a mãe e o atual companheiro são casados. Marque "civil" se forem casados apenas no civil; "religioso" se apenas no religioso; "ambos" se casada no religioso e no civil; "outro" se a mãe der outra resposta anote por extenso.

PERG.125 Ler e escrever: somente perguntar se o esposo ou companheiro sabe ler escrever, caso for referida a sua presença dentro de casa na questão \#98.

PERG.126 Escolaridade: anotar somente a última série concluida na escola para os pais que vivem com a criança (biológicos ou adotivos). Exemplo: a mãe referiu $4^{a}$ série do $1^{\circ}$ grau, perguntar: completou, concluiu a $4^{a}$ série? Caso não tenha concluido nenhum ano de escolaridade (analfabeto) codificar 00.

PERG.127 Estuda fora: aqui interessa se a mãe estudou/estuda fora, nos últimos 12 meses, no último ano.

PERG.128 Trabalhou nos últimos 12 meses, no último ano. aqui interessa se a mãe trabalhou ou trabalha para fora, ou ainda, trabalha em casa para fora(ex. costureira, lavadeira); se mora no emprego e esta trabalhando (ex. caseira), nos últimos 12 meses ou último ano. Não importa a situação legal - com ou sem carteira assinada, ou a forma de remuneração (cuida a casa e em troca pode morar nela, por exemplo). Caso tenha voltado a trabalhar e parado, considere SIM. Na negativa, vá para \#131

PERG.129 Quantos meses: não aceite arredondamentos, tente precisar ao máximo a data, caso a mãe não se lembre ao certo.

Se a mãe está empregada mas em licença gestante, não considere os meses de licença no cálculo.

Quantos dias: considerar quantos dias por semana a mãe fica fora de casa ou se mora no emprego quantos dias por semana dedica-se ao trabalho.

Quantas horas: considerar quantas horas por dia a mãe fica fora de casa ou se mora no emprego quantas horas por dia dedica-se ao trabalho.

PERG.130 Tipo de trabalho: anotar o mais detalhadamente possivel o tipo de trabalho da mäe. É importante diferenciar se é proprietário, autônomo ou empregado. Por exemplo se é "comerciária ou comerciante", saber se é dona, empregada ou vendedora ambulante? Portanto é necessário detalhar. Interessa saber o trabalho feito por ela no último ano e não o que ela fazia antes dos últimos doze meses.

PERG.131 Renda: perguntar quais as pessoas da casa que recebem salário ou aposentadoria e responder nos itens correspondentes. Perguntar separadamente a 
renda que cada pessoa recebeu. Ex. se a mãe refere $\mathrm{R} \$ 900,00$. Perguntar 900,00 de uma pessoa que recebeu?

Se a resposta for em salários minimos, fazer a conversão para reais no momento da codificação. Quando não houver renda, preencher com zeros e não 88.

Importante: considerar apenas a renda do mês anterior. Considerar em salário líquido. Se uma pessoa começar a trabalhar no mês corrente, não incluir seu salário. Se uma pessoa está atualmente desempregada, mas trabalhou no mês que passou e ainda recebeu salário, deve ser incluido no orçamento familiar. Se estiver desempregado há mais de um mês, considerar a renda do trabalho ou biscate atual. Se tiver seguro desemprego, somar aos biscates. Incluir aposentadorias.

Quando a mãe não souber informar a renda de outros membros da familia, tentar aproximar ao máximo, aceitando a resposta "ignorado" somente em último caso. Quando isto ocorrer, anotar detalhadamente o tipo de ocupação desta pessoa de renda ignorada, para que se possa tentar estimar o seu salário posteriormente.

Se mais de quatro pessoas tiverem renda no último mês, anotar na margem do questionário e, por ocasião da codificação, somar a renda, por exemplo da quarta e quinta pessoa e anotar na renda da quarta pessoa.

PERG.132 Outra renda: se a familia recebe regularmente rancho de alguma instituição, tentar saber a quanto corresponde este rancho em dinheiro, mesmo que aproximado, e anotar em outra renda. Isto também é válido para aluguéis, etc.

PERG.133 Propriedade do terreno: assinalar se o terreno que a familia mora é própria ou não. Se for alugada, anotar o valor do aluguel pago no último mês ao lado da alternativa "alugada".

PERG.134 Tipo de casa: o tipo da casa não deve ser perguntado, mas sim observado pelo entrevistador. Observar a maior parte da casa. Por exemplo se casa mista com madeira e alvenaria, considere a maior pate. Se houver dúvidas, pergunte.

PERG.135 O tipo de piso não deve ser perguntado, mas sim observado pelo entrevistador. Se houver dúvidas, pergunte.

PERG.136 Quantas peças usam para dormir: muitas vezes as pessoas não possuem quartos, mas dormem em outras peças (como sala ou cozinha), por isso devemos perguntar por peças da casa que são usadas para dormir.

PERG.137 Observar e se necessário perguntar: caso utilize água encanada do vizinho, anotar "não". Se tem água encanada, mas apenas do lado de fora da casa, dentro do terreno, responder com a opção 2 (Sim, no quintal).

PERG.138 De onde vem a água: anotar se é da rede pública ou poço. Se água de cacimba, caminhão, bica etc, anotar em outros.

PERG.139 Banheiro: se a família usa o sanitário de outras casas no mesmo terreno, aceitar como se fosse da casa e especificar o tipo. Perguntar também se o vaso sanitário tem descarga. 
PERG.140 Equipamentos: observar e se necessário perguntar sobre a presença e funcionamento dos equipamentos domésticos. Perguntar cada item e apenas no final perguntar se algum destes não funciona.

PERG.141 Atualmente grávida: esta pergunta visa saber se a mãe já esta grávida.

SE SIM: pule para a pergunta \#145.

PERG.142 Engravidar de novo: visa saber os planos da mãe da criança com relação a uma outra gravidez. Pergunte mesmo que ela tenha respondido que não tem companheiro ou esposo na questão \#123.

SE SIM: pular para a questão \#145.

PERG.143 Contracepção: Visa saber o que ela está fazendo ou fez com relação a evitar outra gravidez. Se a resposta for NẢO vá para a \#145.

Atenção: se a mãe referir que não está fazendo nada pois já fez laqueadura, anotar como SIM e na questão 144 codificar o número 05 referente a laqueadura.

PERG.144 O quê? Considere a resposta dada, anotando qual o método anticoncepcional que a mãe da criança esta usando para evitar outra gravidez.

PERG.145 Métodos naturais: visa saber se a mãe tem conhecimento a respeito de métodos naturais para evitar filhos. SE NÃO: Leia o enunciado abaixo. SE SIM: FAÇA $\# 146$.

PERG.146 Quais: assinalar as opçōes referidas; se outro, anotar detalhadamente.

PERG.147 Onde aprendeu: visa saber se a mãe assistiu alguma palestra, ou alguém Ihe falou em alguma reunião ou grupo, sobre metodo natural para evitar filhos.

PERG.148 Quem ensinou: anotar com quem ou onde a mãe aprendeu sobre métodos naturais.

PERG.149 Religião: se participa ou tem alguma religião e qual é esta religião, anotar detalhadamente, caso a mãe refira evangélica, perguntar qual evangélica. SE NÃO: pular para a questão \#154.

PERG.150 Culto: queremos saber se no mês que passou ela participou de alguma missa, culto ou cerimônia religiosa. SE SIM: anotar o número de vezes.

PERG.151 Participa de atividade religiosa: atividades como grupos religiosos, novenas, reuniões, etc. SE SIM: anotar detalhadamente.

PERG.152 Educação religiosa da criança: ouvir a opinião da mãe e anotar detalhadamente.

PERG. 153 Idade de inicio para a educação religiosa: anotar em anos e meses e perguntar como, deixar a mãe falar livremente, após anotar detalhadamente. Caso a mãe diga "quando nasce", codificar 0000 , se disser "quando falar", codificar 6666 , 
quando a mãe referir que è "quando começar a entender", insistir pela idade que ela acha que a criança vai começar a entender.

PERG.154 Agentes Comunitários de Saúde: visa saber se a mãe já ouviu falar dos agentes comunitários de saúde.

SE NÃO: pular para a questão \#161.

PERG.155 Foi visitada: queremos saber se ela foi visitada pelos agentes comunitários de saúde. SE NÃO: pular para a questão 161 .

PERG.156 Acompanhamento na gestação: visa saber se durante a gestação da criança em estudo a mäe foi acompanhada por algum agente comunitário da equipe de saúde.

PERG.157 Visita depois: visa saber se no primeiro mês depois que a criança em estudo nasceu, a mãe recebeu visita do Agente Comunitário de Saúde ou alguém da equipe de saúde, SE NÃO: pular para a questão \#159.

SE SIM: anotar quem e fazer a pergunta \#158.

PERG.158 Conversaram sobre aleitamento: se a resposta é positiva na questão \#104 queremos saber se conversaram sobre aleitamento materno. Se necessário especificar para a mãe os pontos como importância do leite materno, horário de mamadas, etc.

PERG.159 Visita nos últimos 3 meses para orientação: visa saber se nos últimos 3 meses, a mãe recebeu visita do Agente Comunitário de Saude.

PERG.160 Satisfação com o trabalho das agentes: visa saber se a mãe está satisfeita com as visitas ou trabalho dos Agentes Comunitários de Saúde.

SE SIM ou SE NĀO: saber o porquê. Anotar tudo detalhadamente.

PERG.161 Pastoral da Criança: visa saber se a mãe já ouviu falar da Pastoral da Criança. SE NÃO: pular para \# 173 e anotar vacinas.

PERG.162 O que ela faz: SE SIM: deixar a mãe falar livremente e após anotar tudo. SE NÃO: Pular para \# 167.

PERG.163 Participa: se participa, anotar porque e se não participa também anotar o porquê. SE NÃO: pular para a questão \#167.

PERG.164 Há quanto tempo: anotar em anos e meses completos.

PERG.165 De quais atividades : anotar de quais atividades da Pastoral que ela participa.

PERG.166 Quais mais gosta: anotar tudo detalhadamente. 
PERG.167 Se foi visitada pela Lider: se não pular para \# 173 e anotar vacinas.

PERG.168 Acompanhamento na gestação: visa saber se durante a gestação da criança em estudo a mãe foi acompanhada por alguém da Pastoral da Criança.

PERG.169 Visita depois: visa saber se no primeiro mês depois que a criança em estudo nasceu, a mãe recebeu visita da Líder da Pastoral da Criança.

PERG.170 Conversaram sobre aleitamento: se a resposta é positiva na questão \#168 queremos saber se conversaram sobre aleitamento materno. Se necessário especificar para a mãe os pontos como importância do leite materno, horário de mamadas, etc.

PERG.171 Visita nos últimos 3 meses para orientação: visa saber se nos últimos 3 meses, a mãe recebeu visita da Lider da Pastoral da Criança.

PERG.172 Satisfação com trabalho da Pastoral: visa saber se a mãe está satisfeita com as visitas ou trabalho da lider da Pastoral.

SE SIM OU SE NÃO: saber o porquê. Anotar tudo detalhadamente.

PERG.173 Vacinas: na caderneta de saúde, página 16. verificar e anotar as dosesde vacinas. Datas de vacinação: se o cartão de vacinas foi visto, copiar as datas na coluna correspondentes as doses anotadas no quadro, e onde constar reforço anotar as doses que constam no cartão. Se o cartão de vacinas não foi visto, preencher o "cartão do questionário" com zero e na última linha preencher o número total de doses referidos pela mãe. A informação referida pela mãe somente será válida quando o método de aplicação da vacina (o qual esta entre parênteses no questionário) for mencionado. Para a vacina BCG, examinar os braços da criança para confirmar a presença de cicatriz vacinal (tanto para as com cartão, como para as sem cartão). Marcar com um visto na segunda linha da coluna BCG quando tiver cicatriz. Anotar somente se foi carimbado no cartão.

PERG.174 Pesagens: nesta questão é necessário anotar todas as datas, idades, pesos e alturas da criança, na página 11 da caderneta de saúde. No espaço onde marcar o local se houver opção, se não, anotar em outro detalhadamente e não codificar. Na hora de codificar optar pela data e assinalar no datac se é data ou idade de acordo com os códigos acima do quadro. Anotar a data em que foi feito o peso. Caso esta não esteja disponivel anotar a idade. Na codificação "douid1" é (1) se foi anotada a data e (2) se a idade da criança. Na hora de codificar o peso, usar apenas casa decimal, poe exemplo: 4,850 na codificação ficaria 4,9 pois o cinco sempre arredonda para cima. Quando o peso ou altura for ignorado IGN, codificar como 009; e quando NSA com 008.

PERG.175 Menos de dois pesos marcados: caso a mãe tenha menos de duas anotações completas, perguntar onde a criança foi pesada.

SE a criança não foi pesada ou nenhuma anotação foi feita. pular para 
PERG.176 A onde: se a criança foi pesada, a mãe não tem anotação, mas esta foi feita, perguntar a onde.

Ver as opções e assinalar o tipo de local e por extenso a data do peso e a localização. Se a criança foi pesada pela Pastoral da Criança, perguntar pelo nome da Lider que a acompanhava. Na dúvida anote por extenso e depois pergunte a supervisora.

Atenção: não codifique esta questão.

PERG. 177 Cor da pele da criança: se necessário pergunte.

PERG.178 Cicatriz da BCG: não esquecer de verificar se existe cicatriz.

\section{ANTROPOMETRIA}

Neste momento, explique à mãe que precisa pesar e medir a criança e que isso é importante para saber se ele(a) está ganhando peso adequadamente. Case a mảe diga que já foi pesado há alguns dias, argumente que crianças assim pequenas ganham ou perdem peso muito rápido e é necessário saber exatamente quanto está ganhando ou perdendo.

Peça para a mãe retirar TODA a roupa da criança. Caso a mãe se recuse a tirar toda roupa da criança, insista. Se mesmo assim recusar, anote cuidadosamente cada peça de roupa com que a criança foi pesada. SIGA AS INSTRUÇÕES DO MANUAL DE ANTROPOMETRIA PARA AS MEDIDAS.

PERG.179 Data da entrevista: anote a data da entrevista. Caso esta seja feita em duas etapas, anote ao lado, especificando o dia que foi feito o recordatório alimentar e o dia de realização da antropometria.

\section{NÃO ESQUEÇA DE AGRADECER A MÃE PELA GENTILEZA E COLABORAÇÃO PRESTADA, AO DEDICAR SEU TEMPO RESPONDENDO AS QUESTÕES!}




ESTUDO SOBRE A SAÚDE
DAS CRIANÇAS MENORES DE 3 ANOS EM
CRICIÚMA - 1996
REVISITA

1 Número do questionário:

2 Setor:

3 Folha de conglomerado:

4 Bairro:

$--$

5 Endereço: _

6 Nome da criança:

Sexo: (1) masc

(2) fem

sexo

7 Nome da mãe:

8 Durante a gravidez de <CRIANÇA> a Sra fez alguma consulta pré-natal?
(1) Sim
(2) Não

\section{SE SIM:}

$9 \mathrm{Em}$ que mês da gravidez de <CRIANÇA> a Sra fez a primeira consulta de pré-natal _ _ $(01=$ primeiro mês, $88=N S A, 99=(G N)$

10 Quantas consultas de pré-natal a Sra fez na gravidez de <CRIANÇA>? (8=não se aplica)

11 <CRIANÇA> chegou a usar mamadeira?

(1) Não

(2) Sim, já parou. Até que idade usou mamadeira? _ _ meses

(3) Sim, ainda usa.

SE SIM:

12 Quando comecou? __ meses__ dias

13 <CRIANÇA> chegou a mamar no peito?
(1) Nunca mamou
(2) Sim, ainda mama

(3) Sim, já parou. Até que idade mamou anos meses dias 
14 Quantas vezes a Sra ficou grávida?

Quantos filhos estão vivos?

(1) aborto

(2) Nasc. morto

(3) nasc. vivo (falecido)

15 A Sra já experimentou alimentaçäo alternativa como a multimistura de farelo, pó de folhas verdes escuras, po'de sementes, csaca de ovo?
(1) $\operatorname{sim}$
(2) não

16 Desde que nasceu <CRIANÇA> teve alguma vez, diarréia que durasse 2 semanas ou mais? (sem interrupção por mais de 48 horas)
(1) Sim
(2) Não
(9) IGN

17 Desde que nasceu, <CRIANÇA> teve pontadal pneumonia? (1) Sim (2) Não

\section{SE SIM:}

18 Quantas vezes?

$(8=N S A ; 9=1 G N)$

19 <CRIANÇA> foi internada em hospital desde <MÊS> do ano passado? (por mais de 24 horas)

(0) Não ( ) Sim. Quantas vezes:

(9) Não sabe

\section{SE FOI HOSPITALIZADA: Qual o motivo?}

Diarréia vezes $(0=$ não foi; $9=$ não sabe; $8=N S A)$

Pneumonia/pontada _ vezes

Acidente vezes

Outro:

20 No mês passado, quanto ganharam as pessoas que trabalharam?

$1^{\text {a pessoa: }} \mathrm{R} \$$ no ültimo mês

¿ pessoa: $R \$$ no último mês

$3^{\mathrm{a}}$ pessoa: $\mathrm{R} \$$ no último mês $4^{\mathrm{a}}$ pessoa: $\mathrm{R} \$$ no último mês

21 A familia tem oulra renda? $\mathrm{R} \$$ no último mês

diapro

pontad

vezpon

inter

hosdia

hospne

hosaci

hosout

renda 1

renda2

renda3

renda4

orend 
22 A Sra sabe o que é método natural para evitar filhos?

(1) $\operatorname{Sim} \rightarrow \# 24$

(2) Não (LER O ENUNCIADO ABAIXO)

Métodos naturais são métodos em que o casal evita ter relaçóes em determinados dias como forma da mulher não ficar grávida.

23 A Sra conhece algum método natural para não engravidar? Quais?
(01) Coito interrompido
(0́2) Tabelinha
(03) Aleitamento
(04) Billings/muco cervical
(77) camisinha/pilula
(06) não conhece ( ) outro
(05) temperatura basal

24. A senhora já foi visitada pelos Agentes Comunitários de Saúde? (1) sim (2) não

SE SIM: 25 Durante a gestação de <CRIANÇA> a senhora já era acompanhada pelo agente comunitário de saúde?
(1) $\operatorname{sim}$
(2)não

26 No primeiro mês depois que <criança> nasceu, a Sra recebeu visita do Agente Comunitário de saúde?
(1) $\operatorname{sim}$
(2) não

conmet

qalmet

visgec

gescom

visnas

27. A senhora participa ou já participou da Pastoral da Criança?

(1) sim, ainda participa

(2) sim, mas não participa mais (j) nunca participou Porque?

SE SIM: 28 Foi visitada pela Líder Comunitária:
(1) $\operatorname{sim}$
(2) não ANOTAR VACINAS

29 Durante a gestação de <CRIANÇA> a senhora já era acompanhada pela Lider da Pastoral da Criança?
(1) $\operatorname{sim}$
(2)não

30 Nos últimos três meses a senhora recebeu alguma visita da Lider da Pastoral da Criança?
(1) Sim
(2) Não
(8)NSA

parti

partpq

vislid

gespac

vis $3 m e$ 
31 PEDIR PARA A MÃE A CADERNETA DE SAÚDE: OBSERVAR SE O PESO ESTA ANOTADO NA CURVA DA CADERNETA DE SAÚDE: (1) Sim

(2) Não

32 Data de nascimento:
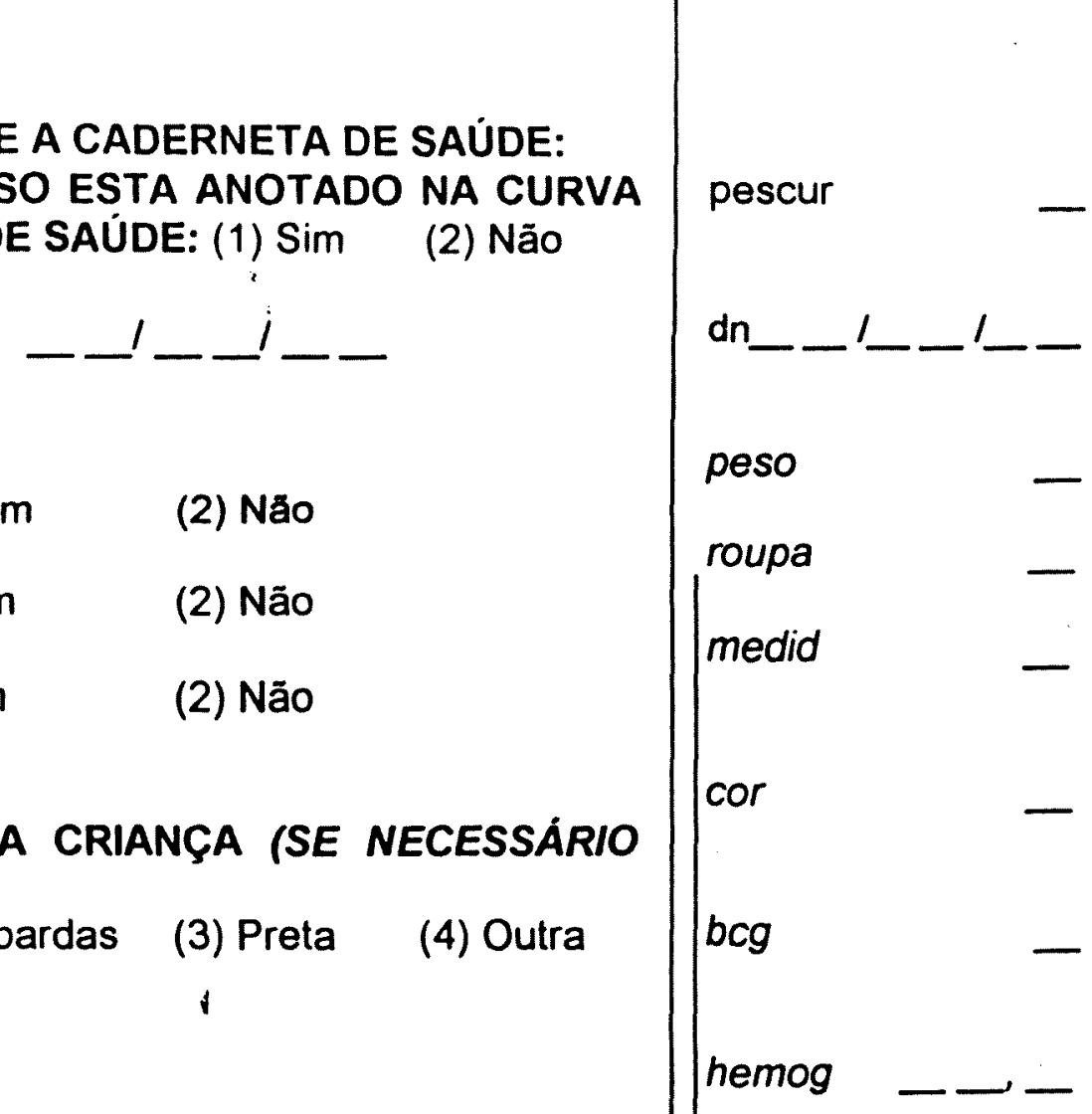

36 Hemoglobina:

Considerar anemia:

$\begin{array}{ll}1 \text { - } 3 \text { dias } & <14,5 \\ \text { até } 2 \text { semanas } & <13,0 \\ \text { até } 1 \text { mès } & <10,5 \\ \text { até } 2 \text { meses } & <9,0 \\ \text { até } 6 \text { meses } & <11,0 \\ \text { até } 2 \text { anos } & <10,5 \\ \text { mais de } 2 \text { anos } & <11.5\end{array}$

34 COR DA PELE DA CRIANÇA (SE NECESSÁRIO PERGUNTAR)::
(1) Branca
(2) pardas
(3) Preta
(4) Outra

35 CICATRIZ DA BCG
(1) $\operatorname{sim}$
(2)não

pescur

(1)
(2) Nåo
Com roupa: (1) $\quad$ Sim $\quad$ (2) Não
$\begin{array}{lll}\text { Se foi medida: } & \text { (1)Sim } & \text { (2) Nāo }\end{array}$
33 Se foi pesada: (1) Sim

1

,

Data entrevista:
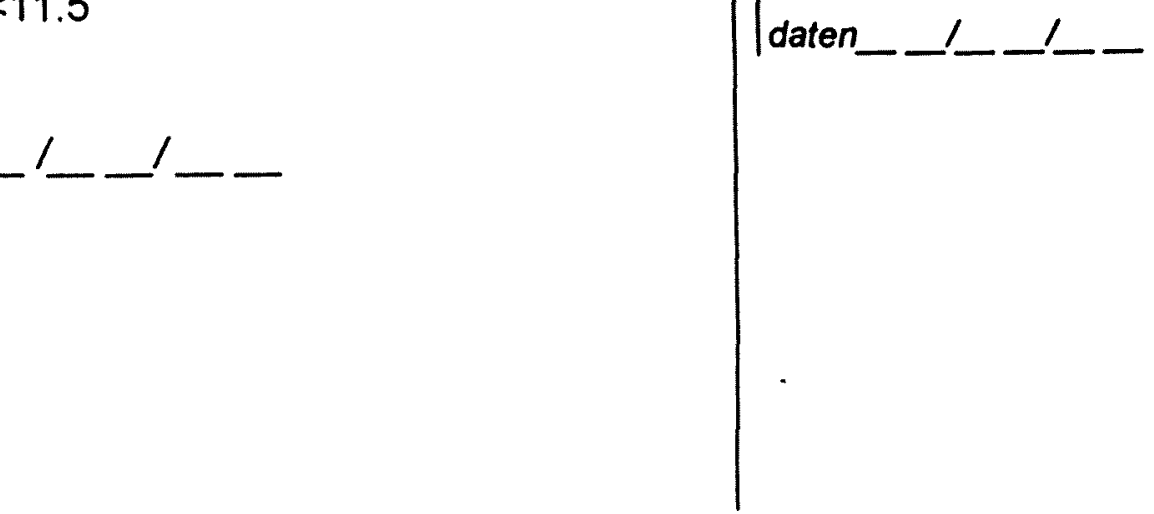
173 NA CADERNETA DE SAUDE (PÁGINA 16) VERIFICAR E ANOTAR A DATA DAS DOSES DE VACINAS

\begin{tabular}{|c|c|c|c|c|c|}
\hline VACINA & $\begin{array}{c}\text { Antipolio- } \\
\text { Sabin } \\
\text { (gotas) }\end{array}$ & $\begin{array}{l}\text { Triplice-DPT } \\
\text { (nadegas) }\end{array}$ & $\begin{array}{c}\text { Anli. } \\
\text { Sarampo }\end{array}$ & $\begin{array}{c}B C G \\
\text { (ver cicatriz } \\
\text { no ombro) }\end{array}$ & Hepatite \\
\hline $1 \cdot$ dose & 1 & 1 & 1 & 1 & 1 \\
\hline $2^{3}$ dose & 11 & 1 & 1 & 1 & ' \\
\hline $3^{2}$ dose & 1 & 1 & 1 & 1 & 1 \\
\hline Reforço & I & 11 & 1 & 1 & / \\
\hline
\end{tabular}

\section{NA CADERNETA DE SAÚdE (PÁGINA 11) COPIAR DATA OU IDADE, PESOS e ESTATURAS DA CRIANÇA}

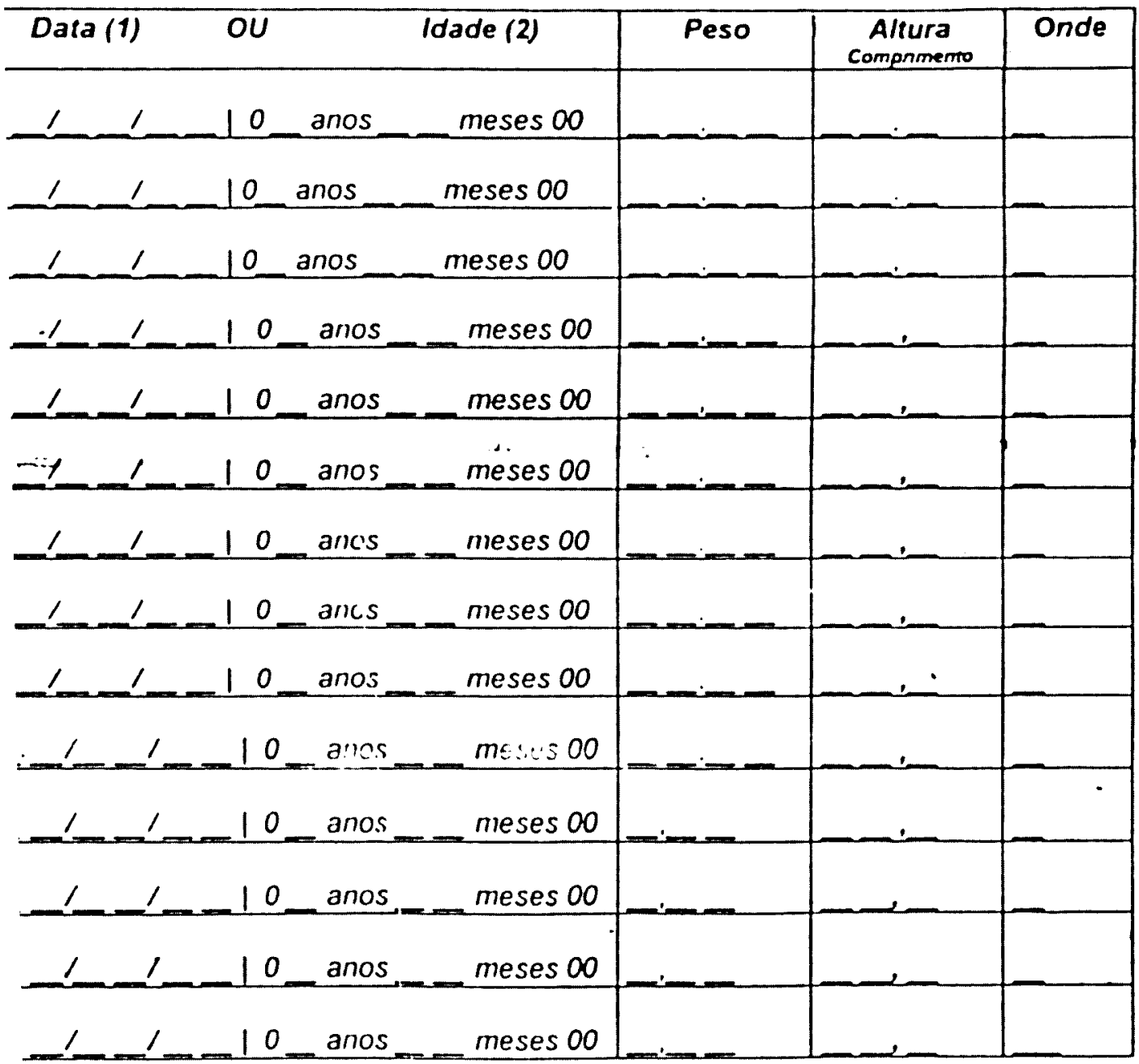

\section{jDIGOS:}
ide : (1) Poslo de saude
(2) Em casa
(3) Pastoral da criança
(4) agente comunitáno

() Oulro

douid1 datac1 pesoc1

altuct

ondect

douid2

dalac2

pesoc2

alluc2

ondec2

douid3

dalac 3

pesoc3

altuc 3

ondec 3

douid 4

dalac 4

pesoc 4

alluc4

ondec4

douid5

datac5

pesoc 5

aftuc 5

ondec 5

douid6

dalac6

pesoc6

altuc6

ondec6

dovid7

datac7

pesoc7

aftuc7

ondec 7

douid8

datac 8

pesoc 8

alluc8

ondec 8

douid9

datac 9

pesocs

allucs

ondec 9

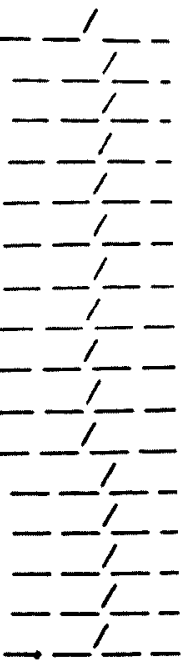

- - -

- -

- -

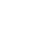

-

$--$

-

-

- - -

- -

-

$$
\text { - }
$$

$-1$

- -

- - -

- - -

- -

-

-

- -

$--$

-

-

-

- -

$--$

-

-

- - . -

$-1$

$-$

- - - - 


\section{Relatório do trabalho de campo}

\section{Seleção e Treinamento dos Entrevistadores:}

A seleção para entrevistadores foi iniciada em novembro de 1995, através de contato com professores e editais na Universidade do Extremo Sul de Santa Catarina (UNESC) visando a busca de candidatos.

$O$ treinamento foi efetivamente realizado na UNESC em 19 a 23 de fevereiro de 1996, incluindo o periodo da manhã e da tarde. No primeiro dia pela manhã foi apresentado o estudo a ser desenvolvido, bem como a função de cada um dos participantes e como trabalhariam. Em seguida, foi feita a primeira seleção, através de prova teórica, com conteúdos de raciocínio lógico e matemática básica. Os melhores colocados foram convocados para continuar participando do treinamento. No periodo da tarde deu-se início à leitura do questionário e do manual de instruçōes. No segundo dia. praticou-se a técnica da entrevista através de simulação da entrevista entre os próprios participantes, com supervisão dos coordenadores da pesquisa. No terceiro dia, dividiu-se os participantes em dois grupos: enquanto o primeiro praticou a antropometria em uma creche o segundo continuou praticando a técnica da entrevista. A tarde houve inversão das atividades entre os grupos. No quarto dia discutiu-se as dúvidas com os participantes e continuou-se a prática de entrevistas pela manhã. Durante o periodo da tarde procedeu-se ao ensaio do trabalho de campo em um bairro próximo, que continuou pela manhã do quinto dia. No periodo da tarde fez-se a avaliação do treinamento, a seleção dos supervisores e a divisāo das equipes para o estudo piloto.

A seleção da equipe de hemoglobina foi realizada posteriormente, dentre técnicos em enfermagem da própria secretaria municipal de saúde. Foram convocados todos os técnicos em enfermagem da secretaria e o teste de seleção foi realizado em duas etapas: prova teórica e prática, realizada no Laboratório Municipal de Criciúma. Dois técnicos em enfermagem foram selecionados entre sete candidatos por sua maior precisão e habilidade com o hemoglobinômetro.

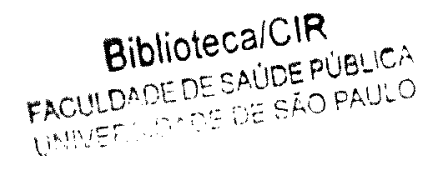




\section{Estudo Piloto}

Para o estudo piloto foram utilizados dois setores não sorteados para esta pesquisa. Durante os três dias, foram realizadas 65 entrevistas. Nenhuma delas foi aproveitada pois as modificações no questionário, especialmente na seqüência das perguntas, foram muitas. Durante o estudo piloto foi utilizado um ônibus da Secretaria de Educação que levava as equipes até o local do estudo. No final do dia era fornecido vale transporte. O seguinte material foi utilizado para o trabalho de campo: mapas, bonés, folhas de conglomerado, questionários, pranchetas, caderneta de saúde, gráfico de conhecimento, lápis e borrachas, apontadores, carta de apresentação, crachás, sacos plásticos transparentes, balanças, ganchos para balança, calças de borracha, antropômetro, saco para antropômetro impermeável, pastas, sacolas para carregar balança e peso para calibrar balanças.

\section{Definição dos Setores}

A amostragem proporcional ao tamanho foi realizada em dois estratos: com e sem cobertura da Pastoral da Criança. Optou-se por visitar todos os setores com Pastoral, com uma amostra fixa em termos percentuais (54\%). Nos demais setores, sorteou-se aleatoriamente 15 setores e um número fixo de 155 domicilios por setor foi visitado

O municipio de Criciúma possui 105 setores censitários, atualizados pela última vez para o Censo Demográfico de 1991. As áreas de ocupação foram levantadas em 1995 pela Secretaria Municipal de Saúde do Municipio e o número de novos domicilios já estava disponivel por setor. Tendo em vista que já no primeiro setor não foram encontradas todas as familias apontadas pela Secretaria como sendo de novas ocupações, optou-se por recontar todos os domicilios de cada um dos setores com ocupações. Este número exato foi utilizado para o cálculo do número de domicilios a serem visitados nos setores Pastoral. 


\section{Coleta de Dados}

Foi organizado um escritório central na Prefeitura de Criciúma em sala com uma mesa grande, ramal telefônico e armário para guardar o material.

A equipe de coordenação foi formada por dois coordenadores, um digitador em cada turno e uma supervisora para auxiliar na revisão. Foram formadas três equipes de trabalho de campo, cada qual com um supervisor. Estas se encontravam todas as manhãs no escritório central para tirar possiveis dúvidas, bem como para esclarecer questões da revisão. Chegavam às $8: 00 \mathrm{~h}$ e dirigiam-se para os setores às $8: 30 \mathrm{com}$ carros fornecidos pela prefeitura. Os motoristas apenas deixavam as equipes nos setores, sendo que estas utilizavam vales-transporte para a passagem de volta. As equipes recebiam cada uma um setor e seu respectivo mapa, já numerado, onde era realizado sorteio da quadra e a esquina que iria se iniciar a coleta.

As balanças portáteis foram aferidas duas vezes por semana e reguladas antes de cada pesagem.

Foi utilizado para a coleta de hemoglobina o hemoglobinômetro da marca BMS, da Omron Healthcare Inc., Illinois E.U.A., modelo 10-101D, álcool 70\%, lancetas, luvas descartáveis e guardanapo de papel.

A coleta de hemoglobina iniciou em abril, após todos os domicilios dos primeiros setores terem sido visitados. Um dos dois técnicos de enfermagem realizou praticamente todos as dosagens de hemoglobina, em virtude de dedicar-se exclusivamente a esta tarefa. O outro técnico realizava as dosagens após o expediente, de 6 horas na época. Houve grande aceitação das mães para a coleta de hemoglobina, em grande parte devida a habilidade da técnica em enfermagem, que na secretaria de saúde, era responsável pelo "teste do pezinho" (fenilcetonúria) em Criciúma. Os maiores fatores de rejeição eram a realização de teste semelhante em data muito próxima: estes exames foram realizados em sua maioria pelo Laboratório Municipal, e seu resultado foi anotado e checado no próprio Laboratório Municipal. Para a coleta de hemoglobina foram visitadas uma a cada quatro crianças entrevistadas, sendo a primeira criança da seqüência sorteada dentre as quatro primeiras crianças entrevistadas de cada setor. Os resultados dos exames de hemoglobina não constam da presente dissertação e serão publicados separadamente. 
O trabalho de campo teve seu inicio em 5 de março e seu término em primeiro de junho. Ao final deste, a equipe central foi aumentada em duas pessoas para a revisão, sendo duas supervisoras e uma entrevistadora. Esta foi escolhida por ter se saido melhor tanto na codificação de seus questionários como na freqüência de erros cometidos.

\section{Controle de Qualidade}

A codificação das questões foi realizada pelo próprio entrevistador e entregue a seu supervisor no dia seguinte à entrevista. Este entregava o questionário revisado à equipe central que novamente revisava antes da digitação. Caso o programa de checagem dos questionários apontasse alguma inconsistência, o questionário percorria o mesmo fluxo só que em sentido inverso. As perguntas abertas foram codificadas exclusivamente pela equipe central

O melhor entrevistador selecionado ficou responsável pelo controle de qualidade $e$ as revisitas. Os questionários revisados pela equipe central que apresentassem dúvida quanto ao seu preenchimento eram repassados para esse supervisor da qualidade, que visitava novamente a familia e reaplicava algumas questōes que constavam em instrumento especifico. Ambos os questionários eram comparados e avaliados quanto à coincidência ou não das respostas. Em caso de discordância, a entrevistadora era chamada e, caso houvesse ainda dúvida, a mesma revisitava a familia, juntamente com a supervisora de sua equipe, para a checagem dos dados. Uma vez constatada alguma diferença, esta era corrigida no questionário original

A partir do momento em que se iniciaram as coletas de hemoglobina, a revisita passou a ser feita por esta equipe, sendo que o supervisor de qualidade continuou comparando os questionários e revisitando os casos em que houve dúvida.

Os coletores de hemoglobina foram acompanhados em suas primeiras 20 coletas por um dos coordenadores e os resultados apurados por um e outro nunca ultrapassaram uma diferença de 0,5 grama de hb/100 ml. Cerca de um terço das coletas foram acompanhadas pelo supervisor de qualidade. 
Durante a seleção dos coletores de hemoglobina percebeu-se que os resultados apontados pelo aparelho portátil foram consistentemente mais baixos que os apontados pelo Laboratório Municipal (cerca de $1 \mathrm{~g} \mathrm{Hb} / 100 \mathrm{ml}$ ). Ao final da pesquisa levou-se a coletora que mais fez coletas para Curitiba e comparou-se a leitura realizada por ela com o aparelho portátil com o aparelho eletrônico de última geração da Faculdade de Farmácia e Bioquimica da Universidade Federal do Paraná, em diversas amostras de sangue.

A revisão foi concluida em 30 de julho. Os questionários à medida em que eram revisados, eram enviados a Curitiba para a segunda digitação. O total de entrevistas ficou em 2208, com 2,8\% de perdas. Para a hemoglobina foram sorteados 556 crianças e realizados efetivamente 502 testes $(9,4 \%$ de perdas).

\section{Questões éticas}

A entrevista e mensuração de hemoglobina só foi feita após autorização verbal da mãe ou responsável pela criança. O valor da hemoglobina foi anotado na Caderneta de Saúde da criança e os valores baixos, segundo uma tabela por faixa etária entregue à equipe de mensuração, foram referidos ao SUS, com a prévia determinação do secretário municipal de saúde que seriam atendidas com prioridade.

As crianças desnutridas foram identificadas em análises parciais dos resultados pelo Epiinfo e seus nomes e endereços entregues às unidades de saúde a que pertencia o setor. O serviço de saúde fez busca ativa destas e incluiu-as no programa de suplementação alimentar. 